Portland State University

PDXScholar

Spring 7-7-2017

\title{
Impact Analysis of Increased Dispatchable Resources on a Utility Feeder in OpenDSS
}

Crystal Eppinger

Portland State University

Follow this and additional works at: https://pdxscholar.library.pdx.edu/open_access_etds

Part of the Power and Energy Commons

Let us know how access to this document benefits you.

\section{Recommended Citation}

Eppinger, Crystal, "Impact Analysis of Increased Dispatchable Resources on a Utility Feeder in OpenDSS" (2017). Dissertations and Theses. Paper 4000.

https://doi.org/10.15760/etd.5884

This Thesis is brought to you for free and open access. It has been accepted for inclusion in Dissertations and Theses by an authorized administrator of PDXScholar. Please contact us if we can make this document more accessible: pdxscholar@pdx.edu. 
Impact Analysis of Increased Dispatchable Resources on a Utility Feeder in OpenDSS

by

Crystal Eppinger

A thesis submitted in partial fulfillment of the requirements for the degree of

\author{
Master of Science \\ in \\ Electrical and Computer Engineering
}

Thesis Committee:

Robert Bass, Chair

Jonathan Bird

Mark Faust

Portland State University

2017 
(C) 2017 Crystal Eppinger 


\section{Abstract}

Oregon utilities are replacing their portfolios of traditional fossil fuel generation with renewable generating sources. Stepping away from carbon-producing energy will leave a deficit of on-demand power, resulting in decreased reliability. To overcome these technical challenges, utilities must maximize the use of their present dispatchable resources. One such resource is the Portland General Electric (PGE) Dispatchable Standby Generation Program (DSG), which is an aggregated $105 \mathrm{MWs}$ of distributed generation (DG). These resources are brought on-line when there is a critical need for power. Resources are added to the program if a transfer trip scheme is in place or a modeling study reveals that the feeder load is at least three times the generator capacity. If the load-to-capacity ratio were lower, more assets could be added to the DSG program.

To investigate the impacts of lowering the DG load-to-capacity ratio on existing distribution feeders, we use Open-Source Distribution System Simulator (OpenDSS). We modeled the Oxford Rural feeder by converting a utility CYME database to instantiation files using several MATLAB programs. A MATLAB control program varies the load-to-capacity ratio of the OpenDSS feeder model and monitors the generator behavior immediately following a fault. We analyzed the results to determine the ideal load-to-capacity ratio that prevents unintentional islanding. The results show that the instantaneous (50) relay element settings 
dictate both the minimum load-to-capacity ratio and the maximum DG capacity. The present three-to-one ratio is very conservative and can be reduced.

Additional dispatchable resources include a five MW battery-inverter system currently used as grid-back up. The battery is grid-tied to a $12.4 \mathrm{kV}$ feeder making it an ideal candidate for conservation voltage reduction (CVR). Using the same feeder model, we investigated the effects of lowering the system voltage to the allowable minimum using injections of reactive power. A lower system voltage reduces the load at peak times. Conversely, increasing the voltage prevents generation conflicts. To determine the benefit of CVR by VAr-injection on the Oxford Rural feeder, we created a MATLAB optimization program to output the optimal feeder voltage for reduced system power. We use a Simulink feedback model to determine the appropriate reactive power needed to achieve the voltage change. We analyze the system model to reveal that the feeder is ideal for CVR but the system capacity must be increased to achieve the maximum power reduction. 
Dedication

This thesis is dedicated to Emily Barrett and Linda Rankin. You two ladies make Wonder Woman look like a real slouch. 


\section{Acknowledgements}

This thesis wouldn't be possible without the efforts of Dr. Bob Bass. You have created an educational atmosphere that has allowed me and so many others to flourish. You have shown me that being an active, loving parent and a successful engineer are not mutually exclusive. You are a champion for women in the sciences. I am so grateful for every educational opportunity you have afforded me. Thank you.

I would like to thank Kevin Whitener and PGE for their generosity and support. Kevin, you are a utility inspiration. I hope you continue to ask tough questions in the industry and allow us at PSU to investigate them.

My little family, Nathan and Nico, you have shown unwavering support in my relentless pursuit of an education. You bring so much silliness and dimension to my life and work. I love you both with all of my heart.

My Mom and Dad taught me to be unapologetic in the pursuit of my dreams. You told me I could do anything, and for once, I listened to you.

Annie, Michael and Tylor, you are the dream team. Thank you for being my people. 


\section{Contents}

$\begin{array}{ll}\text { Abstract } & \text { i }\end{array}$

Dedication iii

Acknowledgements $\quad$ iv

List of Tables $\quad$ vii

List of Figures $\quad$ viii

1 Introduction 1

1.0.1 Problem Statement . . . . . . . . . . . . . . 3

1.0.2 Details about Problem Statement . . . . . . . . . . . . . . 3

1.0.3 Related Research . . . . . . . . . . . . . . . . . . 4

1.0.3.1 Distribution Network . . . . . . . . . . . . 4

1.0.3.2 Distributed Generation ............. 5

1.0.3.3 Transfer Trip . . . . . . . . . . . . . 6

1.0.3.4 Distribution Feeder Modeling Software . . . . . . . . 7

1.0.3.5 CYME to OpenDSS Converter . . . . . . . . . . . 7

1.0.3.6 Load Modeling . . . . . . . . . . . . . . 8

1.0.3.7 Conservation Voltage Reduction and VAr control . . . . . 9

1.0.3.8 Model based Volt-VAr Optimization . . . . . . . . . . . 11

1.0.3.9 Lagrange Multipliers . . . . . . . . . . . . . 12

2 Design Methodology $\quad 14$

2.1 Feeder Modeling . . . . . . . . . . . . . . . . . . . . 14

2.1.1 CYMDIST data . . . . . . . . . . . . . . . . 14

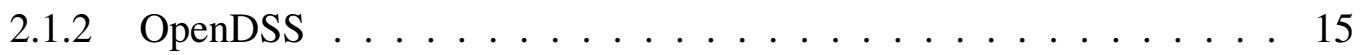

2.1.3 Oxford Rural Distribution model . . . . . . . . . . . . . . . . . 17

2.1.3.1 Oxford Rural Feeder Model Validation . . . . . . . . . 19

2.1 .4 Loadshape ... . . . . . . . . . . . . . . 21

2.1.5 Relay Curve ..................... 22

2.2 MATLAB Dynamic Study . . . . . . . . . . . . . . . . 23

2.2.1 Resource Availability MATLAB program . . . . . . . . . . . . . 26

2.3 CVR by VAr-injection Study . . . . . . . . . . . . . . . . . 28 
2.3.1 Load Modeling . . . . . . . . . . . . . . . . . . . . . . 28

2.3.1.1 Model Sensitivity to ZIP Coefficient Parameters . . . . . 29

2.3.2 Plant Model . . . . . . . . . . . . . . . . . . . . . . . . . 30

2.3.3 Cost Equation Development . . . . . . . . . . . . . . . 37

2.3.4 MATLAB Optimization Routine . . . . . . . . . . . . . . 37

2.3.5 Fmincon . . . . . . . . . . . . . . . . . . . . . . 39

2.3.6 Lagrange Multipliers . . . . . . . . . . . . . . . . . . 40

2.3.7 Model based Volt-VAr Optimization Algorithm . . . . . . . . . . 41

3 Results \& Analysis $\quad 44$

3.0.1 MATLAB Dynamic Study . . . . . . . . . . . . . . . 44

3.0.1.1 DG Customer Site $1 \ldots \ldots$. . . . . . . . . . . 46

3.0.1.2 DG Customer Site $2 \ldots \ldots$. . . . . . . . . . 48

3.0.1.3 Resource Availability and Load to Capacity Ratio . . . . 50

3.0.2 Model based Volt-VAr Optimization . . . . . . . . . . . . . 52

3.0.2.1 CVR by Volt-VAr Injection . . . . . . . . . . . . . 52

3.0.2.2 Smooth Feeder Profile . . . . . . . . . . . . . . . 53

3.0.2.3 Lagrange Multipliers vs. Interior-Point Method . . . . . . 54

4 Discussion $\quad 56$

5 Conclusion $\quad \mathbf{5 7}$

5.0.0.1 MATLAB Dynamic Study . . . . . . . . . . . . . . 57

5.0.0.2 Model Based Volt-VAr Optimization _. . . . . . . 58

$\begin{array}{lr}\text { Bibliography } & 60\end{array}$

Appendix A: MATLAB Dynamic Study 63

A.0.1 Oxford Rural Feeder Model Validation Results . . . . . . . . . 63

A.0.2 Load Multiplier . . . . . . . . . . . . . . . . . . 67

A. 0.3 MATLAB Dynamic Study . . . . . . . . . . . . . . 72

Appendix B: Model Based Volt-Var Injection 93

B.0.1 Fmincon . . . . . . . . . . . . . . . . . . . . . 993

B. 0.2 Lagrange Multipliers . . . . . . . . . . . . . . . . . . . 94

B.0.3 Optimization Routine . . . . . . . . . . . . . . . . . . 96 


\section{List of Tables}

2.1 ZIP Coefficient Parameters $[1] \ldots \ldots$

2.2 ZIP Coefficient Sensitivity Analysis for Line Currents . . . . . . . . . . . . . . 29

2.3 ZIP Coefficient Sensitivity Analysis for Load Voltages . . . . . . . . . . . 30

2.4 Voltage Change as a Function of kVAr Injection . . . . . . . . . . . . 30

3.1 Distributed Generation Resource Availability for 2015 Peak Day . . . . . . . . 51

3.2 Power Savings using Volt-VAr Injection and Traditional CVR Methods . . . . . 52

3.3 Power Savings using Lagrange Multipliers and Interior Point Algorithms . . . . 54 


\section{List of Figures}

1.1 Distribution Circuit $[2] \ldots \ldots \ldots \ldots$

1.2 One Line diagram with Distributed Generation [2] . . . . . . . . . . . . 6

1.3 ZIP Load Model $[1] \ldots \ldots$. . . . . . . . . . . . . . . . . . . . . 9

1.4 Traditional CVR Equipment Diagram [3] . . . . . . . . . . . . . . . . . 10

1.5 Power Triangle[4] . . . . . . . . . . . . . . . . . . . . . . . . . 10

1.6 Volt/VAr Optimization Approach . . . . . . . . . . . . . . . . . . 12

2.1 CYME Database Relationship Diagram for Overhead Lines . . . . . . . . . . 15

2.2 OpenDSS Structure $[5] \ldots \ldots \ldots \ldots \ldots$

2.3 CYME to OpenDSS Overhead Line Conversion . . . . . . . . . . . . . 18

2.4 OpenDSS Oxford Rural Feeder Model . . . . . . . . . . . . . . . . . . . . . . 19

2.5 OpenDSS Oxford Rural Feeder Per Unit Voltage . . . . . . . . . . . . . . . 20

2.6 OpenDSS Oxford Rural Feeder Line Loading . . . . . . . . . . . . . . . . . 21

2.7 Load Multiplier Curve . . . . . . . . . . . . . . . . . . . . . . . . . . 22

2.8 Extremely Inverse Curve $\mathrm{U} 4 \ldots \ldots$

2.9 Dynamic Study Flow Chart . . . . . . . . . . . . . . . . . . . . . . 25

2.10 Resource Availability Program Flow Chart . . . . . . . . . . . . . . . 27

2.11 Battery Inverter System Reactive Power Injections . . . . . . . . . . . . . . 31

2.12 Oxford Rural Feeder Voltage Response Data . . . . . . . . . . . . . . . . . 31

2.13 Plant Model Response - $100 \mathrm{kVAr}$. . . . . . . . . . . . . . . . . 32

2.14 Plant Model Response - $500 \mathrm{kVAr}$. . . . . . . . . . . . . . . . . 33

2.15 Plant Model Response $-1000 \mathrm{kVAr} \ldots \ldots \ldots$

2.16 Plant Model Response - 2000 kVAr . . . . . . . . . . . . . . . . . . . . . 34

2.17 Plant Model Response - $4000 \mathrm{kVAr}$. . . . . . . . . . . . . . . . . . . . 34

2.18 Voltage and Reactive Power Relationship for the BIS and OpenDSS Model . . 35

2.19 System Block Diagrams . . . . . . . . . . . . . . . . . . . . . . . 35

2.20 OpenDSS Model Power and Voltage and Cost Equation . . . . . . . . . . 37

2.21 Autonomous Control Program Flow Chart . . . . . . . . . . . . . . . 43

3.1 DG Site 1, 50/51 Element Operating Times, 2.4xRated . . . . . . . . . . 46

3.2 DG Site 1, 50/51 Element Operating Times, 2.5xRated . . . . . . . . . . . . 46

3.3 DG Site 1, 50/51 Element Operating Times, 2.6xRated . . . . . . . . . . . 47

3.4 DG Site 1, 50/51 Element Operating Times, 2.7xRated . . . . . . . . . . 47

3.5 DG Site 2, 50/51 Element Operating Times, 2.4xRated . . . . . . . . . . 48 
3.6 DG Site 2, 50/51 Element Operating Times, 2.5xRated . . . . . . . . . . . . . 49

3.7 DG Site 2, 50/51 Element Operating Times, 2.6xRated . . . . . . . . . . . . 49

3.8 DG Site 2, 50/51 Element Operating Times, 2.7xRated $\ldots \ldots \ldots \ldots$

3.9 Load Consumption, LCR Varied from 3.0 to $1.7 \ldots \ldots \ldots \ldots$. . . . . . 51

3.10 Minimized Power using CVR and VVO . . . . . . . . . . . . . 52

3.11 Optimized Power Using the Smooth Feeder Profile Algorithm . . . . . . . . 53

3.12 Lagrange Multipliers . . . . . . . . . . . . . . . . . . 55 


\section{Introduction}

Oregon's Renewable Portfolio Standard (RPS) requires utilities to meet 50\% of demand with renewable energy by 2040 [6]. According to its 2016 Integrated Resource Plan (IRP), Portland General Electric (PGE) will meet this standard by investing in new, renewable generation sources and closing Oregon's only coal-fired plant [7]. As of 2009, the $550 \mathrm{MW}$ Boardman coal plant was responsible for $15 \%$ of PGE's energy production. Switching from coal-fired generation to renewable resources will result in an increase in stochastic supply and a deficit of dispatchable power. This combination of consequences makes it difficult to provide affordable, reliable power.

A possible solution is the strategic use of presently available dispatchable resources. One such resource, is the PGE Dispatchable Standby Generation (DSG) program. PGE has acquired 105 MWs of DSG by partnering with local businesses with back-up generators [8]. This generating capacity counts toward their non-spinning reserves, a resource that is not connected to the system but can be brought on-line within a ten minute window [9]. PGE does not use the distributed generation (DG) resources unless a transfer trip scheme is in place that will cause the generator breaker to trip in the event of a feeder fault, or a modeling study reveals that the load of the feeder is at least three times the generator capacity. This long standing protection ratio is thought to ensure that the feeder load is so large it will trip the generator breaker and prevent unintentional islanding. This approach utilizes already 
existing GenOnSys control software (K. Whitener, personal communication, July 2, 2015), which eliminates the costly installation of transfer-trip scheme.

Additional dispatchable resources include a 5 MW, lithium-ion Battery Inverter System (BIS) at the Salem Smart Power Center (SSPC), located south of Portland, in Salem, Oregon. The battery is a remnant of the Pacific Northwest Smart Grid Demonstration Project but presently serves as grid back-up [10]. Since the BIS is grid-tied to a 12.4 kilovolt (kV) feeder, it can be utilized for conservation voltage reduction (CVR). This is the process of running a system at its minimum voltage without violating the American National Standard Institute for Electric Power Systems and Equipment (ANSI C84.1) voltage ratings, which states that service voltage must fall between $+/-5 \%$ of the system nominal voltage [11]. Both customer and utility equipment are designed to work within these ranges. If the voltage falls outside the ANSI voltage rating the utility can be fined and equipment could suffer damage. To ensure that the load voltages do not drop below the minimum, the head voltage at the substation is generally maintained at approximately $4 \%$ greater than the system nominal voltage. However, the head node voltage can be decreased to a minimal value without violating the ANSI standard. Conservation voltage reduction can be achieved with VAr injection; utilizing the support function of the BIS inverter to inject reactive power is injected into the system. These injections increase or decrease the system voltage. When the voltage is decreased at peak times, the power consumption is reduced. Conversely, the system voltage can be increased when the demand is low. Increasing the load accommodates must-run scenarios, e.g. non-dispatchable resources such as hydro, wind or solar generation. 
The BIS "creates" reactive power by changing the phase lag or lead of the injection current with respect to the bus voltage. The system's apparent power is affected by the change in reactive power. However, the real power remains the same. This allows the battery to be used to alleviate the load in times of generation shortage or alleviate excess supply in times of overabundant generation.

\subsubsection{Problem Statement}

PGE requested that the Portland State University (PSU) Power Group investigate the impacts of lowering the DG load to capacity ratio (LCR) on existing distribution feeders. Lowering the LCR increases the availability of the dispatchable resource and prevents the costly installation of a transfer trip protection scheme. Additionally, we examined the real power savings resulting from CVR by VAr-injection on the Oxford Rural feeder. The power savings must be between three and five percent to warrant the installation of an active voltage controller that autonomously performs CVR.

\subsubsection{Details about Problem Statement}

To investigate the effects of increased dispatchable resource use on PGE's Oxford Rural feeder, we used OpenDSS, an open-source distribution system simulator as our modeling software. We converted PGE's CYME model of the Oxford Rural feeder to instantiation files using several MATLAB programs. A MATLAB control program varies the load to capacity ratio of the OpenDSS feeder model and monitors the generator behavior immediately 
following a fault. We analyzed the results to determine the ideal load to capacity ratio to prevent unintentional islanding.

Using the same OpenDSS model, we modified the loads, using ZIP coefficients to monitor the changing relationship between power and voltage. To capture the dynamics of the BIS, we collected power and voltage data at the SSPC and modeled the system in Simulink. Lastly, we created an optimization loop in MATLAB to achieve the optimal system voltage that minimizes the power of the load at peak times.

\subsubsection{Related Research}

\subsubsection{Distribution Network}

The distribution network is the last stage of the standard three phase power delivery process. It begins at the substation, where transmission or sub-transmission voltages are stepped down to a medium voltage, which varies from $4120 \mathrm{~V}$ to $33 \mathrm{kV}$, depending on utility requirements. A substation contains transformers, breakers and protective relaying schemes and may also have voltage support equipment like capacitors and voltage regulations. Several feeders radiate from the substation. Overhead and underground lines branch off of the main feeder, resembling an arterial system. If the feeder is long it may have capacitor banks or voltage regulators at some distance from the substation to prevent voltage from dropping below the ANSI standard. The arterial system terminates at a load, where the voltage is stepped down once more, in preparation for consumer delivery. Figure 1.1 displays a typical distribution network. 


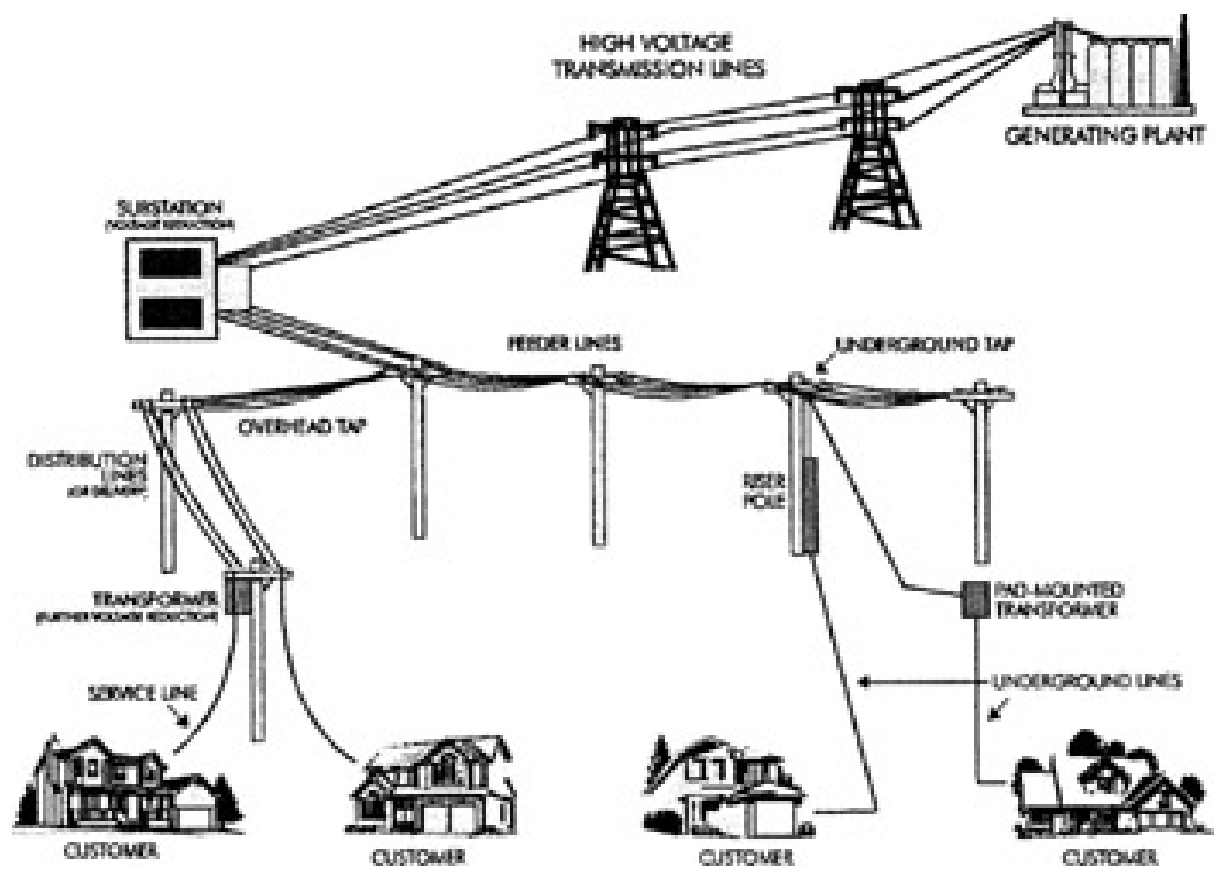

Figure 1.1: Distribution Circuit [2]

\subsubsection{Distributed Generation}

A conventional distribution system has a single generating point and terminates at a load. A system with integrated DG is referred to as an active distribution system due to bidirectional power flow. The many potential benefits of an active distribution system include increased reliability, peak power consumption reduction and reactive power compensation. The primary disadvantage of DG is the concern for islanding, which occurs when the feeder substation encounters a fault and the generator continues to power the load. In such circumstance, the standby generator and the grid become significantly out of phase. If the recloser operates and energizes the feeder, it could result in damages as catastrophic as a complete shearing of the generator shaft [12]. Protection schemes, such as transfer trip, aim 
to prevent islanding, but the high cost of installation can far outweigh the benefits. As a result, DG adoption by utilities has historically been low [13].

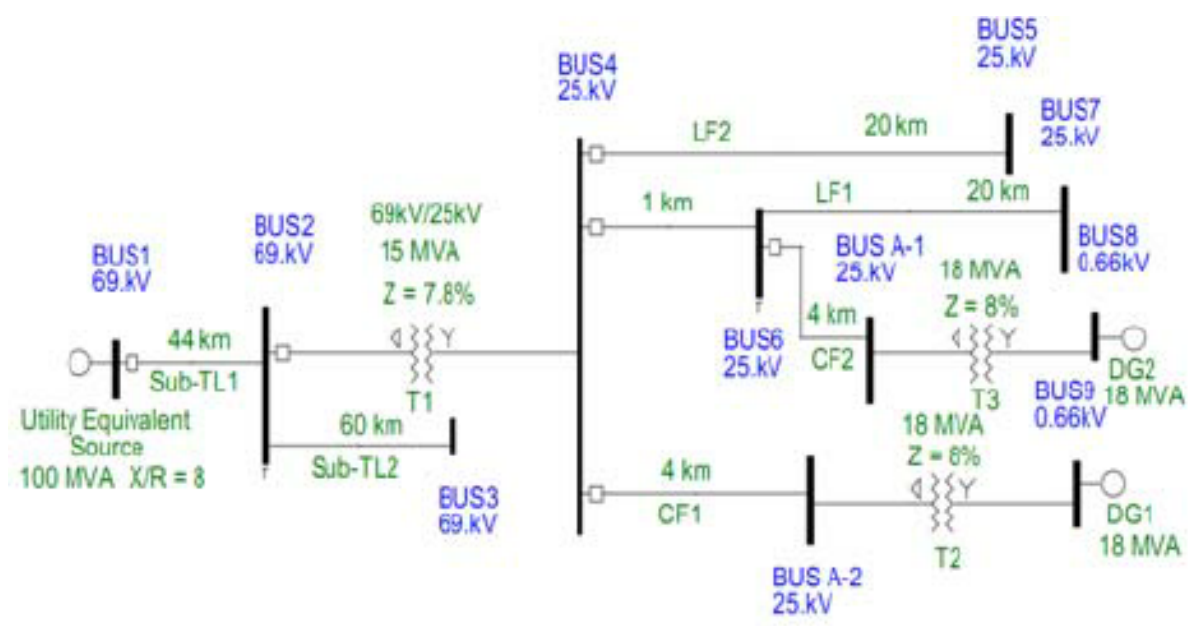

Figure 1.2: One Line diagram with Distributed Generation [2]

\subsubsection{Transfer Trip}

Many utilities require a transfer trip (TT) protective relaying scheme for DG interconnection. The scheme ensures that in the event of a fault or equipment failure at a substation, a lockout relay will trip all of the breakers connected to it. One of the contacts from the lockout relay will initiate a TT signal to a remote breaker at the DG asset [14], which ensures that the DG will not unintentionally island. The communications and equipment cost between $\$ 50,000$ and $\$ 100,000$. This high cost can render some projects infeasible. PGE will not bring DG on-line unless it has a TT scheme or if a feeder modeling study reveals that the load is more than three times greater than the generator capacity. This feeder modeling study uses available GenOnSys equipment, which reduces the cost of interconnect projects. 


\subsubsection{Distribution Feeder Modeling Software}

Due to the inherent imbalance of the distribution network, the software choices for modeling utility feeders are limited. PGE uses CYME as their distribution analysis software. A customized package is tailored to fit the needs of each utility. Licensed, proprietary software promises security and reliability but limits availability due to the high cost. To increase availability and promote standardization, the Department of Energy (DOE) encouraged the development of an open-source software model platform as part of its grid modernization effort [15]. The Electric Power Research Institute (EPRI) purchased and maintains an open-source distribution system simulator (OpenDSS) for distributed generation integration research in 2008. Among the open-source software available at the time of this project, OpenDSS was able to analyze unbalanced loads and conduct dynamic analysis. Additionally, the program receives commands from scripts, files or an external driver, such as MATLAB. This functionality allows us to create a component database using text files of instantiation statements. Using the OpenDSS script we created the Oxford-Rural feeder model using a series of redirect statements to the component database. MATLAB drove the circuit, creating a custom solution mode and allowing for dynamic modification and recording of the results.

\subsubsection{CYME to OpenDSS Converter}

At the start of the research project, EPRI did not offer a CYME-to-OpenDSS conversion program. EPRI now offers Python 2.7 or Excel VBA converters upon request to utility customers. EPRI does not have a universal converter. One of many converters may be used 
depending on the version of CYME software the utility uses. In addition, the converter itself must be modified to account for the custom tailoring of the CYME program.

\subsubsection{Load Modeling}

The real power consumption of a load varies with changing voltage depending upon whether it is a constant impedance $(\mathrm{Z})$, constant current $(\mathrm{I})$ or constant power $(\mathrm{P})$ load. Most loads behave like a mixture of the three. ZIP coefficients can be used to create models of loads that predict the power response in response to a changing voltage.

The ZIP coefficients used in this project are found in the 2014 paper, "Experimental Determination of the ZIP Coefficients for Modern Residential, Commercial, and Industrial Loads" by Bokhari, et al. [1]. To obtain the coefficients, they conducted load composition field surveys for residential, commercial and industrial customers. Collected data from voltage variation tests on modern devices was fit to ZIP coefficients using constrained optimization methods. The coefficients were tested against real composite loads to determine the accuracy.

The load composition of a residential customer is predictable. The ZIP coefficients can be stratified based on the power consumption. Commercial customers loads are more complex. For instance, a laundromat load has drastically different behavior than a retail store. The commercial loads are classified first by consumption and then divided into subclasses by the type of business. Industrial customers have a separate class. 


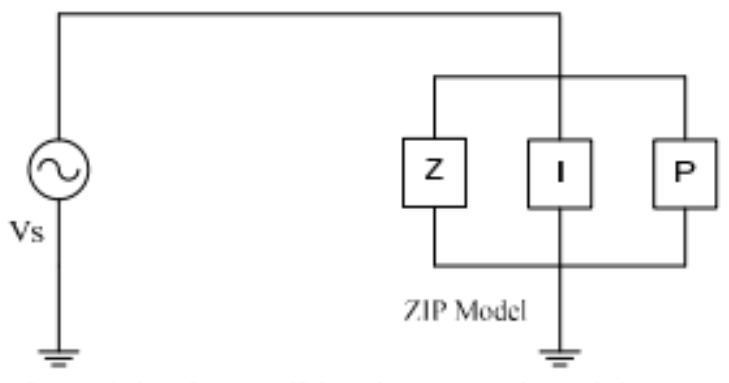

Figure 1.3: ZIP Load Model [1]

\subsubsection{Conservation Voltage Reduction and VAr control}

Conservation voltage reduction generally refers to changes in distribution equipment and operations to reduce line losses and peak loads. It is a reduction in the system voltage to a minimum value that still maintains customer service voltage within $+/-5 \%$ of the nominal voltage. Volt/VAr optimization is an advanced form of CVR that includes VAr control. This can reduce both capacity needs and energy use. Traditional CVR equipment includes fixed capacitors, voltage regulators and load tap changers (LTC) as seen in Figure 1.4. 


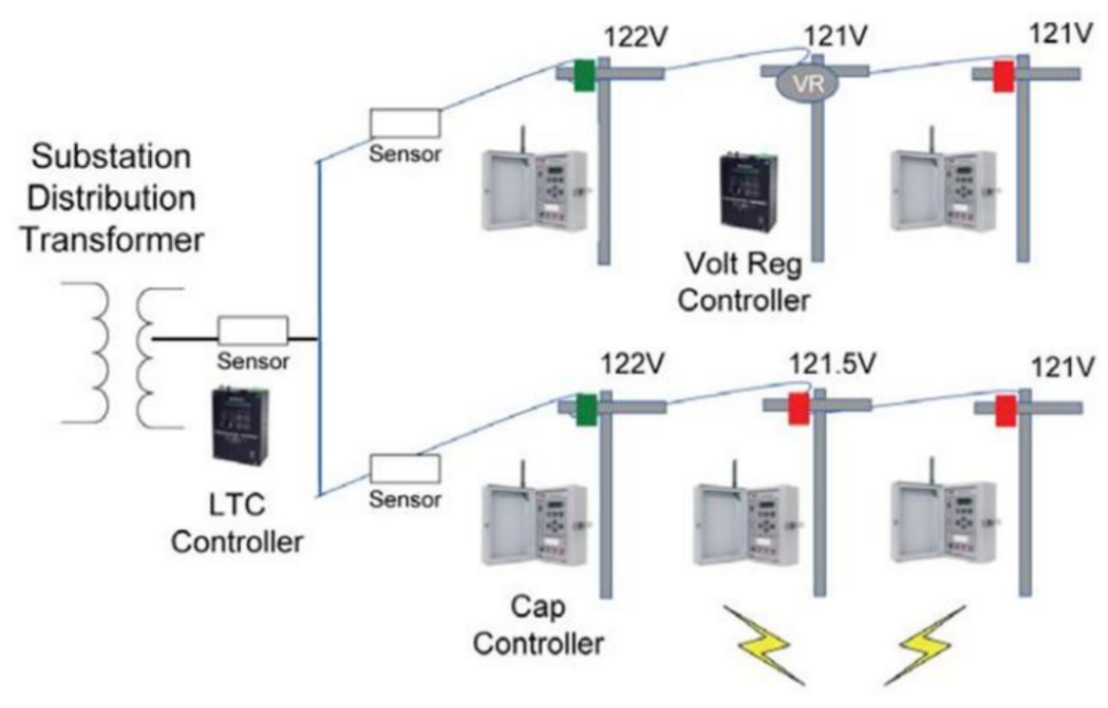

Figure 1.4: Traditional CVR Equipment Diagram [3]

Using the BIS for CVR does not affect the kWh storage. As can be seen in Figure 1.5 changing the power factor angle will change the apparent and the reactive power but the real power remains the same. The battery has tremendous value as a frequency responsive spinning reserve, a generating capacity that can respond within ten seconds [16]. Using the BIS for volt-VAr optimization is considered economically viable because it can function as grid back-up and participate in CVR at the same time.

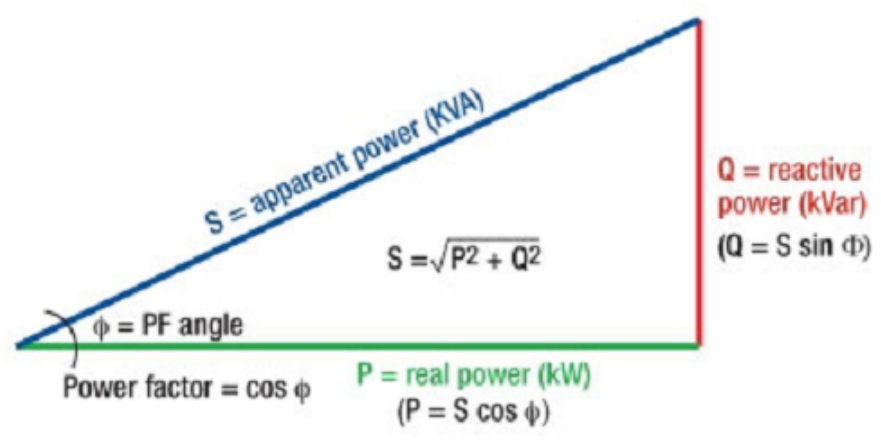

Figure 1.5: Power Triangle[4] 


\subsubsection{Model based Volt-VAr Optimization}

The primary purpose of Volt-VAr control is to maintain a voltage within the standard ANSI range. Advanced volt-VAr objectives are peak electrical demand reduction through CVR. Several options for volt-VAr control are available, such as the "Standalone" method that uses voltage regulators and LTC controls as depicted in Figure 1.4.

Our approach uses a MATLAB optimization program that determines the optimal voltage based on the load. A Simulink BIS plant model calculates the reactive power injection to achieve the desired voltage. For investigative purposes we use the Oxford Rural OpenDSS feeder model. Figure 1.6 displays the sequence of events for the model based approach. This approach increases the value of existing assets, such as the BIS. The changes to the system and implementation at the SSPC would be minimal when compared to the "Standalone" method. 


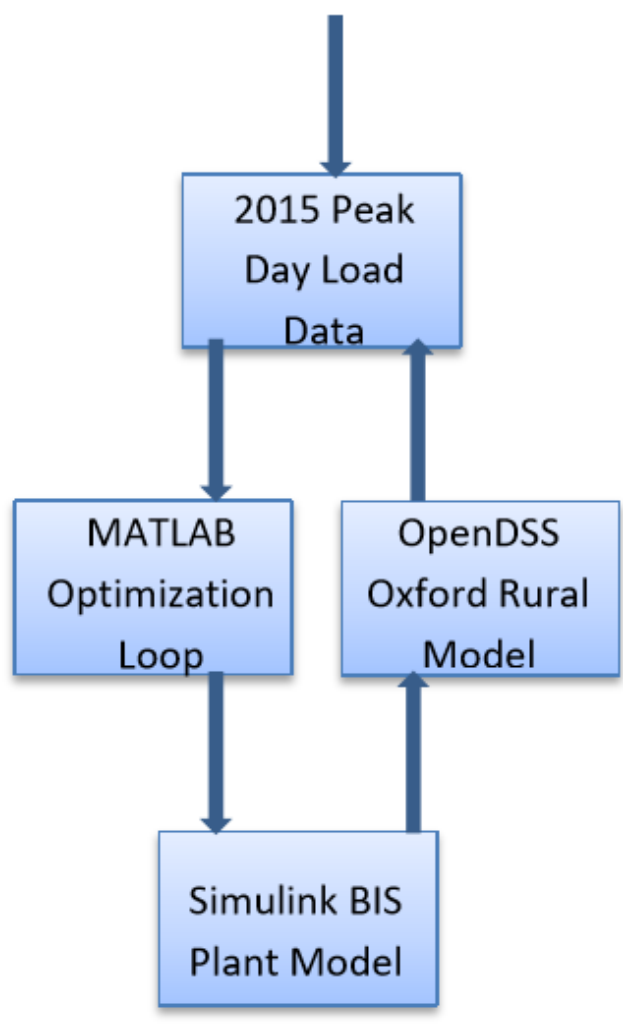

Figure 1.6: Volt/VAr Optimization Approach

\subsubsection{Lagrange Multipliers}

The Lagrange multipliers method is a mathematical tool used in optimization to find the maximum or minimum of an objective function with equality constraints [17].

$$
\left\{\begin{array}{l}
\min _{x, y} f(x, y) \\
\text { subject to } \\
g(x, y)=c
\end{array}\right.
$$


The Lagrange multiplier $\lambda$, is multiplied by the constraints and added or subtracted from the objective function to form the Lagrangian.

$$
L(x, y, \lambda)=f(x, y)-\lambda(g(x, y)-c)
$$

We take the partial derivative of the Lagrange with respect to $\mathrm{x}, \mathrm{y}$ and $\lambda$ to form a system of equations, which is set to zero and solved. The resulting solution is the minimizer to the objective function subject to the constraints. The variable $\lambda$ indicates the sensitivity of the objective function to a changing constraint. This is particularly interesting because it indicates the likelihood of an ANSI violation at each node as we move along the feeder. 


\section{Design Methodology}

\subsection{Feeder Modeling}

To investigate the impacts of lowering the DG load to capacity (LCR) ratio on existing distribution feeders, we built an OpenDSS model of the Oxford Rural feeder. The BIS is grid-tied to the $12.47 \mathrm{kV}$, Oxford-Rural feeder. Additionally, it has two generator sites that participate in the Distributed Generation Standby Program.

\subsubsection{CYMDIST data}

The CYMDIST data for the Oxford Rural model is spread across two ACCESS databases and ninety tables. The network database holds information specific to each feeder; for example, the overhead line conductor type and the number of phases. These network parameters are linked to the equipment database that holds manufacturing specifications such as conductor resistance and geometric mean radius (GMR). To develop the algorithms for component instantiation, we created a database map for each device. Figure 2.1 displays the database relationship for the overhead lines. 


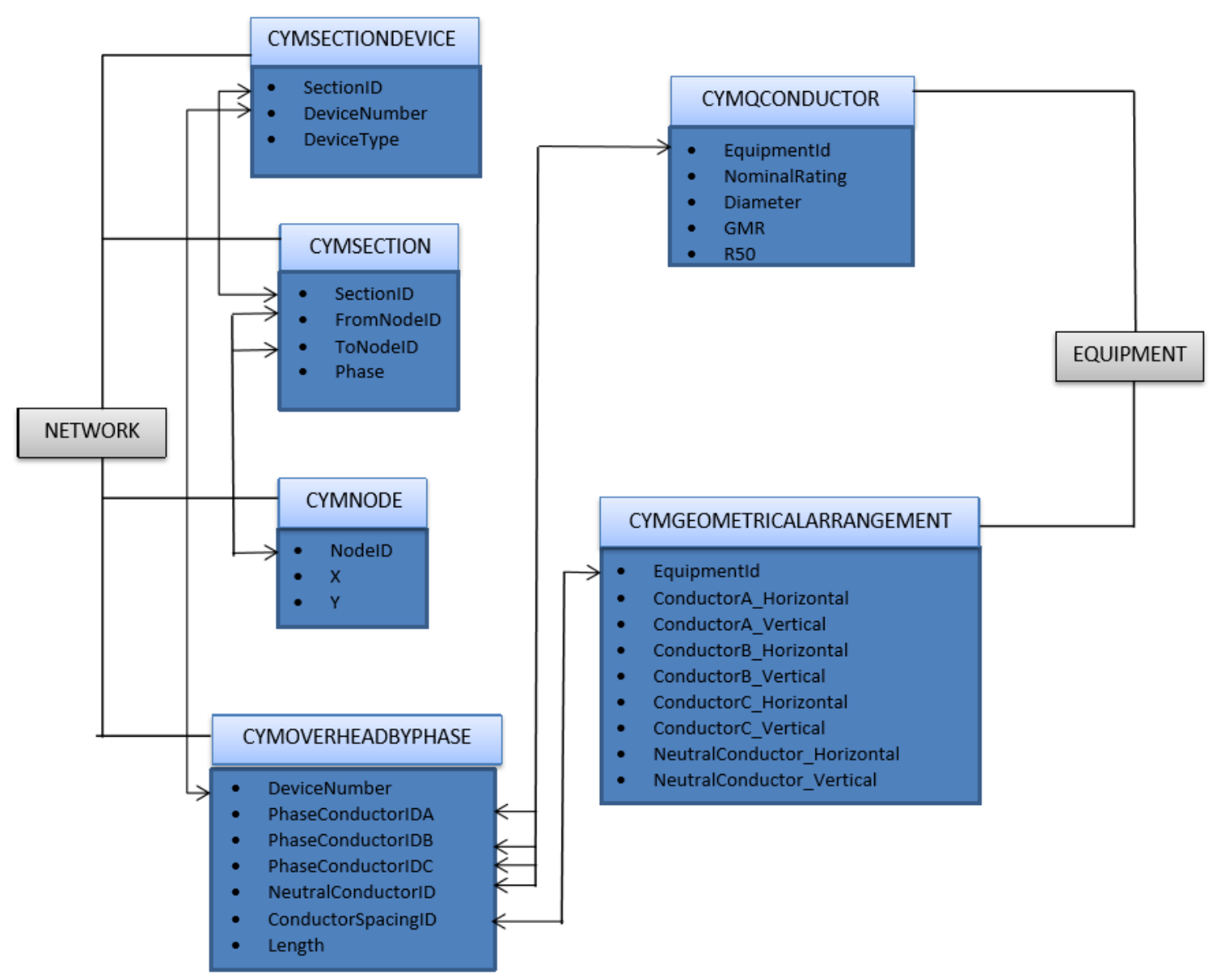

Figure 2.1: CYME Database Relationship Diagram for Overhead Lines

\subsubsection{OpenDSS}

OpenDSS is a distribution system simulator capable of handling unbalanced systems [5]. It was purchased by EPRI, initially for distributed generation analysis. We chose OpenDSS because it is an open-source program capable of conducting a dynamics study on distributed generation. It can be used alone or in conjunction with an external driver such as MATLAB. 
The primary OpenDSS structure is represented by Figure 2.2.

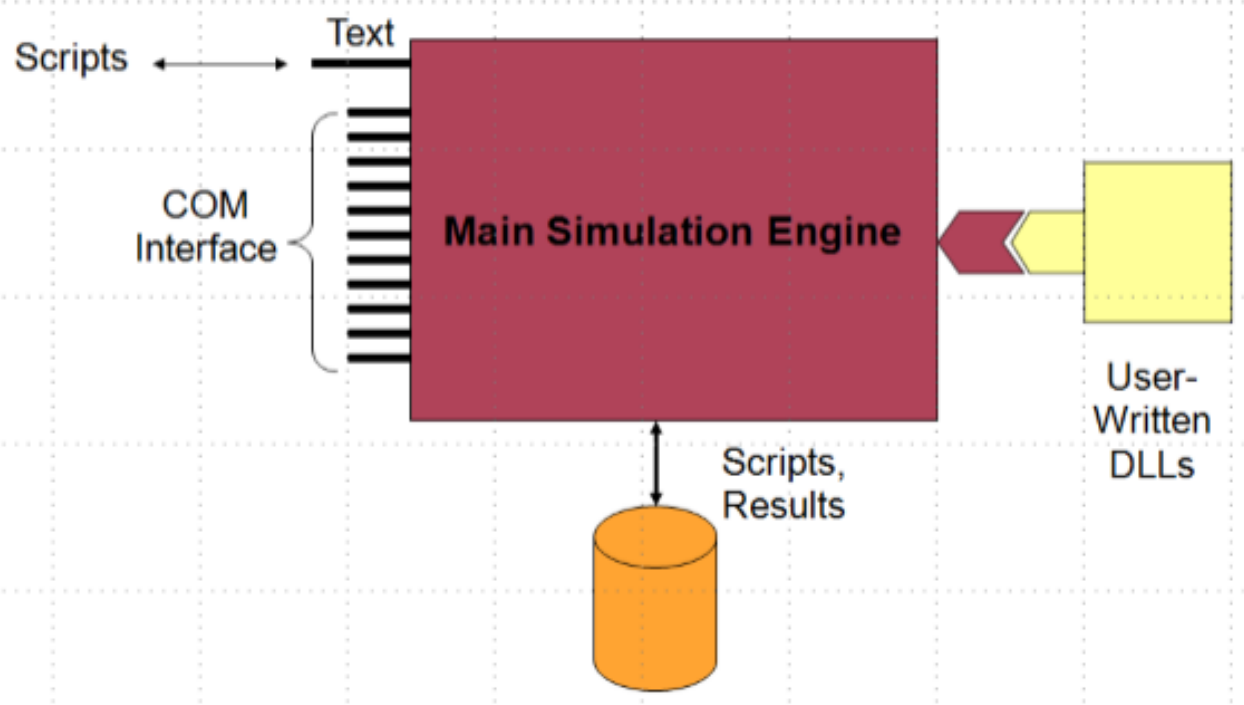

Figure 2.2: OpenDSS Structure [5]

Dynamic solution mode is utilized for the study of the effects of DG on the Oxford Rural feeder. In dynamic mode the generator is modeled as a simple swing equation as opposed to a negative load. The generator model used is the standard OpenDSS element with parameter modifications to best simulate standard PGE generators. The mathematical characteristics of the generator model in dynamic mode are described as:

\section{Derivative Calculation:}

$$
\begin{gathered}
\frac{d v}{d t}=\frac{P_{\text {shaft }}-P_{\text {term }}-D v}{M} \\
\frac{d \theta}{d t}=v
\end{gathered}
$$

Where, 


$$
\begin{gathered}
v=\text { shaft speed relative to synchronous speed } \\
\theta=\text { shaft, or power angle (relative to synchronous reference frame) } \\
\qquad \begin{array}{c}
P_{\text {term }}=\text { terminal power out } \\
D=\text { power damping coefficient } \\
M=\text { inertia coefficient }
\end{array}
\end{gathered}
$$

\section{Integration}

$$
\theta_{n+1}=\theta_{n}+\frac{\Delta t}{2}\left[\left.\frac{d \theta}{d t}\right|_{n}+\left.\frac{d \theta}{d t}\right|_{n+1}\right]
$$

$\Delta t=$ time step size

\subsubsection{Oxford Rural Distribution model}

OpenDSS functions are carried out from text based commands through the COM interface, text files or execution of a script. We created a component database of the Oxford Rural feeder model in text files that contain instantiation statements. OpenDSS instantiation syntax statements take the form:

$$
\text { New Object.Name Parameter } 1=\text { Value } 1 \text { Parameter } 2=\text { Value } 2 \ldots
$$

To develop the algorithms for the component instantiation statements, we compared the database map for each CYME distribution system component to the OpenDSS device 
parameters. In some cases the conversion was a one-to-one database mapping. In the case of the overhead and underground lines, it required a more detailed conversion process. Figure 2.3 displays the CYME parameters used to develop the OpenDSS overhead line components.

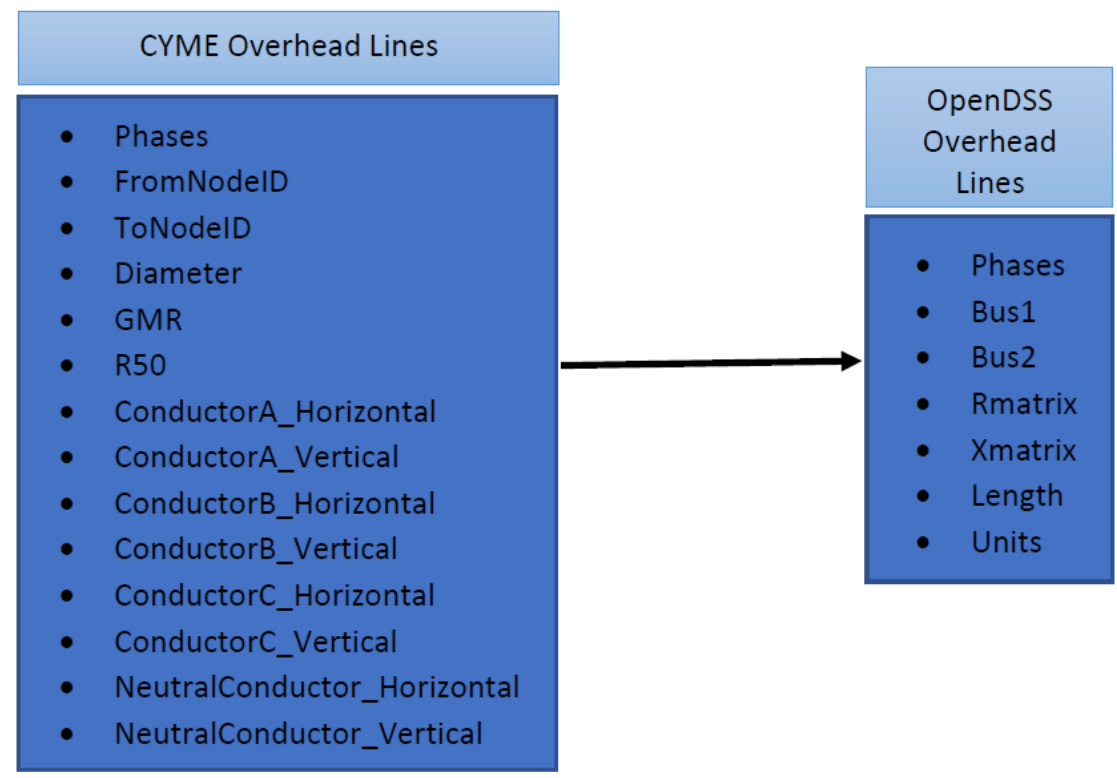

Figure 2.3: CYME to OpenDSS Overhead Line Conversion

Figure 2.4 displays the Oxford Rural Model in OpenDSS. 


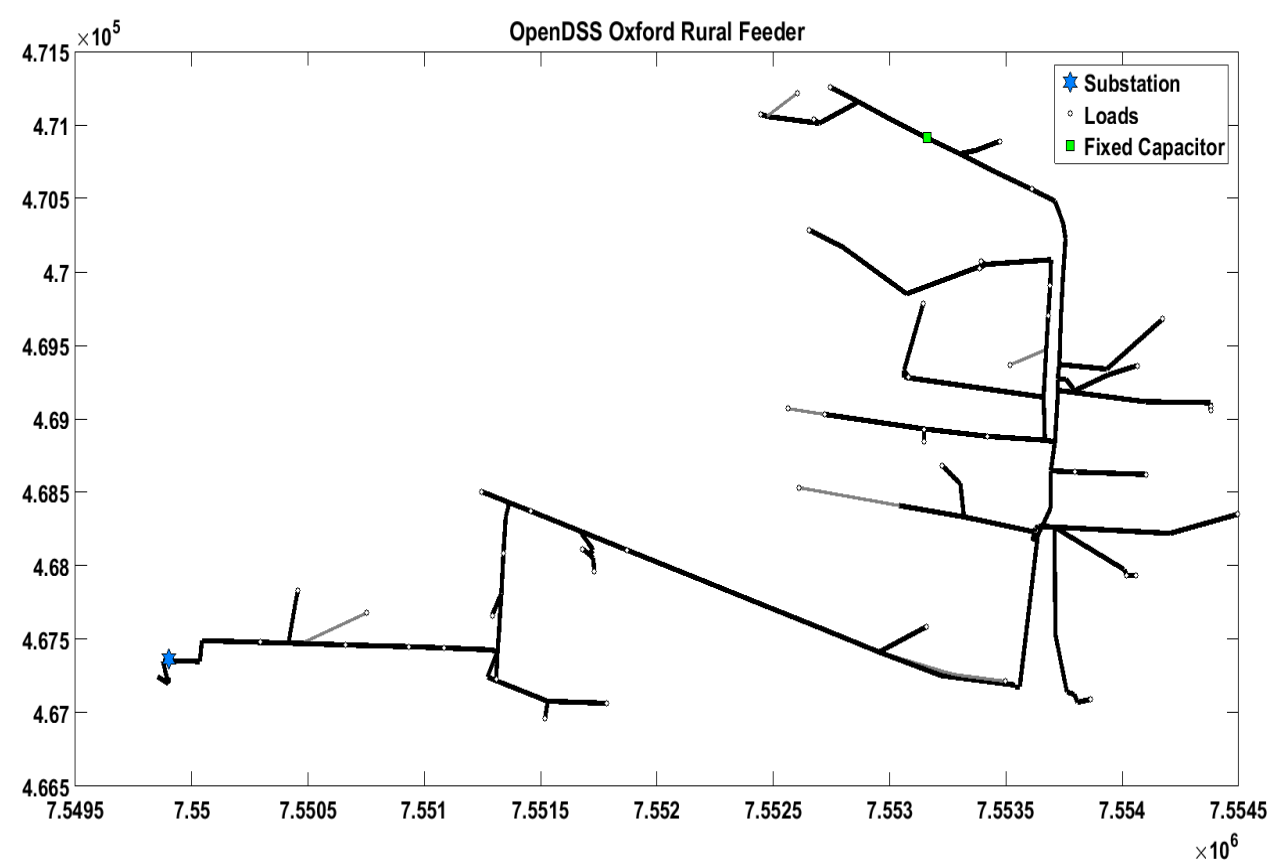

Figure 2.4: OpenDSS Oxford Rural Feeder Model

\subsubsection{Oxford Rural Feeder Model Validation}

The OpenDSS model is not a replica of the utility CYME model, nor is it intended to be. It is a system model of the Oxford Rural feeder, created from utility database information. For this reason, the OpenDSS model is validated against system behavior, not the likeness to its CYME counterpart. We evaluated the model behavior by solving the circuit in five minute increments for 24 hours using the loadshape from the peak day in 2015. At each solution step the program queried the voltage at every load and the current in all feeder lines. A line is considered overloaded if the current exceeds the rated value per the utility database information. A voltage violation is defined by falling outside of the ANSI standard of +/$5 \%$ of the system base voltage. A load voltage violation or line overload indicates the model 
is an inaccurate representation of the system. The validation program shows that neither the voltage nor currents exceeds their respective limits for the peak 2015 day. Appendix A.0.1 contains the line current and load voltages of the 2015 peak hour.

Figure 2.5 shows a snapshot of the per unit voltage of the model at the maximum load. The line voltage decreases as the distance from the substation increases. This is the expected system behavior and is due to line losses. All per unit voltages fall within the ANSI standard of $+1-5 \%$ of the system base voltage.

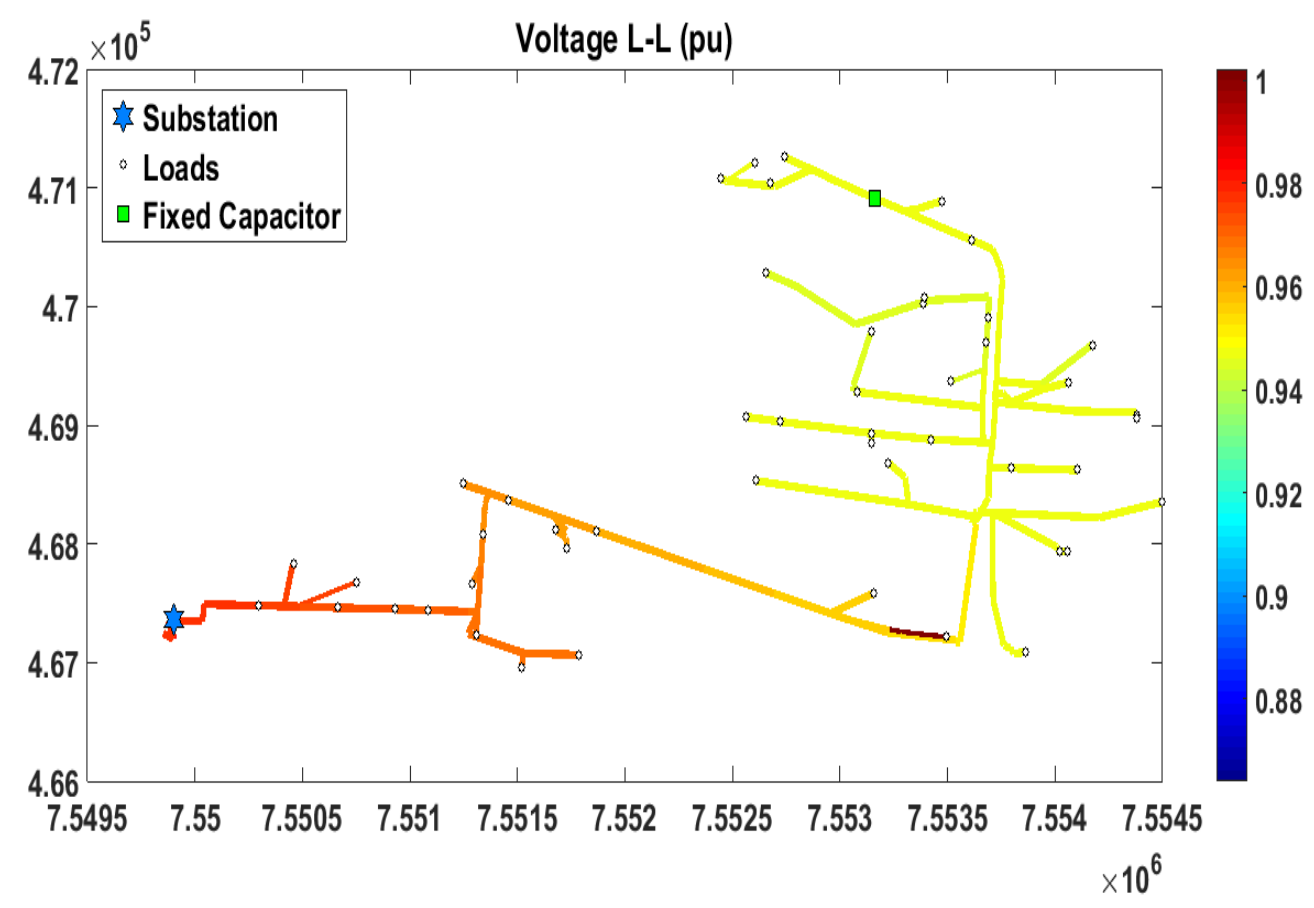

Figure 2.5: OpenDSS Oxford Rural Feeder Per Unit Voltage

Figure 2.6 shows the snapshot solution of the ratio of the system current to the nominal cable rating, at the maximum load. While the loading varies, the lines do not exceed rated current. 


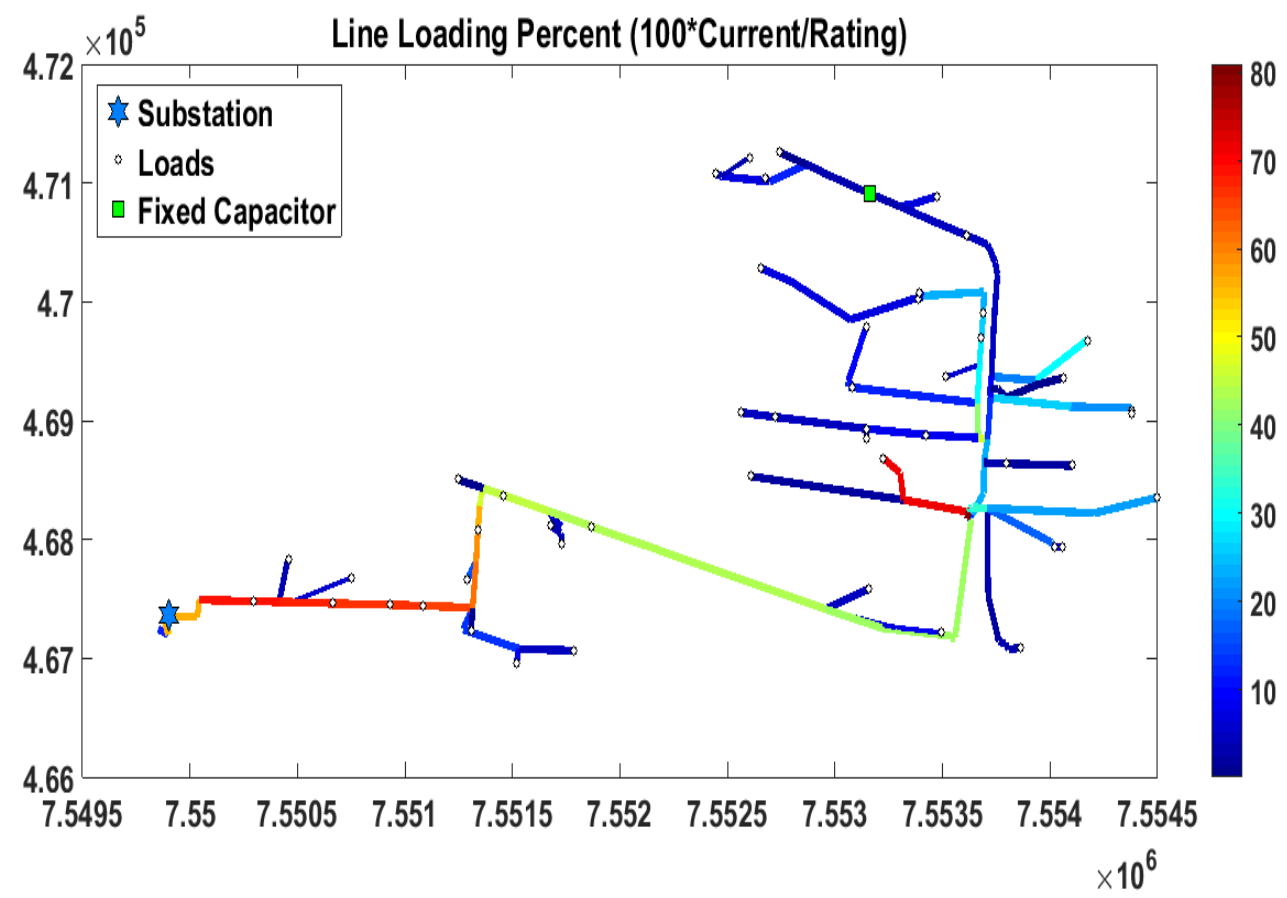

Figure 2.6: OpenDSS Oxford Rural Feeder Line Loading

\subsubsection{Loadshape}

We created the load multiplier using the PGE Oxford Rural 2015 hourly load data, which we interpolated to create a 1440 point curve. We used one minute resolution to increase the likelihood of meeting the load to capacity ratio. The curve data are from the peak day load, on October 21st, 2015. The loadshape multiplier for the peak day in 2015 is found in Appendix A.0.2. 


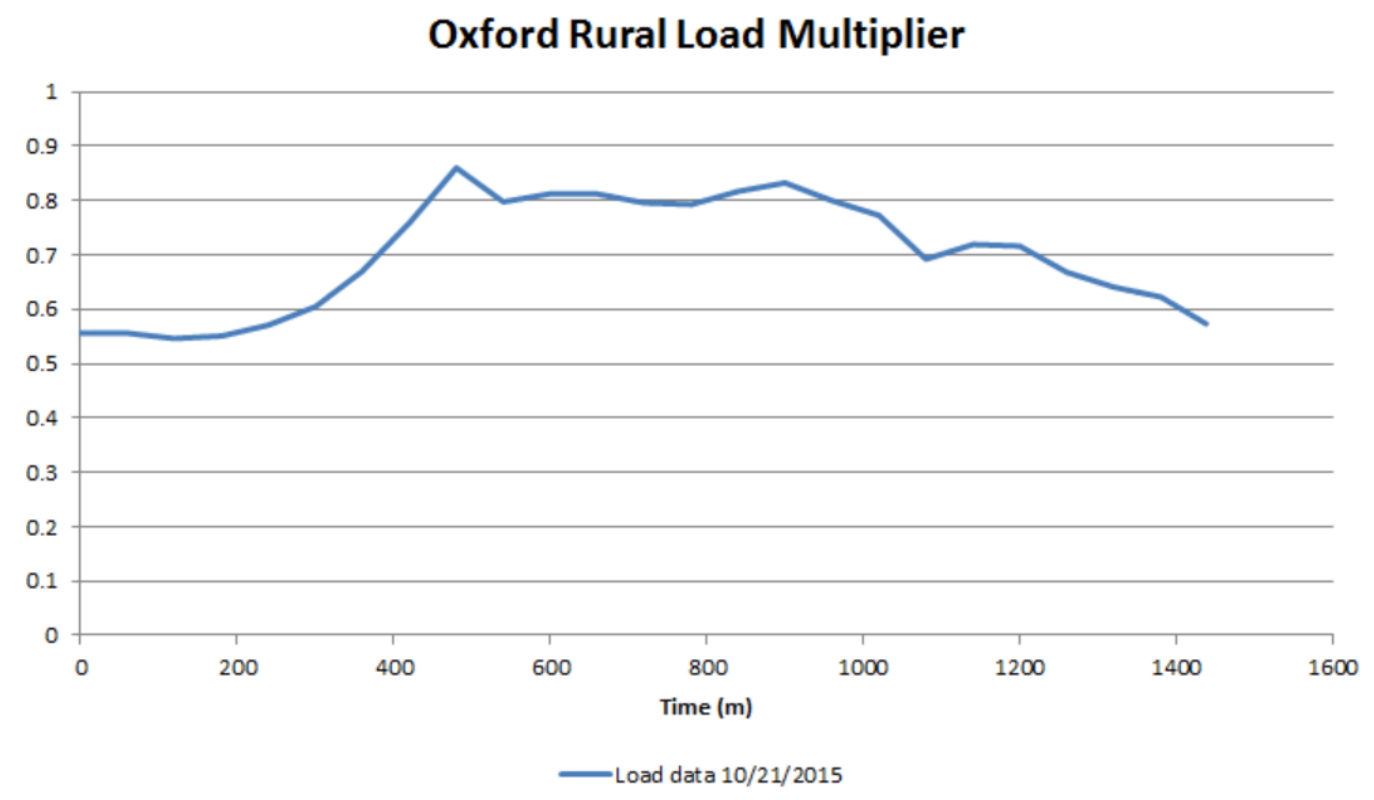

Figure 2.7: Load Multiplier Curve

\subsubsection{Relay Curve}

A relay object in OpenDSS is represented as a curve constructed from a series of time and current values. We used the "extremely inverse" U4 time-overcurrent relay curve as a basis for all generator relay protection. We used current and time values from the SEL U4 curve with a time dial setting of 1 . We varied the instantaneous (50) setting from 2.4 to 2.7 times the rated current. 


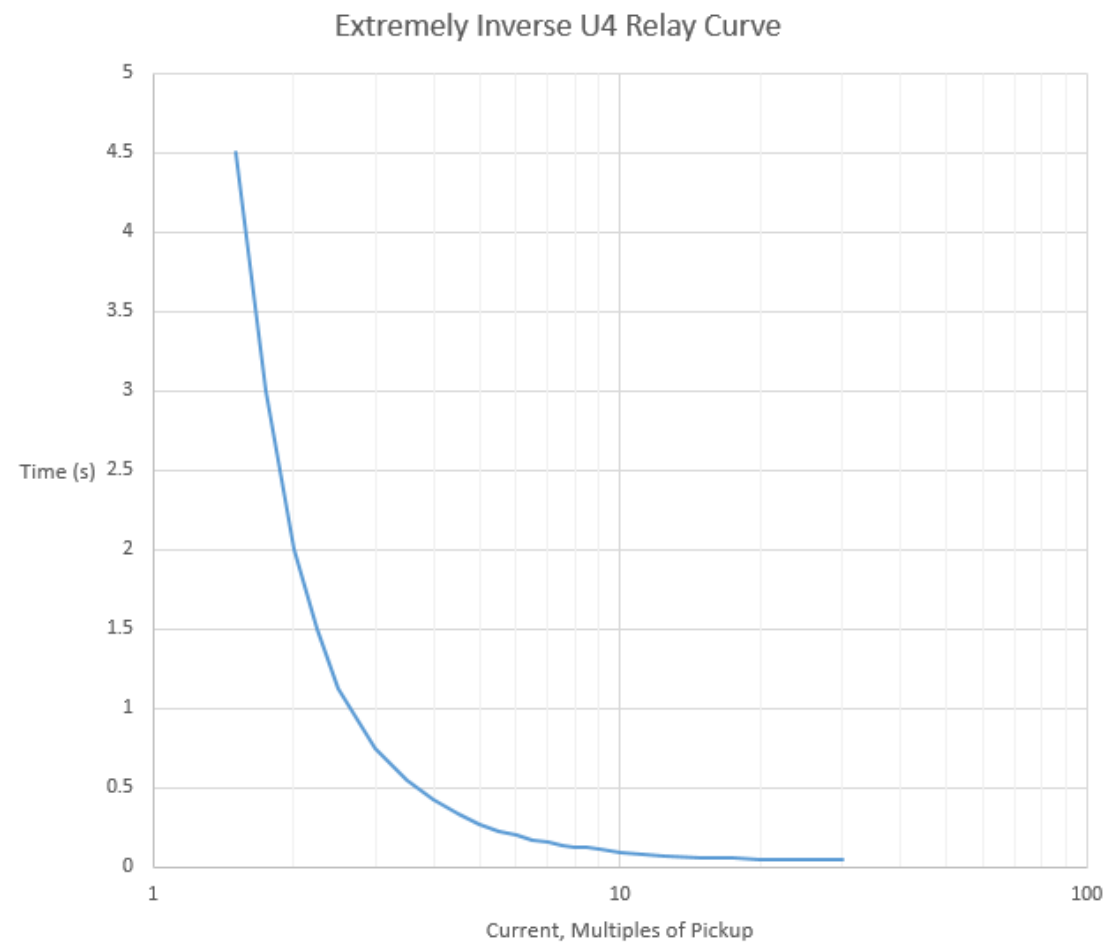

Figure 2.8: Extremely Inverse Curve U4

\subsection{MATLAB Dynamic Study}

We used MATLAB to drive OpenDSS for the dynamic study of the Oxford Rural feeder. We built a loadshape from the PGE 2015 load data, featuring the peak day: October 21, 2015. A 24 hour day is simulated in time steps of one minute, equaling 1440 data points. The generator model capacity varies from $250 \mathrm{~kW}$ to $5000 \mathrm{~kW}$ in steps of $250 \mathrm{~kW}$. The load to capacity ratio (LCR) decrements from three to one in steps of 0.10 .

At each one minute time step, the load multiplier updates and the circuit solves in time mode. The substation current and voltage exports to a CSV file. The control program calculates the apparent power from the exported values. If the generator capacity (kVA) 
is found to be equal to or greater than the load to capacity ratio multiplied by the feeder load, the generator enables and the circuit solves in time mode for one minute, until the generator reaches its rated current. At which point, the solution mode switches to dynamic mode and the circuit solves again. Changing the solution mode converts the generator from a negative load to a Thevenin equivalent model governed by a simple swing equation, as referenced in Equation 2.1 and Equation 2.2. The substation relay opens to simulate a fault. The circuit solves every one millisecond for a maximum of five seconds. At each solution step, the program queries the generator relay to see if it has activated. If the generator relay is active, the program records the time, disables the generator and closes the substation relay. Figure 2.9 displays the dynamic study flow chart. The MATLAB control program is found in Appendix A.0.3. 


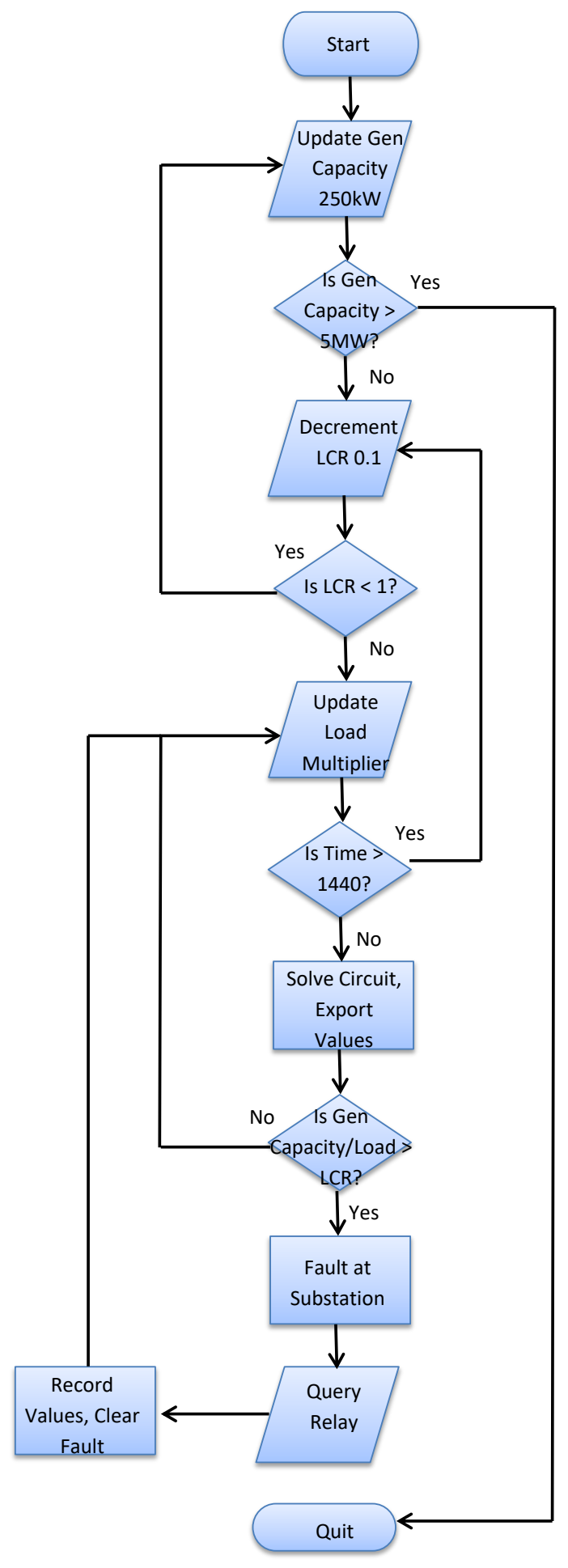

Figure 2.9: Dynamic Study Flow Chart 


\subsubsection{Resource Availability MATLAB program}

The resource availability program monitors and records the substation power for the 2015 peak day to evaluate the potential peak shaving associated with a decreasing load-to-capacity ratio. The generator power capacity is fixed at $2250 \mathrm{~kW}$. The instantaneous (50) element is set at $2.7 \times$ rated for the generator located at customer site 1 . The program reads the substation power in five minute intervals and calculates the load to capacity ratio. If the LCR is met, the generator enables and activates. The program decrements the LCR from three to one in increments of 0.1 . Figure 2.10 displays the resource availability program flow chart. 


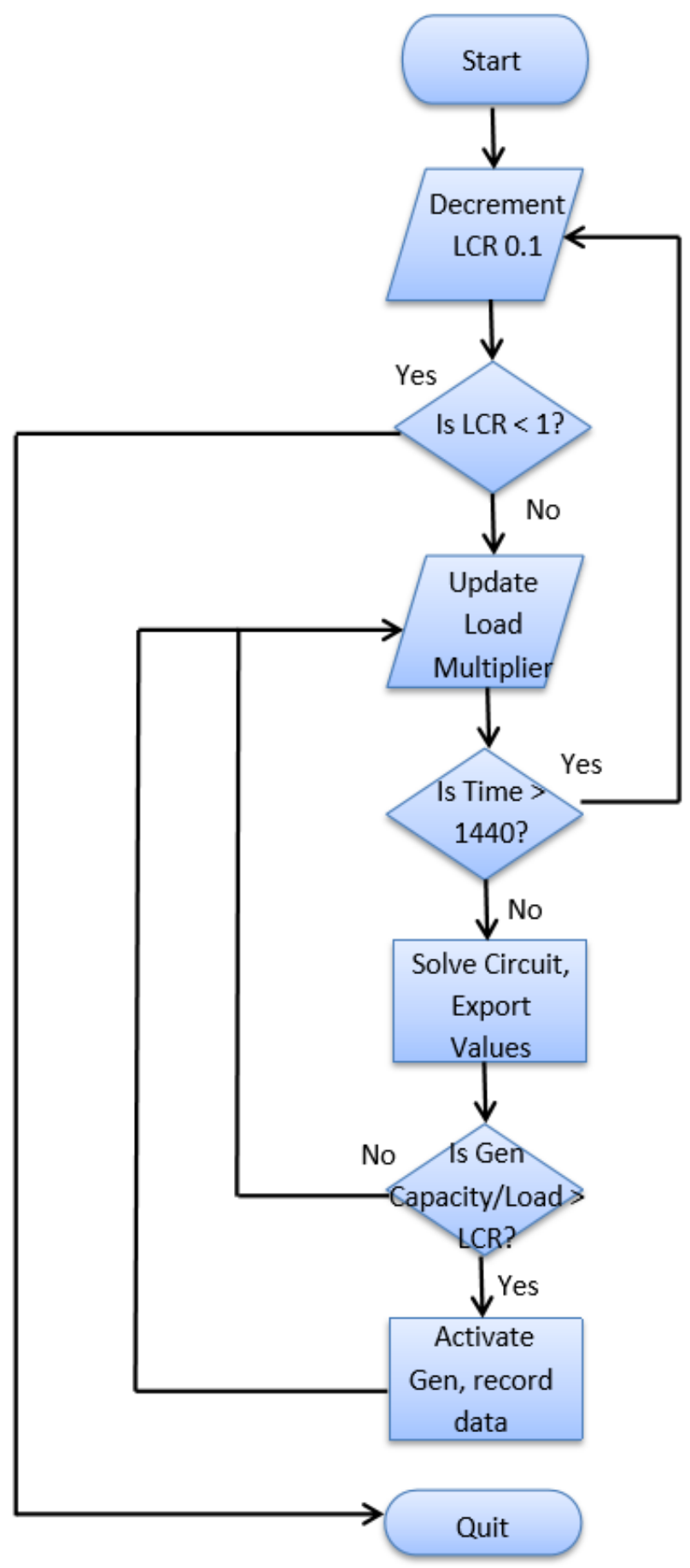

Figure 2.10: Resource Availability Program Flow Chart 


\subsection{CVR by VAr-injection Study}

We examine the real power savings resulting from CVR by VAr-injection on the Oxford Rural feeder to determine the worth of installing an autonomous control program at the substation. The OpenDSS Oxford Rural model loads are modified to account for the varying relationship between power and voltage. We built a battery inverter system feedback model to determine the reactive power injections necessary to raise or lower the voltage. An optimization routine using either the interior-point method or the Lagrange multipliers method determines the optimal voltage. An autonomous control program determines the power savings for the peak 2015 day.

\subsubsection{Load Modeling}

Each load is assigned a ZIP coefficient value based on the customer class and kilowatt hour (kWh) consumption. In practice, the coefficient that best models a commercial business depends on the type of equipment that is used. Due to privacy concerns, this information is unavailable to us. In an effort to maintain diversity among the commercial classifications, we stratified the commercial loads based on consumption, similar to that of residential loads. Table 3.1 displays how we applied ZIP coefficients based on consumer class and consumption. The ZIP coefficients build upon the work of Bokhari, et al [1]. 


\begin{tabular}{lllllllll} 
Customer Class & $\mathbf{L o w}(\mathbf{k W})$ & $\mathbf{H i g h}(\mathbf{k W})$ & $\mathbf{Z p}$ & $\mathbf{I p}$ & $\mathbf{P p}$ & $\mathbf{Z q}$ & $\mathbf{I q}$ & $\mathbf{P q}$ \\
Residential 1 & 0 & 1948 & 1.5 & -2.31 & 1.81 & 7.41 & -11.97 & 5.55 \\
Residential 2 & 1948 & 2897 & 1.57 & -2.48 & 1.91 & 9.28 & -15.29 & 7.01 \\
Residential 3 & 2897 & 3897 & 1.56 & -2.49 & 1.93 & 10.1 & -16.75 & 7.65 \\
Residential 4 & 3897 & 5239 & 1.31 & -1.94 & 1.63 & 9.2 & -15.27 & 7.07 \\
Residential 5 & 5239 & 7741 & 0.96 & -1.17 & 1.21 & 6.28 & -10.16 & 4.88 \\
Residential 6 & 7741 & 20000 & 1.18 & -1.64 & 1.47 & 8.29 & -13.67 & 6.38 \\
Small Commercial 1 & 0 & 1000 & 0.27 & -0.33 & 1.06 & 5.48 & -9.7 & 5.22 \\
Small Commercial 2 & 1000 & 5000 & 0.69 & 0.04 & 0.27 & 1.82 & -2.24 & 1.43 \\
Small Commercial 3 & 5000 & 15000 & 0.77 & -0.84 & 1.07 & 8.09 & -13.65 & 6.56 \\
Small Commercial 4 & 15000 & 50000 & 0.55 & 0.24 & 0.21 & 0.55 & -0.09 & 0.54 \\
Large Commercial 1 & 50000 & 150000 & 0.4 & -0.41 & 1.01 & 4.43 & -7.98 & 4.56 \\
Large Commercial 2 & 150000 & 250000 & 0.76 & -0.52 & 0.76 & 6.92 & -11.75 & 5.83 \\
Industrial & 250000 & 500000 & 1.21 & -1.61 & 1.41 & 4.35 & -7.08 & 3.72 \\
\hline
\end{tabular}

Table 2.1: ZIP Coefficient Parameters [1]

\subsubsection{Model Sensitivity to ZIP Coefficient Parameters}

We analyzed the sensitivity of the model voltage and currents to changes in the ZIP parameters by varying the coefficients $+/-10 \%$ and solving the circuit for the peak day in 2015. Table 2.2 displays the average, minimum and maximum change in line current. The relationship shows a proportionality constant of nearly -1 for both the $10 \%$ increase and decrease. The current did not exceed the rated value in any of the feeder model lines as a result of the ZIP coefficient changes.

Table 2.2: ZIP Coefficient Sensitivity Analysis for Line Currents

\begin{tabular}{lll} 
Percent Change & $\mathbf{- 1 0 \%}$ & $\mathbf{+ 1 0 \%}$ \\
$\Delta_{\text {Average }}$ & 9.02 & -9.23 \\
$\Delta_{\text {Maximum }}$ & 10.76 & -10.8 \\
$\Delta_{\text {Minimum }}$ & -0.79 & 0.71 \\
\hline
\end{tabular}

Table 2.3 shows the average, minimum and maximum change in per unit load voltages. The voltage is significantly less sensitive to changes in the ZIP parameters than the current. 
The system load voltages did not exceed $+/-5 \%$ of the system base voltage as the load modeling parameters were varied.

Table 2.3: ZIP Coefficient Sensitivity Analysis for Load Voltages

\begin{tabular}{lll} 
Percent Change & $\mathbf{- 1 0 \%}$ & $\mathbf{+ 1 0 \%}$ \\
$\Delta_{\text {Average }}$ & -0.28 & 0.28 \\
$\Delta_{\text {Maximum }}$ & -0.04 & 0.87 \\
$\Delta_{\text {Minimum }}$ & -0.86 & 0.04 \\
\hline
\end{tabular}

\subsubsection{Plant Model}

We captured the relationship between reactive power and feeder voltage on March 13, 2016 at the Salem Smart Power Center (SSPC). The inverter system injected reactive power at the feeder head node and we recorded the resulting Oxford Rural feeder voltage. Figure 2.11 and Figure 2.12 display the interpolated data. The largest reactive power step of $4000 \mathrm{kVAr}$ results in a voltage change of $2.3 \%$.

\begin{tabular}{lllll} 
Injection (kVAr) & Volt Min (V) & Volt Max (V) & Volt Change (V) & Volt Change (\%) \\
\hline 100 & 12813 & 12842 & 29 & 0.23 \\
500 & 12762 & 12832 & 70 & 0.56 \\
1000 & 12669 & 12761 & 92 & 0.73 \\
2000 & 12636 & 12802 & 166 & 1.31 \\
4000 & 12651 & 12943 & 292 & 2.31 \\
\hline
\end{tabular}

Table 2.4: Voltage Change as a Function of kVAr Injection 


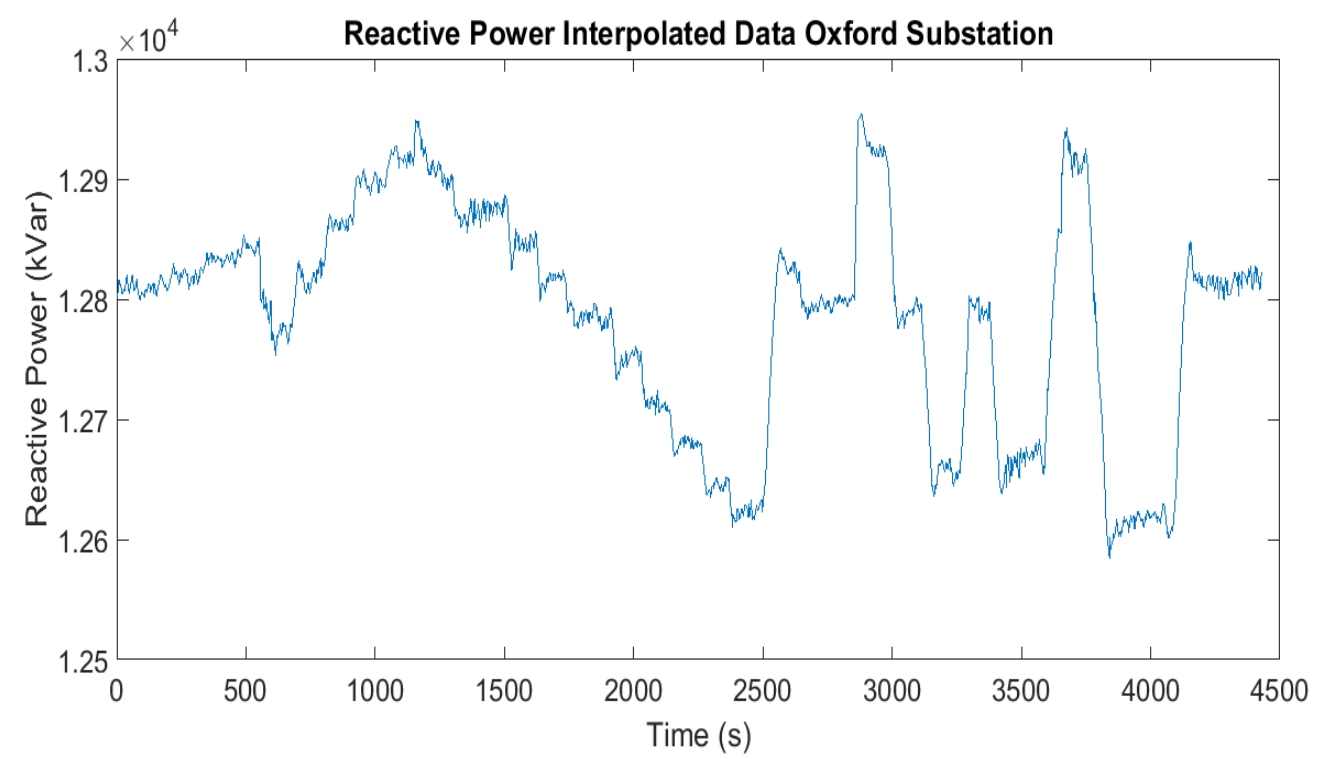

Figure 2.11: Battery Inverter System Reactive Power Injections

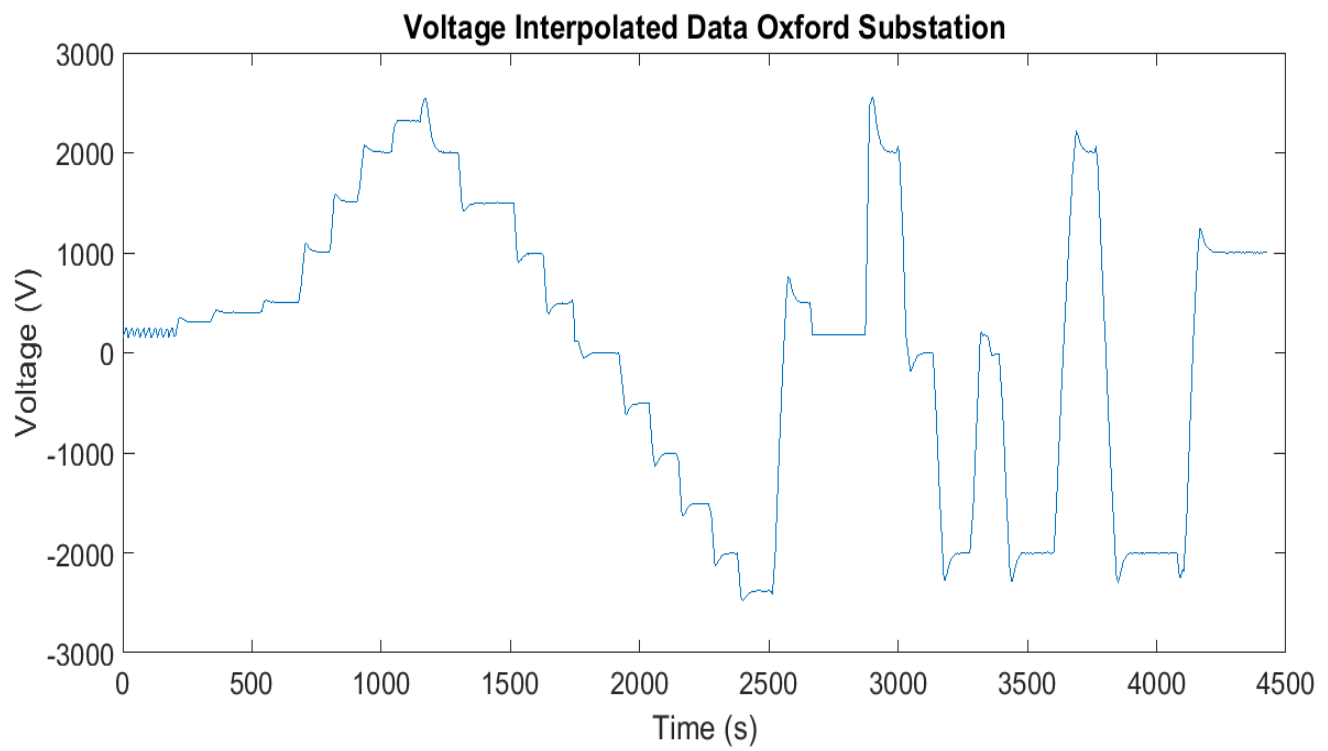

Figure 2.12: Oxford Rural Feeder Voltage Response Data

We used the MATLAB System Identification toolbox to create the transfer functions based on the interpolated data. The system dynamics depend upon the amount of kVAr injected. The larger the injection, the larger the overshoot and the longer the settling time. 
To retain the system dynamics, we created five different feedback system models. Table 2.4 summarizes the selected data used to build the plant models in Simulink. The feedback models were verified against the collected data. We confirmed the system stability by plotting the frequency response and confirming the real eigenvalues were positive numbers. Figures 2.13 through Figure 2.17 display the frequency response of each plant model.

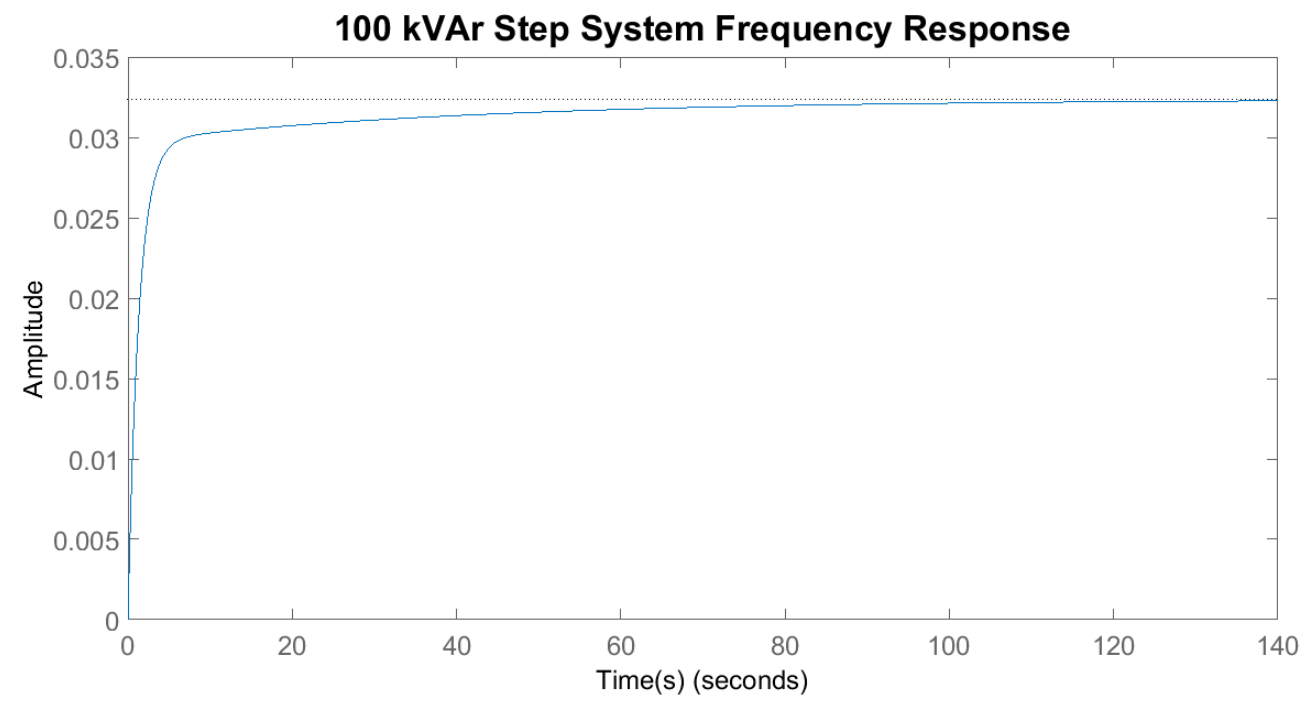

Figure 2.13: Plant Model Response - $100 \mathrm{kVAr}$ 


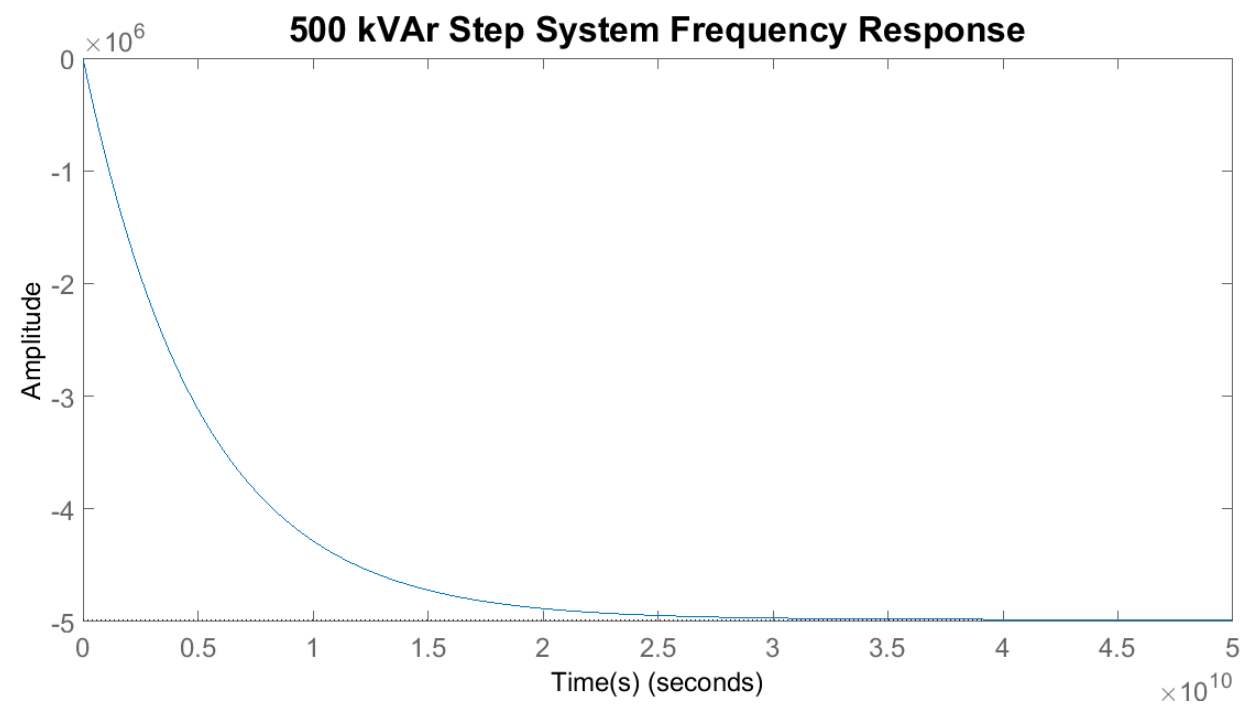

Figure 2.14: Plant Model Response - $500 \mathrm{kVAr}$

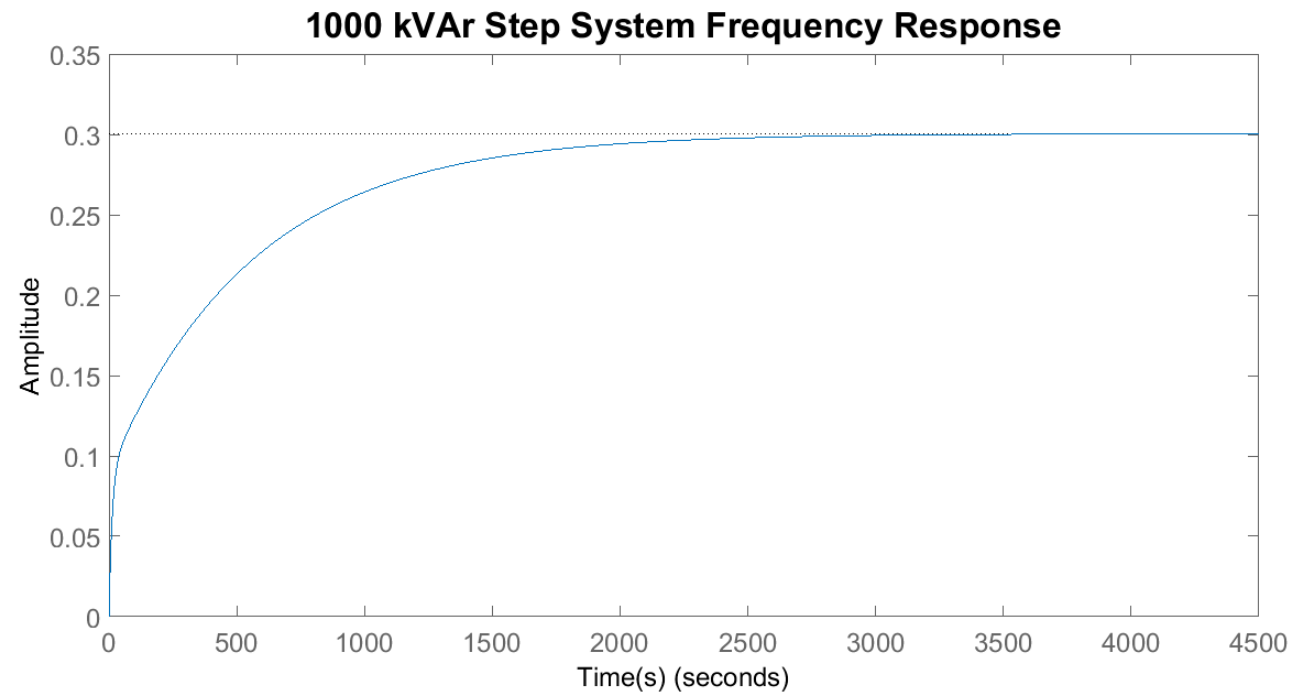

Figure 2.15: Plant Model Response - $1000 \mathrm{kVAr}$ 


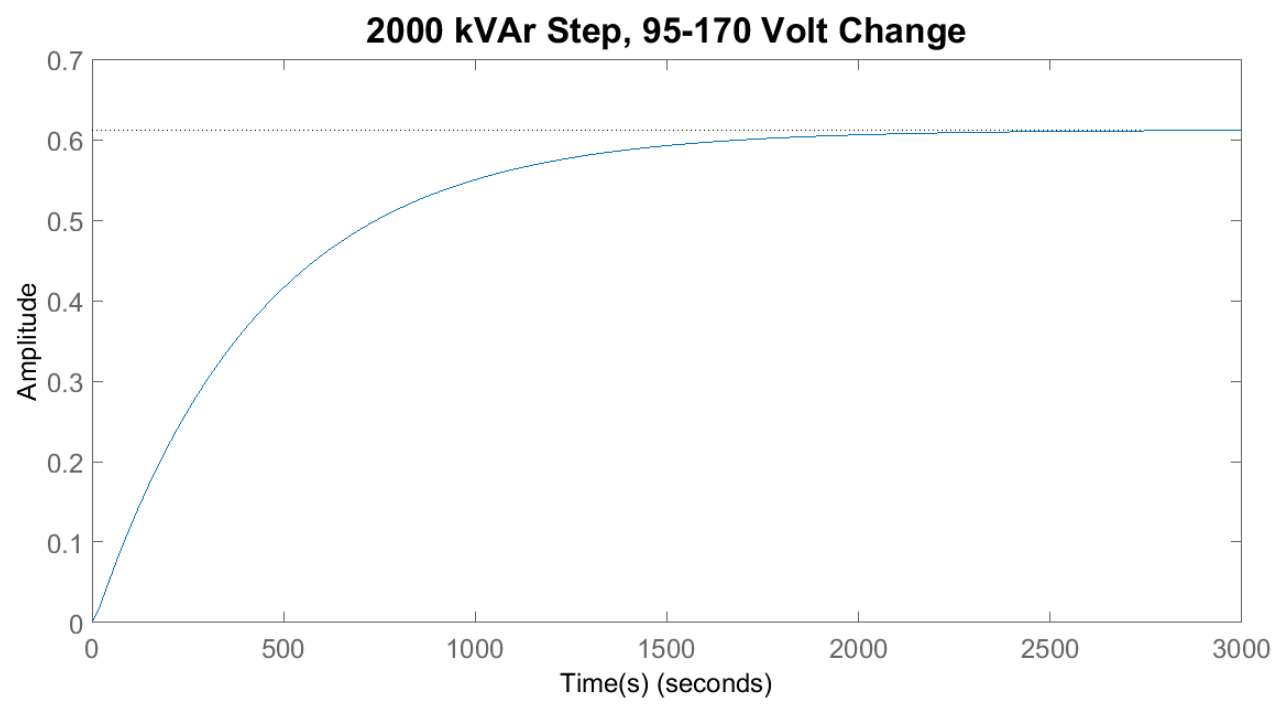

Figure 2.16: Plant Model Response - 2000 kVAr

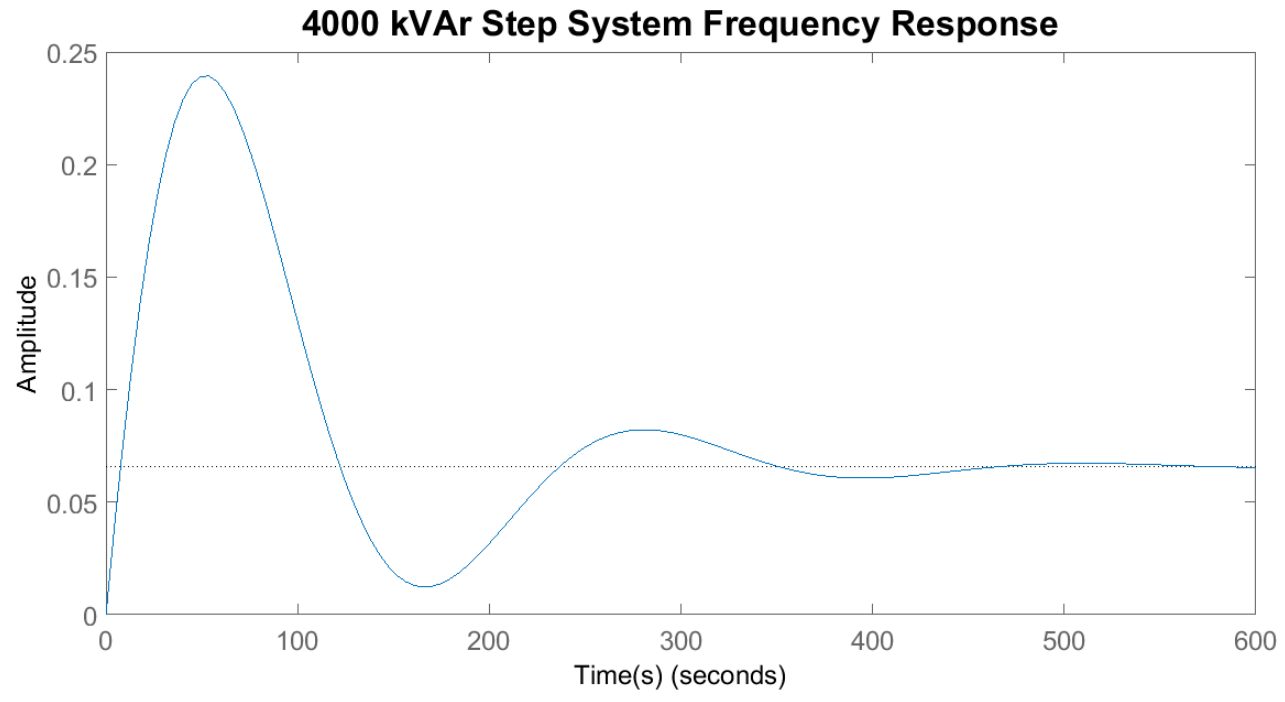

Figure 2.17: Plant Model Response - $4000 \mathrm{kVAr}$

The BIS is grid-tied to the Oxford Rural feeder. Therefore, the system response data is influenced by the connection to the load. We created a multiplier to ensure continuity between the plant model response and that of the OpenDSS Oxford Rural feeder. Figure 3.9 displays the relationship between reactive power and voltage for the two systems. 


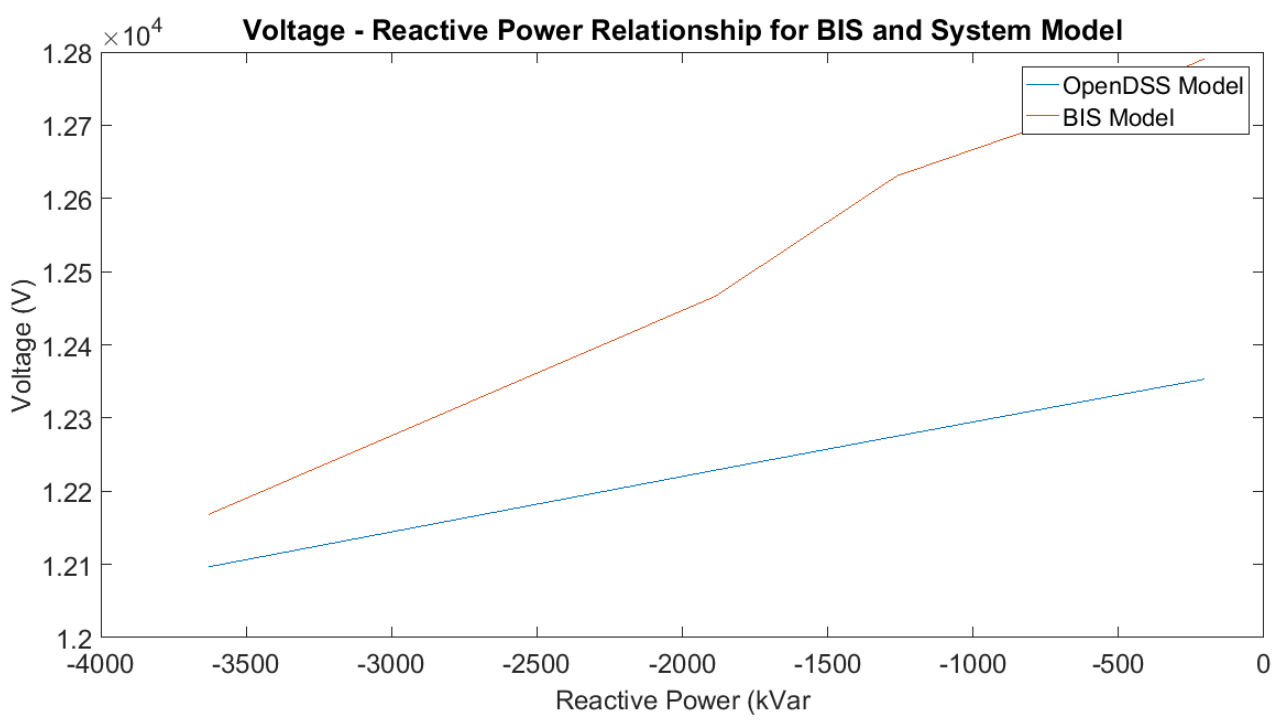

Figure 2.18: Voltage and Reactive Power Relationship for the BIS and OpenDSS Model

The MATLAB polyfit function determined the linear relationship for each respective system. Figure 2.19 shows the block diagram relationship for the voltage and reactive power systems.

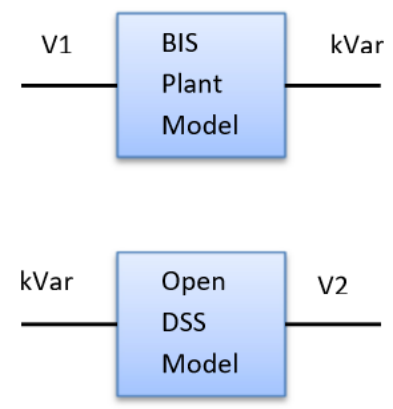

Figure 2.19: System Block Diagrams

The BIS and Oxford Rural feeder system can be described by Equation 2.4 :

$$
V_{1} X=k V A r
$$


Where,

$$
\begin{aligned}
V_{1} & =\left[v_{\text {opt }}, 1\right] \\
X & =[5.40,-6.93 e+04]^{T} \\
v_{\text {opt }} & =\text { Optimized Voltage } \\
k V A r & =\text { BIS Plant Model Output }
\end{aligned}
$$

The OpenDSS model of the BIS and the Oxford Rural feeder can be described by Equation 2.5:

$$
k V A r Y=V_{2}
$$

Where,

$$
\begin{aligned}
V_{2} & =\left[v_{\text {out }}, 1\right] \\
Y & =[0.075,1.24 e+05]^{T} \\
v_{\text {out }} & =\text { System Voltage }
\end{aligned}
$$

The output voltage of the OpenDSS model $V_{2}$, as a function of the optimized voltage $V_{1}$, can be described by Equation 2.6.

$$
V_{2}=\frac{\frac{(V 1-Y(1,2)}{Y(1,1)}-X(1,2)}{X(1,1)}
$$

The volt-VAr optimization program transforms the output voltage of the optimization routine using the relationship between $V_{1}$ and $V_{2}$. The revised voltage acts as an input to the BIS feedback model. When the resulting reactive power is injected into the OpenDSS model it creates a system voltage equivalent to the original optimized value. 


\subsubsection{Cost Equation Development}

We developed the relationship between power and voltage by sweeping the Oxford Rural OpenDSS model from the minimum to the maximum allowable ANSI voltage. At each solution step the circuit solves, the head voltage is decremented and the power and voltage exports to a CSV file. We used the curve fitting tool in MATLAB to determine the coefficients of the linear relationship for the head feeder node and all system loads. Figure 2.20 displays the voltage and power relationship at the feeder node for the OpenDSS model. Equation 2.7 describes the linear relationship.

$$
P(v)=0.198 v+1603.840
$$

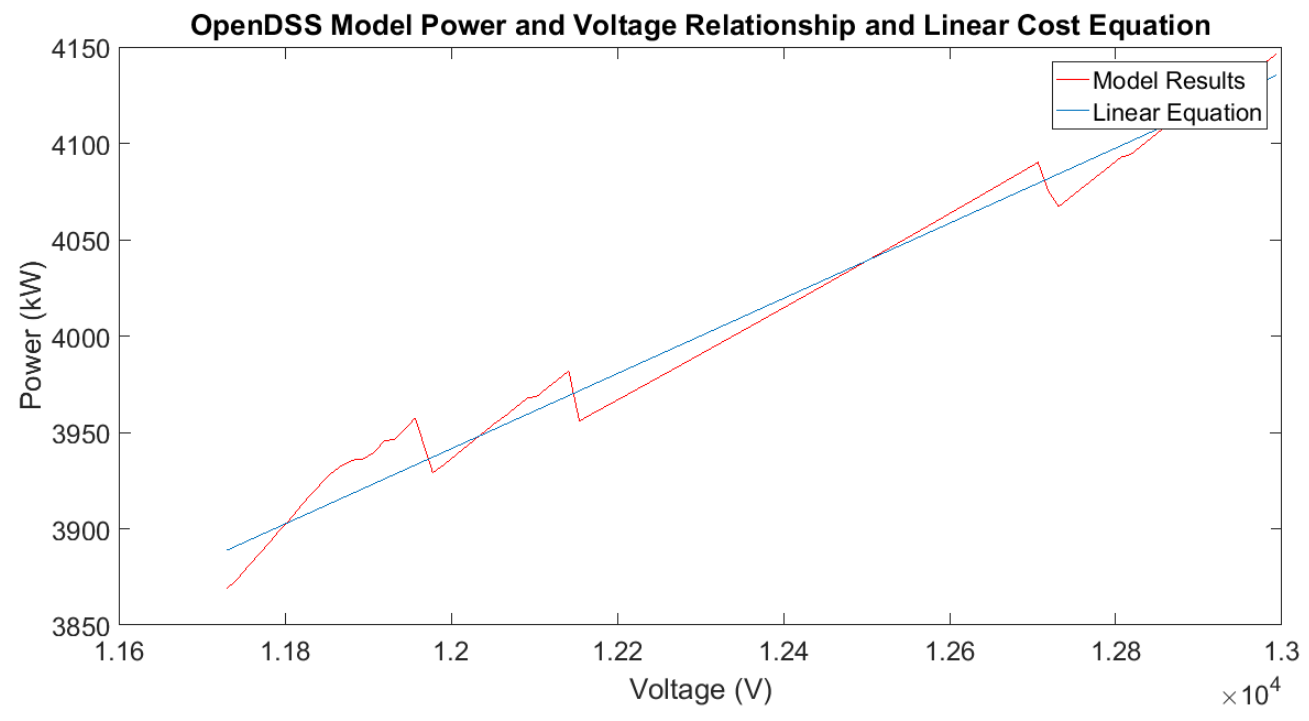

Figure 2.20: OpenDSS Model Power and Voltage and Cost Equation

\subsubsection{MATLAB Optimization Routine}

The CVR by VAr-injection study is a constrained optimization problem. The routine must minimize the system power while maintaining a voltage at each load which falls within the 
ANSI standard range.

$$
\left\{\begin{array}{l}
\min _{v} P(v) \\
\text { subject to } \\
0.95\left(V_{\text {base }}\right)<=v<=1.05\left(V_{\text {base }}\right) \\
0.95\left(V_{\text {base }}\right)<=V<=1.05\left(V_{\text {base }}\right)
\end{array}\right.
$$

Where,

$$
\begin{array}{r}
P(v)=0.198 v+1603.840 \\
v=\text { substation voltage }, v \epsilon \Re^{1} \\
V=\text { load voltages }, V \epsilon \Re^{137 x 1} \\
V_{\text {base }}=12470
\end{array}
$$

Two different methods are used to obtain the ideal system voltage, the interior-point algorithm from the built-in MATLAB function 'fmincon' and the Lagrange mutlipliers method. Since the constrained, optimization problem is relatively simple, using the built-in MATLAB function would generally suffice. However, the information we receive from the Lagrange Multipliers method informs us of any nodes which are particularly sensitive to the voltage constraints, indicating that the system may benefit from monitoring or additional equipment to ensure the voltage does not drop below the ANSI standards. 


\subsubsection{Fmincon}

The built-in MATLAB function, fmincon finds the minimum of an objective function within a defined upper and lower bound, subject to the constraints, $A x=b$. The upper and lower bounds are defined by the ANSI voltage standards. We create the constraint system of equations by determining a linear relationship between the load voltage at each node as a function of the substation voltage. Each load node voltage equation is set to less than the maximum allowable voltage or greater than the minimum voltage. The equation is then rearranged to comply with MATLAB standards. The remaining set of equations form the constraint matrix A and vector $\mathrm{b}$.

$$
\begin{array}{r}
V_{i}(v)=c_{i} v+d_{i} \\
V_{i}(v) \geq 0.95\left(V_{\text {base }}\right) \\
V_{i}(v) \leq 1.05\left(V_{\text {base }}\right)
\end{array}
$$

Becomes,

$$
\begin{array}{r}
A(i, 1) x \leq b(i, 1) \\
A(i+1,1) x \leq b(i+1,1)
\end{array}
$$

Where,

$$
\begin{array}{r}
A(i, 1)=c_{i} \\
A(i+1,1)=-c_{i} \\
b(i, 1)=1.05\left(V_{\text {base }}\right)-d_{i} \\
b(i+1,1)=-0.95\left(V_{\text {base }}\right)+d_{i}
\end{array}
$$


The MATLAB code used to create the linear constraint system is found in Appendix

\section{B.0.1 Fmincon.}

\subsubsection{Lagrange Multipliers}

The method of Lagrange Multipliers is used to convert a constrained optimization problem into an unconstrained optimization problem. Slack variables convert the inequality constraints to equality constraints. The Lagrangian function, $\mathrm{L}(\mathrm{x})$ is formed by subtracting the constraints from the objective function. The system of equations is formed by taking the gradient with respect to each variable, including the Lagrange Multipliers. The system of equations is set to zero and the resulting vector is the minimized solution. The values of $\lambda$, the Lagrange multipliers, indicate the sensitivity of the constraints to the objective function.

$$
L\left(v, \lambda_{1}, \lambda_{2}, \lambda_{3}, \lambda_{4}, s, t, S, T\right)=P(v)-\lambda_{1}(c 1)-\lambda_{2}(c 2)-\lambda_{3}(c 3)-\lambda_{4}(c 4)
$$

Where,

$$
\begin{gathered}
P(v)=0.198 v+1603.840 \\
c 1=-v+0.95\left(V_{\text {base }}\right)+s^{2} \\
c 2=v-1.05\left(V_{\text {base }}\right)+t^{2} \\
c 3=-V+0.95\left(V_{\text {base }}\right)+S^{2} \\
c 4=V-1.05\left(V_{\text {base }}\right)+T^{2}
\end{gathered}
$$

And,

$$
\nabla_{L\left(v, \lambda_{1}, \lambda_{2}, \lambda_{3}, \lambda_{4}, s, t, S, T\right) v}=0.198+\lambda_{1}-\lambda_{2}+\lambda_{3} \frac{\partial V}{\partial v}-\lambda_{4} \frac{\partial V}{\partial v}
$$




$$
\nabla_{L\left(v, \lambda_{1}, \lambda_{2}, \lambda_{3}, \lambda_{4}, s, t, S, T\right) \lambda_{1}, \lambda_{2}, \lambda_{3}, \lambda_{4}}=\left|\begin{array}{c}
v-0.95\left(V_{\text {base }}\right)-s^{2} \\
v+1.05\left(V_{\text {base }}\right)-t^{2} \\
V-0.95\left(V_{\text {base }}\right)-S .^{2} \\
-V+1.05\left(V_{\text {base }}\right)-T .^{2}
\end{array}\right|
$$

The MATLAB code used to create the linear constraint system is found in Appendix B.0.2 Lagrange Multipliers.

\subsubsection{Model based Volt-VAr Optimization Algorithm}

The autonomous control program is capable of CVR and feeder smoothing. The CVR program calculates the voltage that minimizes the system power and determines the corresponding kVAr value that will achieve the optimal voltage. The feeder smoothing profile option minimizes or maximizes the system power depending upon the load consumption and renewable energy generation. If the renewable energy generation is lower than the consumption, the routine will minimize the voltage and decrease the system power. If the generation is greater than the consumption, the routine calculates the maximum allowable voltage. Once the target voltage set point is found the routine retrieves the reactive power necessary 
to achieve the optimized voltage. Figure 2.21 displays autonomous control program flow chart. The optimization routine MATLAB code is found in Appendix B.0.3. 


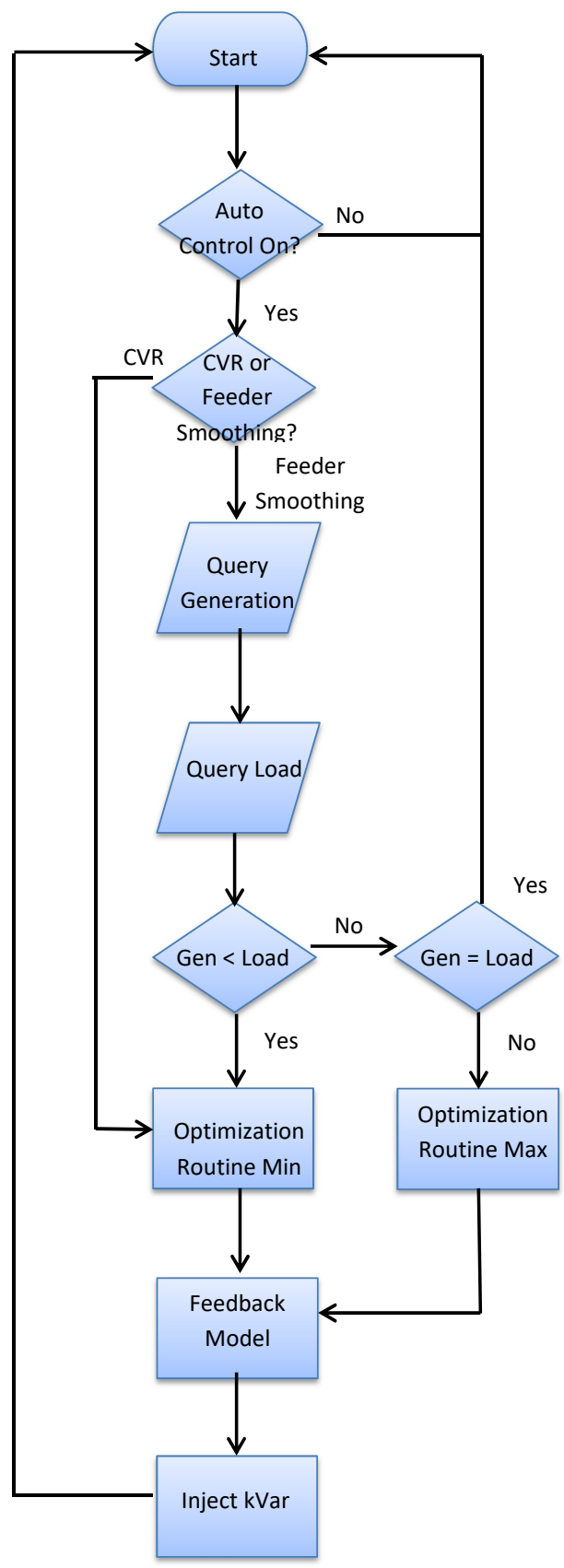

Figure 2.21: Autonomous Control Program Flow Chart 


\section{Results \& Analysis}

\subsubsection{MATLAB Dynamic Study}

The results of the MATLAB control program for both DG customer sites show that the instantaneous (50) setting of the generator protection relay dictates the maximum load to capacity ratio (LCR).

The power consumption of the feeder is measured at the substation. When the DG is not active, the power measured at the substation, $P_{S u b}$, and the load power, $P_{\text {Load }}$, are equivalent.

$$
\begin{gathered}
P_{\text {Sub }}=P_{\text {Load }}-P_{\text {Gen }} \\
L C R=\frac{P_{\text {Sub }}}{P_{\text {Gen }}}
\end{gathered}
$$

When the LCR is defined, as in Equation 3.2, the DG is made available as a resource. If the DG is brought on-line, the power measured at the substation reduces by an amount equal to the generator capacity. Once the generator turns on, the ratio of the load to the generator capacity, $P_{G e n}$ may be expressed in terms of $P_{\text {Load }}$ and $P_{\text {Gen Rated }}$ as: 


$$
\begin{aligned}
& L C R=\frac{P_{\text {Sub }}}{P_{\text {Gen }} \text { Rated }} \\
& =\frac{P_{\text {Load }}-P_{G e n_{\text {Rated }}}}{P_{G e n_{\text {Rated }}}} \\
& =\frac{P_{\text {Load }}}{P_{\text {Gen }}}-1
\end{aligned}
$$

The generator protection settings are determined by the ratio of the load power to the generator power. Once the ratio of the load to the generator exceeds the instantaneous (50) element setting, GENOC50, the relay will activate.

$$
G E N O C 50=\frac{P_{\text {Load }_{\text {Max }}}}{P_{\text {Gen }}}
$$

Substituting Equation 3.4 into Equation 3.3 reveals the minimum ratio that ensures the instantaneous (50) protection element will activate as expected is:

$$
\begin{aligned}
& L C R_{\text {Min }}=\frac{P_{\text {Load }_{\text {Max }}}}{P_{\text {Gen }}}-1 \\
& =G E N O C 50-1
\end{aligned}
$$

Additionally, the maximum DG capacity on a feeder that guarantees the instantaneous (50) element will operate is:

$$
P_{G e n_{M a x}}=\frac{P_{\text {Load }_{M a x}}}{L C R_{M i n}+1}
$$




\subsubsection{DG Customer Site 1}

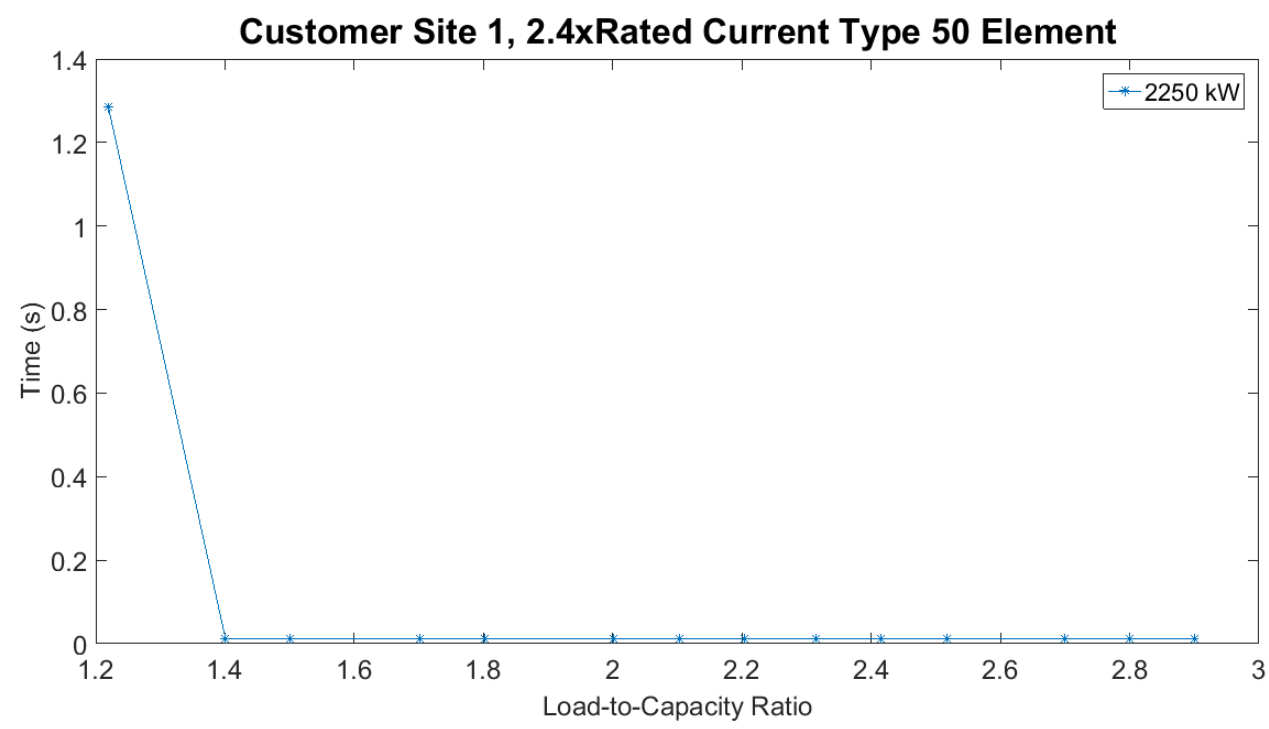

Figure 3.1: DG Site 1, 50/51 Element Operating Times, 2.4xRated

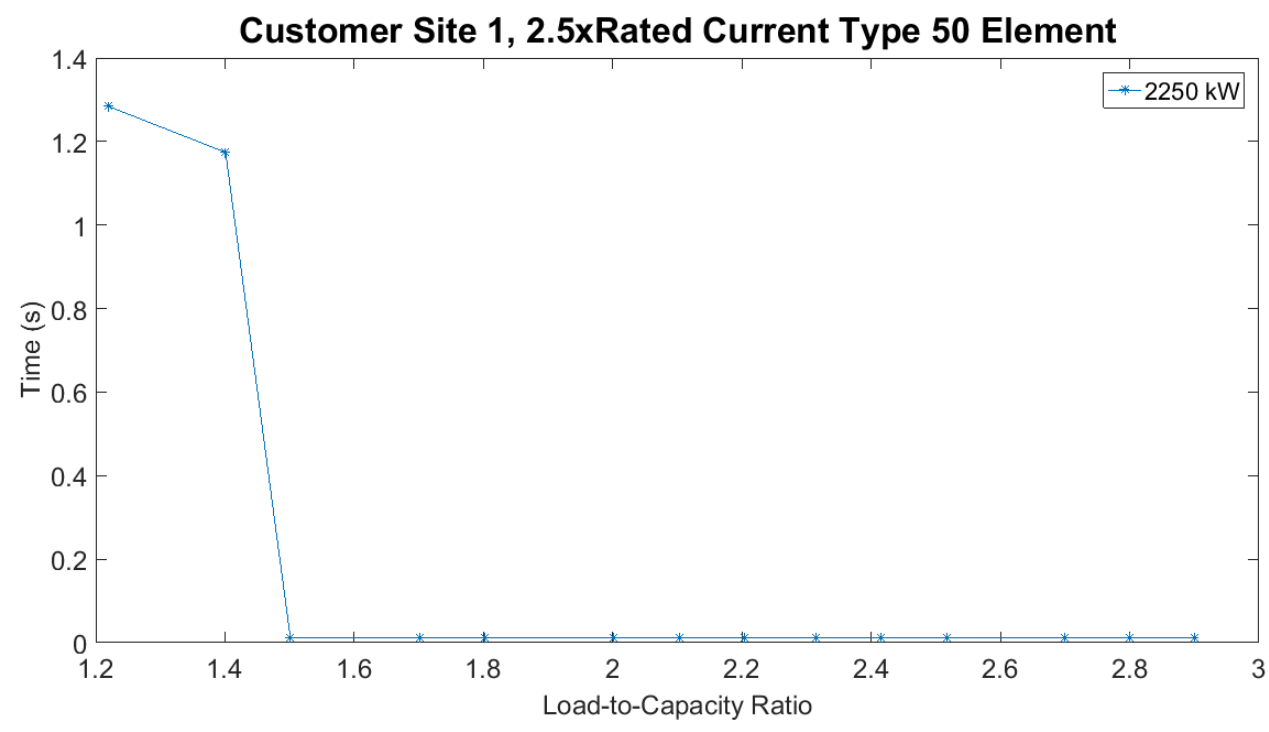

Figure 3.2: DG Site 1, 50/51 Element Operating Times, 2.5xRated 


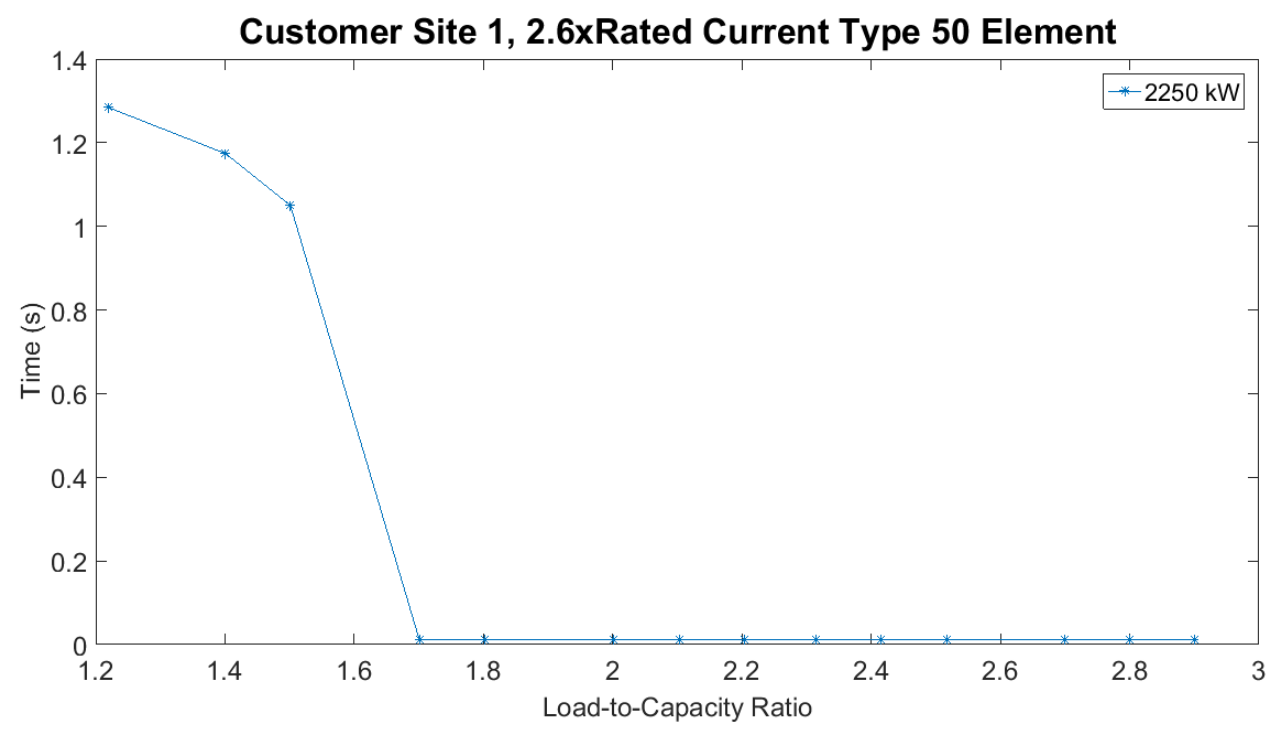

Figure 3.3: DG Site 1, 50/51 Element Operating Times, 2.6xRated

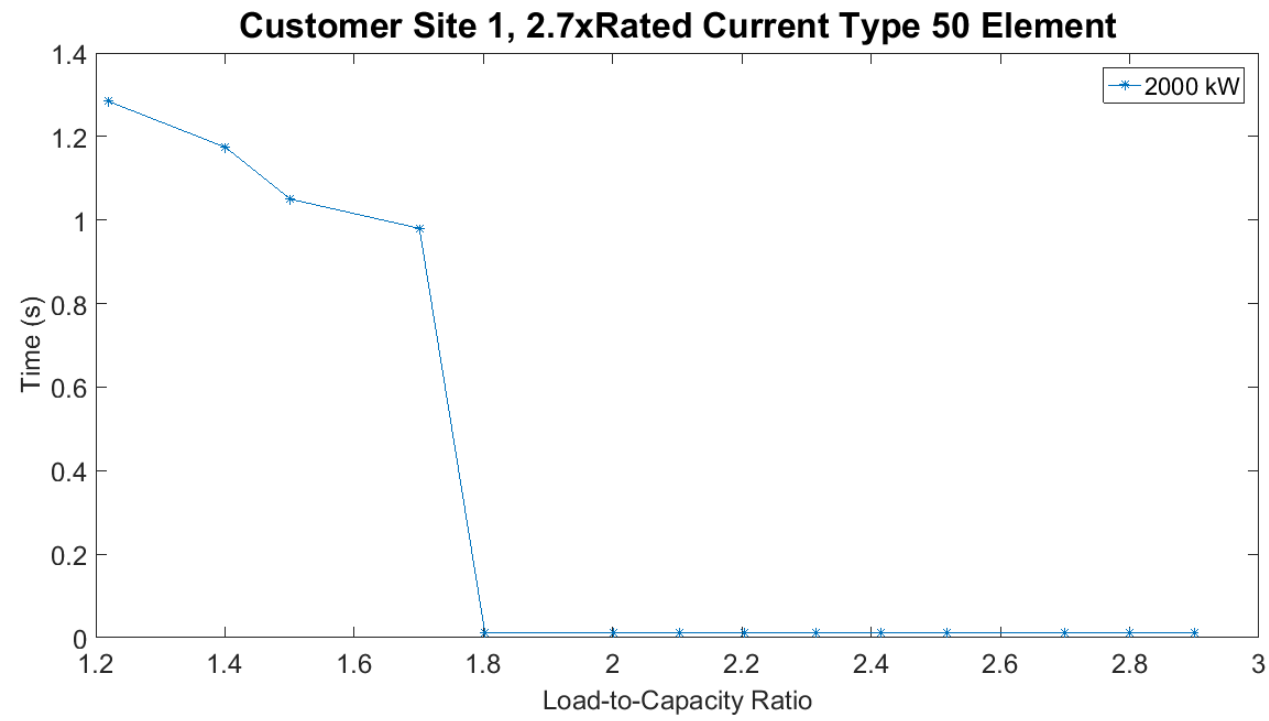

Figure 3.4: DG Site 1, 50/51 Element Operating Times, 2.7xRated

Figure 3.1 through Figure 3.4 display the generator 50/51 protection element operating times. The instantaneous (50) element activates whenever the generator capacity exceeds the maximum as calculated in Equation 3.6 and the ratio drops below the minimum as calculated in Equation 3.5. Thus, the relay operates as expected, until the ratio falls below: 


$$
L C R<G E N O C 50-1
$$

In the case of the Figure 2.8, it appears as though the results deviate from the trend. However, the program is written to search for a target window surrounding the load to capacity ratio. Throughout the 24 hour period the load did not reach $1.6+/-0.09$ times the generator capacity. While there is not a data point for this ratio, the relay behaved as though governed by the calculations above. The instantaneous (50) element did not activate after the calculated ratio fell below the minimum.

\subsubsection{DG Customer Site 2}

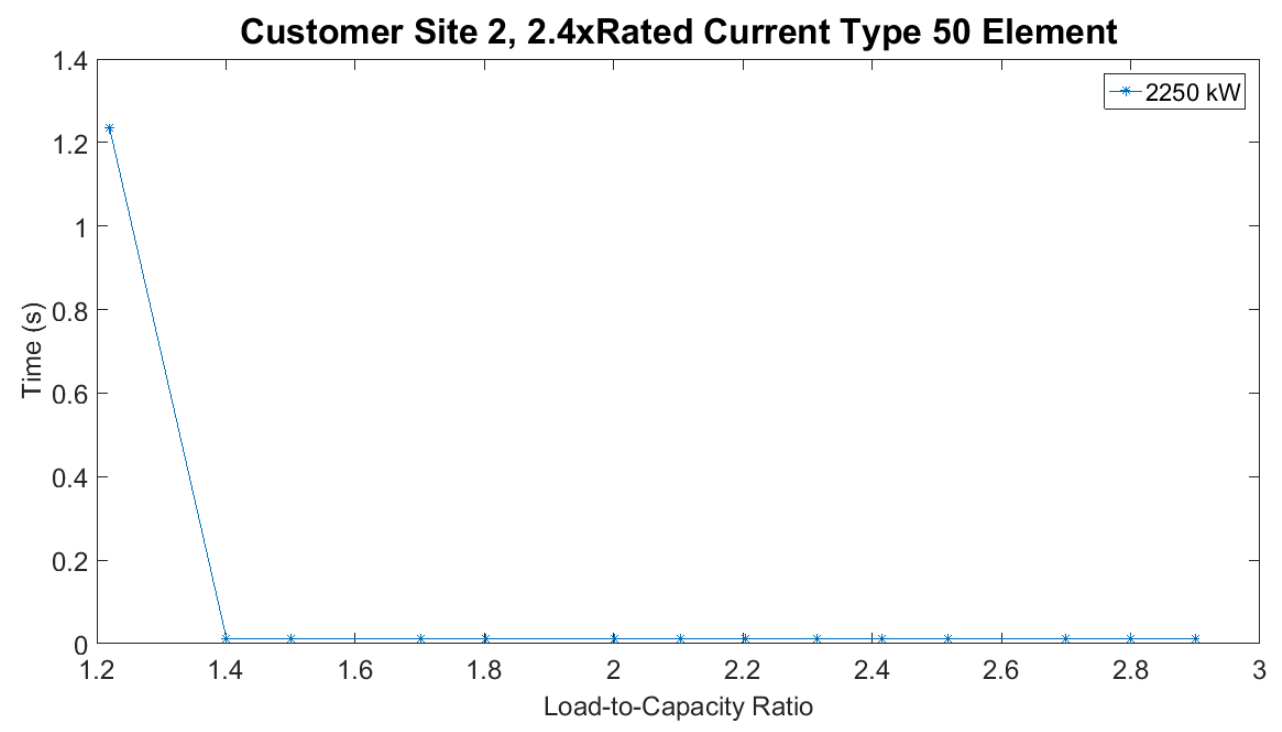

Figure 3.5: DG Site 2, 50/51 Element Operating Times, 2.4xRated 


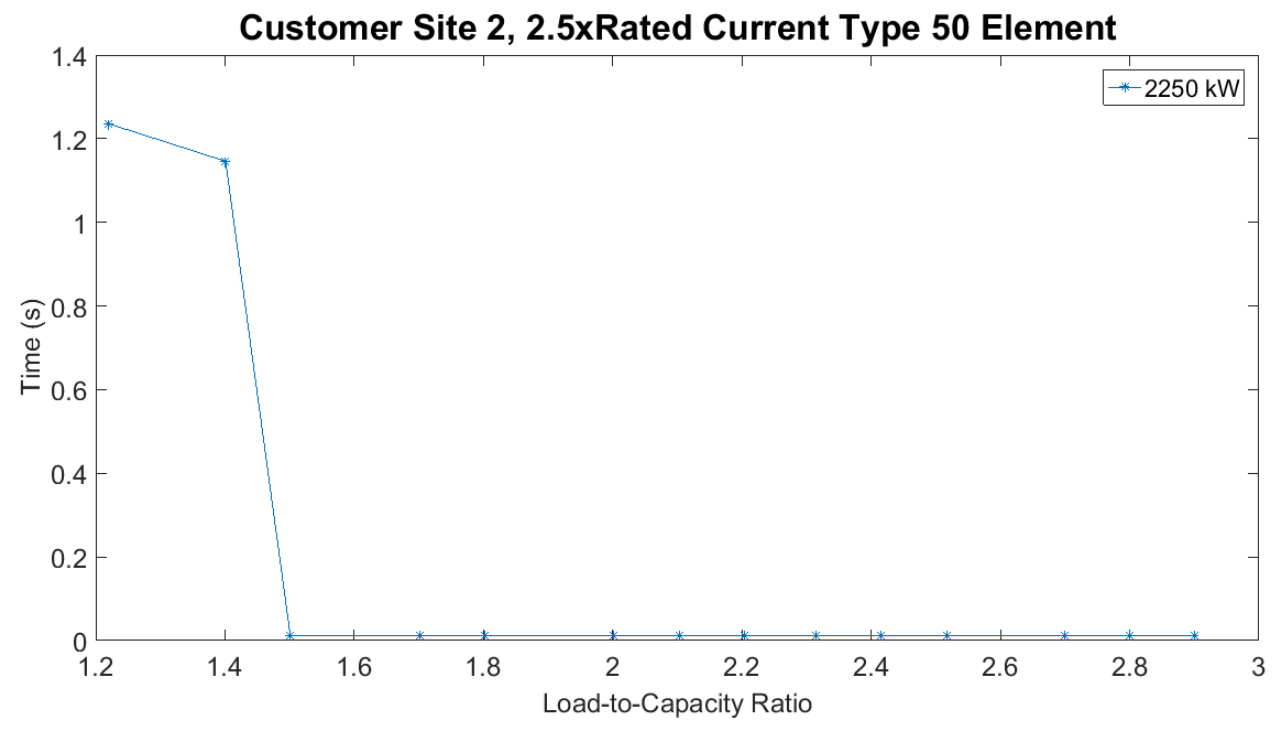

Figure 3.6: DG Site 2, 50/51 Element Operating Times, 2.5xRated

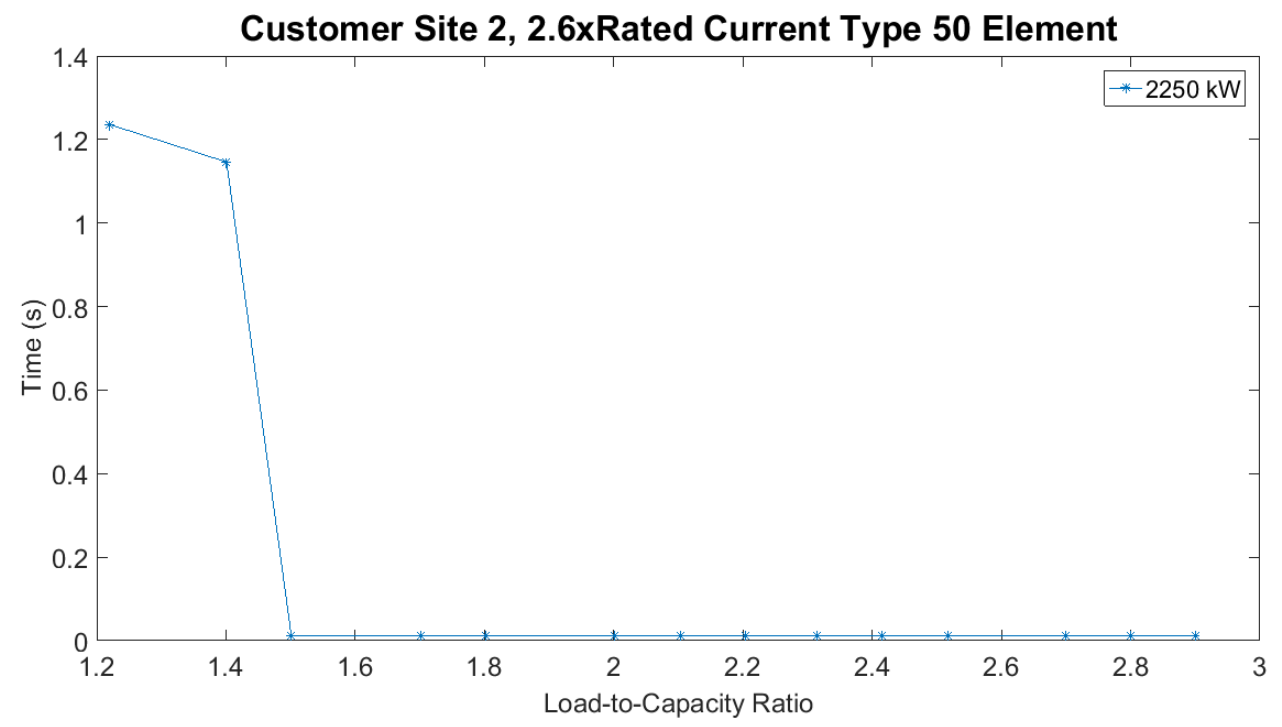

Figure 3.7: DG Site 2, 50/51 Element Operating Times, 2.6xRated 


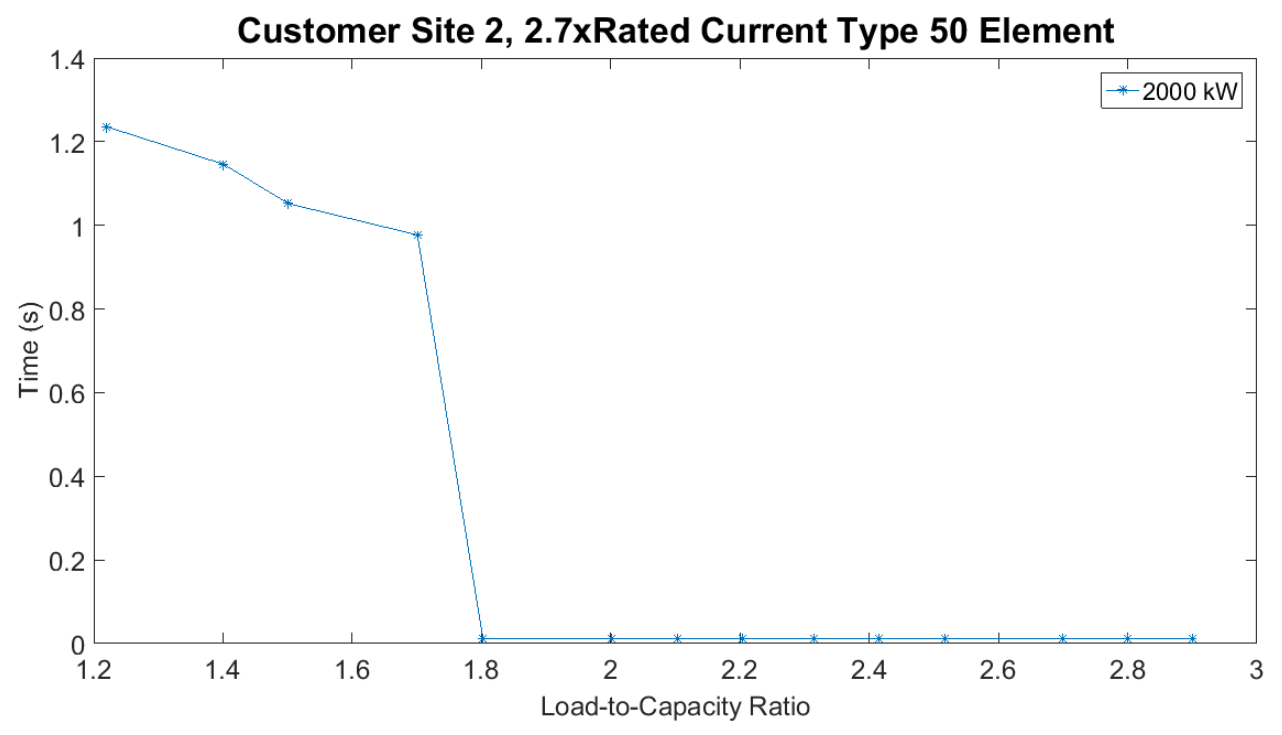

Figure 3.8: DG Site 2, 50/51 Element Operating Times, 2.7xRated

Results for customer site 2 are very similar to customer site 1 . The non-instantaneous (51) element times differ, but the instantaneous element reacts as governed by equations 3.5 and 3.6 .

\subsubsection{Resource Availability and Load to Capacity Ratio}

Figure 3.9 displays the results of the MATLAB resource availability program for the 2015 peak day. The present load to capacity ratio is only met during peak loads. 


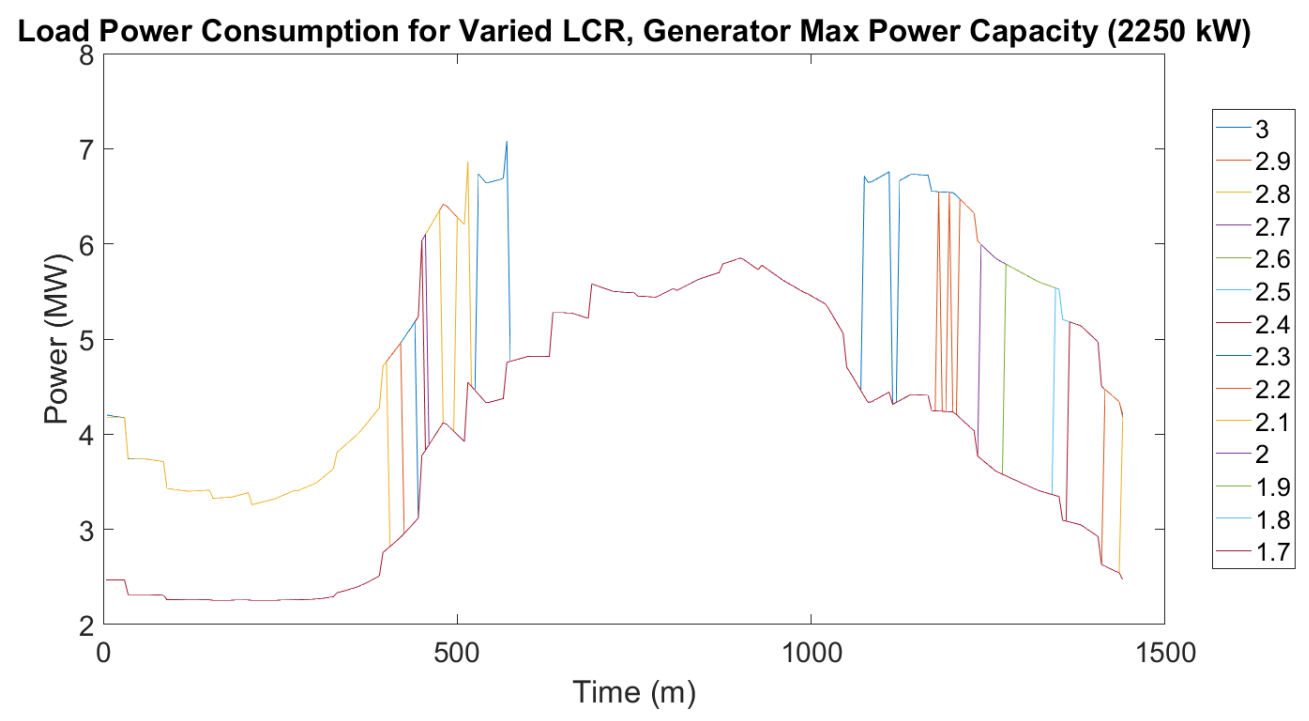

Figure 3.9: Load Consumption, LCR Varied from 3.0 to 1.7

Table 1 displays how the resource availability increases for a decreasing load to capacity ratio on the peak day of 2015 .

Table 3.1: Distributed Generation Resource Availability for 2015 Peak Day

\begin{tabular}{|l|c|}
\hline LCR & Resource Availability \\
\hline 3.0 & $36 \%$ \\
2.9 & $46 \%$ \\
2.8 & $51 \%$ \\
2.7 & $54 \%$ \\
2.6 & $57 \%$ \\
2.5 & $62 \%$ \\
2.4 & $63 \%$ \\
2.3 & $67 \%$ \\
2.2 & $69 \%$ \\
2.1 & $72 \%$ \\
2.0 & $100 \%$ \\
1.9 & $100 \%$ \\
1.8 & $100 \%$ \\
1.7 & $100 \%$ \\
\hline
\end{tabular}




\subsubsection{Model based Volt-VAr Optimization}

\subsubsection{CVR by Volt-VAr Injection}

Traditional CVR methods result in a power savings of $4 \%$ at peak load. The CVR by VArinjection method reduces the peak load by only $3 \%$. The BIS cannot output the maximum system reactive power without jeopardizing its function as a frequency responsive spinning reserve. This restriction reduces the maximum voltage differential, thus preventing the system from ever reaching the optimized voltage. While the CVR by VAr-injection method does not result in the maximum power reduction, it still meets the PGE prerequisite criteria of 3 to $5 \%$ power savings. Figure 3.10 compares the power savings using the volt-VAr injection CVR approach and traditional methods.

Table 3.2: Power Savings using Volt-VAr Injection and Traditional CVR Methods

\begin{tabular}{|c|c|}
\hline CVR Method & Max Peak Reduction \\
\hline VAr-Injection & $3 \%$ \\
Traditional & $4 \%$ \\
\hline
\end{tabular}

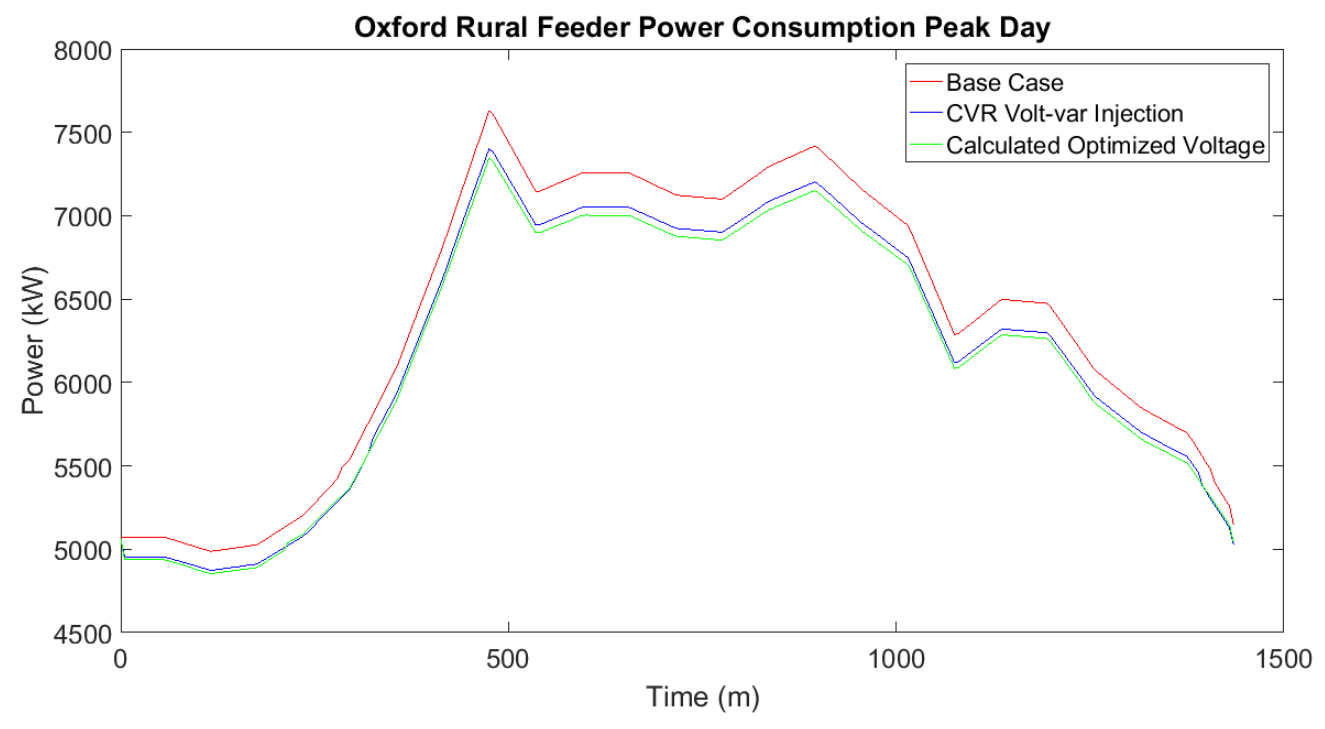

Figure 3.10: Minimized Power using CVR and VVO 


\subsubsection{Smooth Feeder Profile}

The smooth feeder profile algorithm resulted in a peak shaving of $3 \%$ and an increase in power consumption during non-peak hours by $1 \%$. PGE can overcommit to renewable resources to avoid shortages that result from the unreliability of a renewable supply. However, curtailing renewable resources at a time of overgeneration can be technologically difficult. According to the 2016 IRP, PGE has more flexibility to ramp up to meet demand than it does to ramp down. Installing the control program at the SSPC not only meets the PGE peak shavings requirement, it has the additional cost benefit of reducing renewable curtailment events. Figure 3.11 displays the optimized power profile achieved with the smooth feeder algorithm.

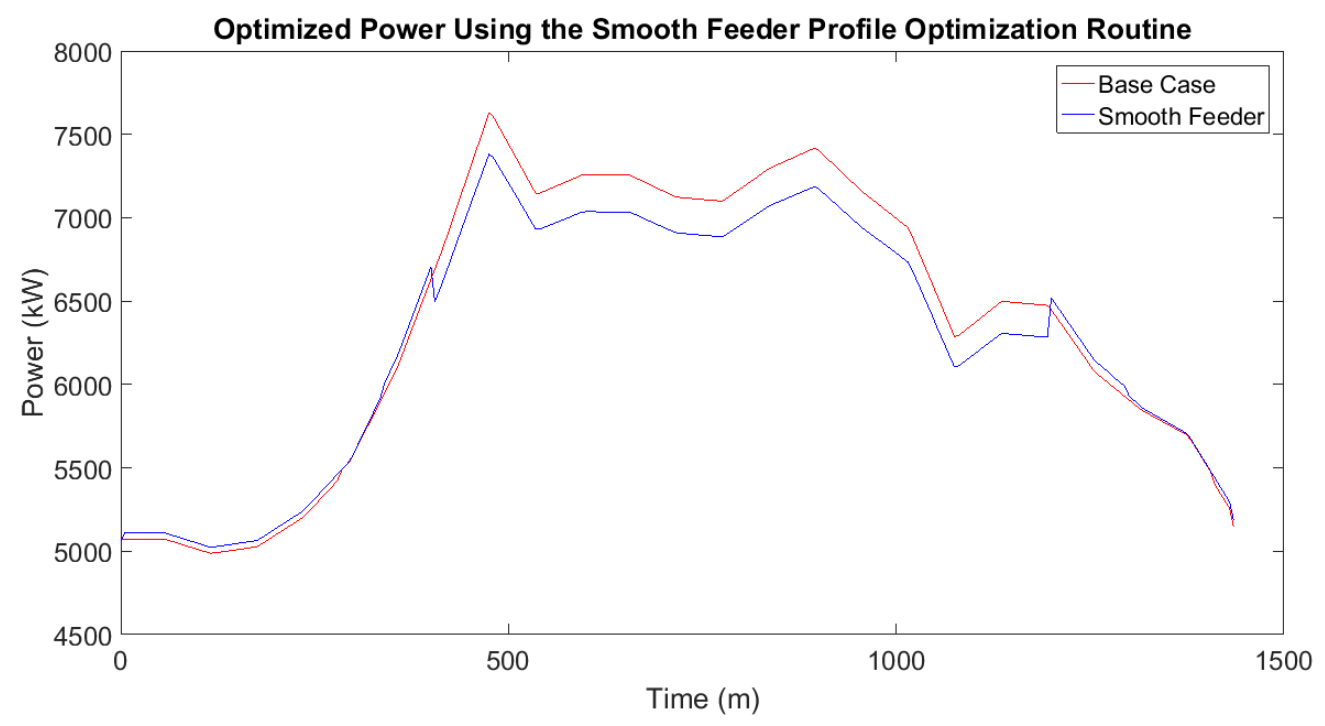

Figure 3.11: Optimized Power Using the Smooth Feeder Profile Algorithm 


\subsubsection{Lagrange Multipliers vs. Interior-Point Method}

The interior-point optimization algorithm achieved the minimal voltage value in less processing time than the Lagrangian Multipliers method. However, the Lagrange multipliers algorithm reveals important information about the sensitivity of the constraints to the objective function. High $\lambda$ values indicate which load nodes are most likely to violate the ANSI regulations.

Table 3.3: Power Savings using Lagrange Multipliers and Interior Point Algorithms

\begin{tabular}{|c|c|c|}
\hline Algorithm & Max Peak Reduction & Max Increase \\
\hline Lagrange Multipliers & $3 \%$ & $1 \%$ \\
Interior-Point & $3 \%$ & $1 \%$ \\
\hline
\end{tabular}

To visualize the lagrange multipliers, we sorted the $\lambda$ values by node location. Since a feeder is not a straight line there are breaks in the ascending order that indicate a discontinuity in the neighboring node location. This is displayed in Figure 3.12 by the large jumps in lambda values. The multipliers are clustered around one, a small number, which indicates the solution is a minimum. 


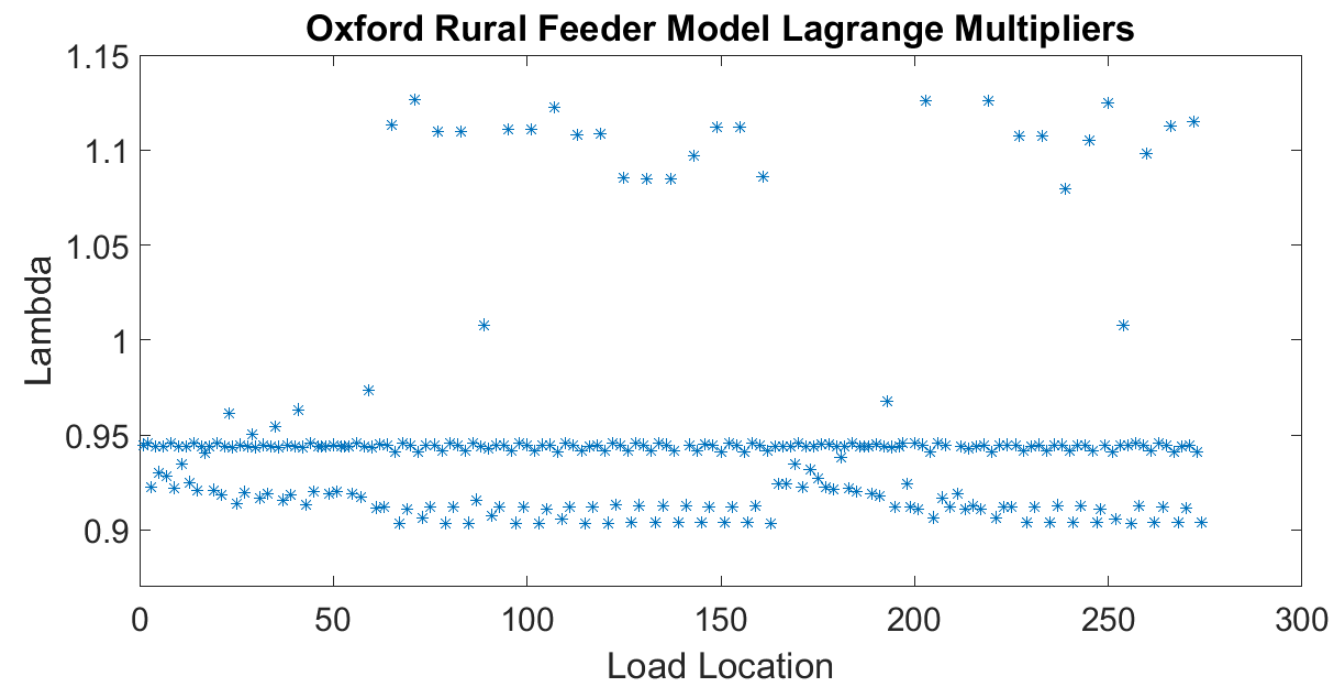

Figure 3.12: Lagrange Multipliers 


\section{Discussion}

The DG dynamic study should be conducted on additional feeders. Testing the program on an IEEE feeder model will confirm the results can be extended beyond PGE feeders.

The OpenDSS model must be validated against system data. Voltage readings from the substation to the "end of line" are needed to confirm the losses are equivalent. The actual system "end of line" voltage may be higher than the model. This would result in a lower optimized system voltage. Being able to run the system at a lower voltage is a benefit to PGE, as it results in a greater cost savings.

The excess reactive power in the system is dissipated in the form of heat. This raises concern for the thermal limits of the system. The cables must be sized to adequately handle the reactive power injections without becoming damaged. The feeder must be analyzed to confirm that the large reactive power injections will not affect the system negatively.

The system does not run at the minimum allowable voltage because the BIS is not large enough to achieve the desired voltage change. The potential power savings at the absolute minimum voltage could exceed the increased capacity costs. 
5 Conclusion

\subsubsection{MATLAB Dynamic Study}

Presently, fifteen percent of PGE energy qualifies as renewables per Senate Bill 1547. To reach the qualifying 50\% RPS by 2040, they plan to bring 515 MW of new wind resources on-line and eliminate their use of coal. This will result in a stochastic resource portfolio that requires PGE to strategically use their dispatchable energy resources, such as the aggregate 105MWs of DG participating in the Dispatchable Standby Generation program.

DSG is projected to grow into the 2030s. To increase the utility of this DSG program, the load to capacity ratio must be reduced, allowing more of these resource to be brought on-line. We analyzed the impact of increased DG on the Oxford Rural feeder and it revealed that the 50/51 protection element settings of the generator dictate both the maximum distributed generation capacity and the minimum load to capacity ratio.

- Currently, the load must be three times greater than the DG capacity for distributed generation to be brought on-line. The results of the study show that the three-to-one ratio is conservative.

- The dynamic study revealed that the generator instantaneous (50) relay will continue to provide protection as long as the load to capacity ratio meets the criteria:

$$
L C R<G E N O C 50-1
$$


Once the load-to-capacity ratio falls below this value, the generator is only protected by the time over-current (51) relay.

The maximum distributed generation capacity allowed on the feeder without concern for unintentional islanding is:

$$
P_{G e n_{M a x}}=\frac{P_{\text {Load }}}{L C R_{\text {Min }}+1}
$$

Decreasing the load to capacity ratio increases the availability of the distributed generation resources. For a LCR of 2.7 the resource availability increases by $18 \%$ percentage points.

\subsubsection{Model Based Volt-VAr Optimization}

Preliminary cost benefit analysis of two PGE, pilot CVR programs show that the power savings benefits outweigh the installation cost of CVR equipment [7].

The power savings criteria to warrant the installation of a control system at the SSPC is between three and five percent of the peak load. We examined the real power reduction that results from CVR by VAr-injection on the Oxford Rural feeder. The model based volt-VAr optimization study revealed that the autonomous control program will result in a peak power savings that meets the PGE criteria for project approval.

- The CVR by VAr-injection method resulted in a peak power savings of $3.0 \%$ and a maximum power reduction of $3.3 \%$. 
- Adding a smooth feeder profile algorithm maintains the peak shaving results while reducing renewable curtailment events by increasing the power consumption at times of overgeneration. 


\section{Bibliography}

[1] Abdullah Bokhari, Ali Alkan, Rasim Dogan, Marc Diaz-Aguilo, Franscisco de Leon, Dariusz Czarkowski, Zican Zabar, Leo Birenbaum, Anthony Noel, and Resk Ebrahem Uosef. Experimental determination of the zip coefficients for modern residential, commercial, and industrial loads. Power Delivery, IEEE Transactions on, 29(3):13721381, June 2014.

[2] James E. Mack. Chapter 5: Distribution Circuits. Web, April 2017. http://www.globalspec.com/reference/67873/203279/chapter-5-distribution-circuits.

[3] Ameren. Conservation Voltage Reduction. Web, January 2017. http://ilsagfiles.org/SAG-files/Meeting-Materials/2017/January-24-2017/AICMES-2013-Presentation.pdf.

[4] Stack Exchange. What does it mean for reactive power to be delivered / consumed? Web, April 2017. https://electronics.stackexchange.com/questions/169957/what-doesit-mean-for-reactive-power-to-be-delivered-consumed.

[5] Roger C. Dugan. The Open Distribution System Simulator (OpenDSS). Web, March 2016. http://download2.nust.na/pub4/sourceforge/e/project/el/electricdss/OpenDSS/OpenDSSManual.pdf. 
[6] Oregon Department of Energy. Renewable Portfolio Standard. Web, April 2017. https://www.oregon.gov/energy/energy-oregon/Pages/Renewable-PortfolioStandard.aspx.

[7] Portland General Electric. PGE 2016 Integrated Resource Plan. Web, November 2016. https://www.portlandgeneral.com/our-company/energy-strategy/resourceplanning/integrated-resource-planning.

[8] Portland General Electric. Dispatchable Generation. Web, April 2017. https://www.portlandgeneral.com/business/get-paid-to-help-meetdemand/dispatchable-standby-generation.

[9] Energy Storage Association. Spinning Reserve. Web, April 2017. http://energystorage.org/energy-storage/technology-applications/spinning-reserve.

[10] Portland General Electric. Salem Smart Power Center. Web, April 2017. https://www.portlandgeneral.com/our-company/energy-strategy/smart-grid/salemsmart-power-center.

[11] National Electric Manufacturers Association. American National Standard For Electric Power Systems and Equipment - Voltage Ratings (60 Hertz) n. Web, December 2006. https://www.nema.org/Standards/ComplimentaryDocuments/Contents-andScope-ANSI-C84-1-2011.pdf. 
[12] Mark T. Osborn. Putting Standby Generators to Work on Grid Support. Web, March 2001. http://www.power-eng.com/articles/print/volume-105/issue-3/features/puttingstandby-generators-to-work-on-grid-support.html.

[13] U.S. Department of Energy. The Potential Benefits of Distributed Generation and Rate-Related Issues That May Impede Their Expansion. Web, February 2007. https://www.ferc.gov/legal/fed-sta/exp-study.pdf.

[14] Power Systems Engineering. Direct Transfer Trip Scheme. Web, May 2011. http://peguru.com/2011/04/direct-transfer-trip-scheme/.

[15] U.S. Department of Energy. DOE Grid Modernization Laboratory Consortium Awards. Web, April 2017. https://energy.gov/under-secretary-science-and-energy/doe-gridmodernization-laboratory-consortium-gmlc-awards.

[16] NERC. Glossary of Terms Used in NERC Reliability Standards. Web, April 2017. http://www.nerc.com/files/glossary-of-terms.pdf.

[17] Jorge Nocedal and Stehen J. Wright. Numerical Optimization. Springer, New York, New York, 2006. 


\section{Appendix A: MATLAB Dynamic Study}

\section{A.0.1 Oxford Rural Feeder Model Validation Results}

Table A.1: OpenDSS Oxford Rural Feeder Model 2015 Peak Load Voltage (p.u.)

\begin{tabular}{|c|c|c|c|c|c|}
\hline \multicolumn{6}{|c|}{ Oxford Rural Feeder Model Peak Load Voltage (p.u.) } \\
\hline Name & Voltage(pu) & Name & Voltage(pu) & Name & Voltage(pu) \\
\hline 764_112_5_b & 1.017 & 26750_50_a & 0.998 & 270_750_c & 0.973 \\
\hline 764_112_5_c & 0.99 & 26750_50_b & 1.033 & 505_0_000001_a & 0.999 \\
\hline 30621_300_a & 0.999 & 26750_50_c & 0.975 & 505_0_000001_b & 1.032 \\
\hline 30621_300_b & 1.032 & 1469_500_a & 0.999 & 505_0_000001_c & 0.973 \\
\hline 30621_300_c & 0.972 & 1469_500_b & 1.032 & 4574_37_5_a & 0.999 \\
\hline 5530_75_a & 1.003 & 1469_500_c & 0.973 & 4574_37_5_b & 1.032 \\
\hline 5530_75_b & 1.008 & 29924_10_a & 0.999 & 4574_37_5_c & 0.972 \\
\hline 5530_75_c & 1.001 & 29924_10_b & 1.031 & 40439_15_a & 1.002 \\
\hline 30463_15_a & 0.999 & 29924_10_c & 0.974 & 40439_15_b & 1.015 \\
\hline 30463_15_b & 1.032 & 963_300_a & 0.999 & 40439_15_c & 0.992 \\
\hline 30463_15_c & 0.973 & 963_300_b & 1.032 & 786_500_a & 1.002 \\
\hline 38175_25_a & 0.998 & 963_300_c & 0.973 & 786_500_b & 1.012 \\
\hline 38175_25_b & 1.033 & 865_300_a & 0.999 & 786_500_c & 0.995 \\
\hline 38175_25_c & 0.975 & 865_300_b & 1.031 & 1104_112_5_a & 0.999 \\
\hline 91542_25_a & 1.003 & 865_300_c & 0.974 & 1104_112_5_b & 1.032 \\
\hline 91542_25_b & 1.009 & 846_300_a & 0.999 & 1104_112_5_c & 0.973 \\
\hline
\end{tabular}




\begin{tabular}{|c|c|c|c|c|c|}
\hline \multicolumn{6}{|c|}{ Oxford Rural Feeder Model Peak Load Voltage (p.u.) } \\
\hline Name & Voltage(pu) & Name & Voltage(pu) & Name & Voltage(pu) \\
\hline $91542 \_25 \_c$ & 0.999 & 846_300_b & 1.031 & 30381_150_a & 0.998 \\
\hline $66323 \_15 \_a$ & 1.004 & 846_300_c & 0.974 & 30381_150_b & 1.033 \\
\hline 66323_15_b & 1.004 & 329_225_a & 0.999 & 30381_150_c & 0.975 \\
\hline $66323 \_15 \_c$ & 1.006 & 329_225_b & 1.032 & 12421_75_a & 1.002 \\
\hline 285_1000_a & 0.999 & 329_225_c & 0.973 & 12421_75_b & 1.017 \\
\hline 285_1000_b & 1.033 & 975_150_a & 1.001 & 12421_75_c & 0.99 \\
\hline 285_1000_c & 0.973 & 975_150_b & 1.023 & 6547_75_a & 1.002 \\
\hline 4517_37_5_a & 1.003 & 975_150_c & 0.983 & 6547_75_b & 1.014 \\
\hline 4517_37_5_b & 1.01 & 187_225_a & 0.999 & 6547_75_c & 0.993 \\
\hline 4517_37_5_c & 0.998 & 187_225_b & 1.032 & 8535_50_a & 1.002 \\
\hline 31502_2000_a & 0.999 & 187_225_c & 0.972 & 8535_50_b & 1.016 \\
\hline 31502_2000_b & 1.03 & 498_0_000001_a & 1.003 & 8535_50_c & 0.991 \\
\hline 31502_2000_c & 0.974 & 498_0_000001_b & 1.011 & 94459_25_a & 0.998 \\
\hline 718_300_a & 0.999 & 498_0_000001_c & 0.997 & 94459_25_b & 1.033 \\
\hline 718_300_b & 1.032 & 5270_15_a & 0.999 & 94459_25_c & 0.974 \\
\hline 718_300_c & 0.972 & 5270_15_b & 1.032 & 35724_50_a & 0.999 \\
\hline 4519_37_5_a & 1.004 & 5270_15_c & 0.973 & 35724_50_b & 1.032 \\
\hline 4519_37_5_b & 1.006 & 270_750_a & 0.999 & 35724_50_c & 0.973 \\
\hline 4519_37_5_c & 1.003 & 270_750_b & 1.031 & 98576_25_a & 0.999 \\
\hline 98576_25_b & 1.031 & 44999_25_a & 0.999 & 663_150_c & 0.997 \\
\hline 98576_25_c & 0.974 & 44999_25_b & 1.032 & 1048_75_a & 0.998 \\
\hline 6642_100_a & 1.003 & 44999_25_c & 0.972 & 1048_75_b & 1.033 \\
\hline 6642_100_b & 1.011 & 8680_75_a & 0.999 & 1048_75_c & 0.975 \\
\hline
\end{tabular}




\begin{tabular}{|c|c|c|c|c|c|}
\hline \multicolumn{7}{|c|}{ Oxford Rural Feeder Model Peak Load Voltage (p.u.) } \\
\hline Name & Voltage(pu) & Name & Voltage(pu) & Name & Voltage(pu) \\
\hline \hline 6642_100_c & 0.997 & $8680 \_75 \_b$ & 1.031 & $62592 \_50 \_a$ & 1.003 \\
\hline 17434_25_a & 0.999 & $8680 \_75 \_c$ & 0.974 & $82033 \_25 \_a$ & 0.998 \\
\hline 17434_25_b & 1.032 & 36151_10_a & 1.002 & $46599 \_15 \_a$ & 0.999 \\
\hline 17434_25_c & 0.973 & 36151_10_b & 1.018 & 5771 75_b & 1.023 \\
\hline 31785_75_a & 1.004 & 36151_10_c & 0.989 & $74463 \_25 \_a$ & 0.999 \\
\hline 31785_75_b & 1.006 & 663_150_a & 1.003 & $65709 \_50 \_c$ & 0.973 \\
\hline 31785_75_c & 1.003 & 663_150_b & 1.011 & & \\
\hline
\end{tabular}

Table A.2: OpenDSS Oxford Rural Feeder Model 2015 Peak Line Current (p.u.)

\begin{tabular}{|c|c|c|c|c|c|}
\hline \multicolumn{5}{|c|}{ Oxford Rural Feeder Model Peak Line Current (\% of Rated) } \\
\hline Name & Loading & Name & Loading & Name & Loading \\
\hline 10209308 & $11 \%$ & 1103543 & $4 \%$ & 1090687 & $13 \%$ \\
\hline 10209311 & $20 \%$ & 1103544 & $8 \%$ & 1090688 & $12 \%$ \\
\hline 10209313 & $20 \%$ & 11912805 & $1 \%$ & 1101098 & $1 \%$ \\
\hline 10209314 & $20 \%$ & 11912806 & $1 \%$ & 1101172 & $61 \%$ \\
\hline 10209315 & $20 \%$ & 11912807 & $1 \%$ & 1101174 & $60 \%$ \\
\hline 10209321 & $20 \%$ & 11912808 & $1 \%$ & 1101176 & $30 \%$ \\
\hline 10209326 & $1 \%$ & 12629136 & $64 \%$ & 1101274 & $2 \%$ \\
\hline 10482389 & $6 \%$ & 12629137 & $2 \%$ & 1103553 & $1 \%$ \\
\hline 10482391 & $3 \%$ & 12629151 & $4 \%$ & 12279297 & $3 \%$ \\
\hline 1090662 & $14 \%$ & 12629152 & $4 \%$ & 1101144 & $68 \%$ \\
\hline 1090663 & $4 \%$ & 12629153 & $4 \%$ & 1101249 & $26 \%$ \\
\hline 1090664 & $2 \%$ & 12629154 & $4 \%$ & 1101250 & $46 \%$ \\
\hline
\end{tabular}




\begin{tabular}{|c|c|c|c|c|c|}
\hline \multicolumn{6}{|c|}{ Oxford Rural Feeder Model Peak Line Current ( $\%$ of Rated) } \\
\hline Name & Loading & Name & Loading & Name & Loading \\
\hline 1090665 & $3 \%$ & 12629155 & $8 \%$ & 1101275 & $28 \%$ \\
\hline 1090666 & $9 \%$ & 12629160 & $20 \%$ & 1101276 & $28 \%$ \\
\hline 1090701 & $11 \%$ & 12629161 & $38 \%$ & 1101277 & $28 \%$ \\
\hline 1090702 & $4 \%$ & 12629163 & $15 \%$ & 1101278 & $27 \%$ \\
\hline 1090739 & $3 \%$ & 12629164 & $15 \%$ & 1101279 & $56 \%$ \\
\hline 1090740 & $3 \%$ & 12629166 & $15 \%$ & 1101280 & $21 \%$ \\
\hline 1090744 & $4 \%$ & 12743299 & $3 \%$ & 1101281 & $21 \%$ \\
\hline 1090745 & $5 \%$ & 12743301 & $3 \%$ & 1103515 & $18 \%$ \\
\hline 1090762 & $5 \%$ & 12969344 & $1 \%$ & 1103516 & $13 \%$ \\
\hline 1101085 & $6 \%$ & 12969345 & $1 \%$ & 1103531 & $1 \%$ \\
\hline 1101086 & $6 \%$ & 12969346 & $3 \%$ & 12686936 & $21 \%$ \\
\hline 1101090 & $4 \%$ & 12969353 & $12 \%$ & 1090761 & $11 \%$ \\
\hline 1101091 & $2 \%$ & 12974264 & $64 \%$ & 1101143 & $32 \%$ \\
\hline 1101102 & $7 \%$ & 12974265 & $64 \%$ & 1101171 & $31 \%$ \\
\hline 1103486 & $3 \%$ & 13008528 & $1 \%$ & 1103561 & $20 \%$ \\
\hline 1103487 & $7 \%$ & 13008529 & $1 \%$ & 1103563 & $20 \%$ \\
\hline 1103488 & $2 \%$ & 12629168 & $1 \%$ & 12279296 & $3 \%$ \\
\hline 1103489 & $1 \%$ & 1103559 & $4 \%$ & 13008527 & $61 \%$ \\
\hline 1103491 & $1 \%$ & 1103560 & $4 \%$ & 10193003 & $11 \%$ \\
\hline 1103493 & $2 \%$ & 12222913 & $2 \%$ & 1101267 & $1 \%$ \\
\hline 1103511 & $10 \%$ & 12743300 & $1 \%$ & 1101268 & $1 \%$ \\
\hline 1103517 & $8 \%$ & 12930298 & $4 \%$ & 1101269 & $21 \%$ \\
\hline 1103519 & $10 \%$ & 13063619 & $2 \%$ & 1101270 & $20 \%$ \\
\hline
\end{tabular}




\begin{tabular}{|c|c|c|c|c|c|}
\hline \multicolumn{5}{|c|}{ Oxford Rural Feeder Model Peak Line Current (\% of Rated) } \\
\hline Name & Loading & Name & Loading & Name & Loading \\
\hline \hline 1103520 & $10 \%$ & 1103499 & $2 \%$ & 1103537 & $20 \%$ \\
\hline 1103523 & $1 \%$ & 1090686 & $13 \%$ & 1103538 & $20 \%$ \\
\hline 1103539 & $20 \%$ & 12969342 & $21 \%$ & 1101251 & $26 \%$ \\
\hline 1103562 & $20 \%$ & 10192996 & $50 \%$ & 1103555 & $4 \%$ \\
\hline 1103566 & $20 \%$ & 10192997 & $50 \%$ & 1103556 & $4 \%$ \\
\hline 1090722 & $1 \%$ & 10192998 & $29 \%$ & 1103557 & $2 \%$ \\
\hline 1090723 & $1 \%$ & 10193001 & $21 \%$ & 12969343 & $2 \%$ \\
\hline 1090724 & $1 \%$ & 10193002 & $9 \%$ & 13270058 & $2 \%$ \\
\hline 1090725 & $1 \%$ & 1090719 & $9 \%$ & 13437513 & $26 \%$ \\
\hline 1090726 & $2 \%$ & 1090720 & $9 \%$ & 13437514 & $26 \%$ \\
\hline 1090727 & $2 \%$ & 1090729 & $9 \%$ & 13437515 & $46 \%$ \\
\hline 1101272 & $20 \%$ & 1101145 & $62 \%$ & 13437516 & $26 \%$ \\
\hline 1103536 & $20 \%$ & 1101173 & $60 \%$ & 13454751 & $9 \%$ \\
\hline 1090728 & $9 \%$ & 1101175 & $60 \%$ & 13536475 & $1 \%$ \\
\hline
\end{tabular}

\section{A.0.2 Load Multiplier}

Table A.3: PGE 2015 Peak Day Load Multiplier

\begin{tabular}{|c|c|c|c|c|c|}
\hline \multicolumn{7}{|c|}{ PGE 2015 Peak Day Load Multiplier } \\
\hline Time(m) & Multiplier & Time(m) & Multiplier & Time(m) & Multiplier \\
\hline 4 & 0.646 & 484 & 0.995 & 964 & 0.928 \\
\hline 9 & 0.646 & 489 & 0.989 & 969 & 0.925 \\
\hline 14 & 0.646 & 494 & 0.983 & 974 & 0.923 \\
\hline
\end{tabular}




\begin{tabular}{|c|c|c|c|c|c|}
\hline \multicolumn{6}{|c|}{ PGE 2015 Peak Day Load Multiplier A.3 } \\
\hline Time(m) & Multiplier & Time(m) & Multiplier & Time(m) & Multiplier \\
\hline 19 & 0.646 & 499 & 0.977 & 979 & 0.920 \\
\hline 24 & 0.646 & 504 & 0.971 & 984 & 0.917 \\
\hline 29 & 0.646 & 509 & 0.965 & 989 & 0.915 \\
\hline 34 & 0.646 & 514 & 0.959 & 994 & 0.912 \\
\hline 39 & 0.646 & 519 & 0.953 & 999 & 0.910 \\
\hline 44 & 0.646 & 524 & 0.947 & 1004 & 0.907 \\
\hline 49 & 0.646 & 529 & 0.941 & 1009 & 0.904 \\
\hline 54 & 0.646 & 534 & 0.935 & 1014 & 0.902 \\
\hline 59 & 0.646 & 539 & 0.929 & 1019 & 0.899 \\
\hline 64 & 0.646 & 544 & 0.929 & 1024 & 0.892 \\
\hline 69 & 0.645 & 549 & 0.930 & 1029 & 0.884 \\
\hline 74 & 0.644 & 554 & 0.931 & 1034 & 0.877 \\
\hline 79 & 0.643 & 559 & 0.933 & 1039 & 0.869 \\
\hline 84 & 0.642 & 564 & 0.934 & 1044 & 0.861 \\
\hline 89 & 0.641 & 569 & 0.936 & 1049 & 0.853 \\
\hline 94 & 0.640 & 574 & 0.937 & 1054 & 0.845 \\
\hline 99 & 0.639 & 579 & 0.939 & 1059 & 0.838 \\
\hline 104 & 0.638 & 584 & 0.940 & 1064 & 0.830 \\
\hline 109 & 0.637 & 589 & 0.942 & 1069 & 0.822 \\
\hline 114 & 0.636 & 594 & 0.943 & 1074 & 0.814 \\
\hline 119 & 0.635 & 599 & 0.944 & 1079 & 0.806 \\
\hline 124 & 0.635 & 604 & 0.945 & 1084 & 0.807 \\
\hline 129 & 0.636 & 609 & 0.945 & 1089 & 0.810 \\
\hline
\end{tabular}




\begin{tabular}{|c|c|c|c|c|c|}
\hline \multicolumn{6}{|c|}{ PGE 2015 Peak Day Load Multiplier A.3 } \\
\hline Time(m) & Multiplier & Time(m) & Multiplier & Time(m) & Multiplier \\
\hline 134 & 0.636 & 614 & 0.945 & 1094 & 0.812 \\
\hline 139 & 0.637 & 619 & 0.945 & 1099 & 0.815 \\
\hline 144 & 0.637 & 624 & 0.945 & 1104 & 0.817 \\
\hline 149 & 0.638 & 629 & 0.945 & 1109 & 0.820 \\
\hline 154 & 0.638 & 634 & 0.945 & 1114 & 0.823 \\
\hline 159 & 0.639 & 639 & 0.944 & 1119 & 0.825 \\
\hline 164 & 0.639 & 644 & 0.944 & 1124 & 0.828 \\
\hline 169 & 0.639 & 649 & 0.944 & 1129 & 0.830 \\
\hline 174 & 0.640 & 654 & 0.944 & 1134 & 0.833 \\
\hline 179 & 0.640 & 659 & 0.944 & 1139 & 0.836 \\
\hline 184 & 0.642 & 664 & 0.943 & 1144 & 0.836 \\
\hline 189 & 0.644 & 669 & 0.941 & 1149 & 0.836 \\
\hline 194 & 0.646 & 674 & 0.940 & 1154 & 0.835 \\
\hline 199 & 0.648 & 679 & 0.938 & 1159 & 0.835 \\
\hline 204 & 0.650 & 684 & 0.937 & 1164 & 0.835 \\
\hline 209 & 0.652 & 689 & 0.935 & 1169 & 0.834 \\
\hline 214 & 0.654 & 694 & 0.933 & 1174 & 0.834 \\
\hline 219 & 0.656 & 699 & 0.932 & 1179 & 0.834 \\
\hline 224 & 0.658 & 704 & 0.930 & 1184 & 0.834 \\
\hline 229 & 0.660 & 709 & 0.929 & 1189 & 0.833 \\
\hline 234 & 0.662 & 714 & 0.927 & 1194 & 0.833 \\
\hline 239 & 0.664 & 719 & 0.926 & 1199 & 0.833 \\
\hline 244 & 0.667 & 724 & 0.925 & 1204 & 0.829 \\
\hline
\end{tabular}




\begin{tabular}{|c|c|c|c|c|c|}
\hline \multicolumn{6}{|c|}{ PGE 2015 Peak Day Load Multiplier A.3 } \\
\hline Time(m) & Multiplier & Time(m) & Multiplier & Time(m) & Multiplier \\
\hline 249 & 0.670 & 729 & 0.925 & 1209 & 0.824 \\
\hline 254 & 0.673 & 734 & 0.924 & 1214 & 0.820 \\
\hline 259 & 0.676 & 739 & 0.924 & 1219 & 0.815 \\
\hline 264 & 0.680 & 744 & 0.924 & 1224 & 0.810 \\
\hline 269 & 0.683 & 749 & 0.923 & 1229 & 0.806 \\
\hline 274 & 0.686 & 754 & 0.923 & 1234 & 0.801 \\
\hline 279 & 0.690 & 759 & 0.923 & 1239 & 0.796 \\
\hline 284 & 0.693 & 764 & 0.923 & 1244 & 0.792 \\
\hline 289 & 0.696 & 769 & 0.922 & 1249 & 0.787 \\
\hline 294 & 0.699 & 774 & 0.922 & 1254 & 0.782 \\
\hline 299 & 0.703 & 779 & 0.922 & 1259 & 0.778 \\
\hline 304 & 0.708 & 784 & 0.924 & 1264 & 0.775 \\
\hline 309 & 0.715 & 789 & 0.926 & 1269 & 0.772 \\
\hline 314 & 0.721 & 794 & 0.928 & 1274 & 0.769 \\
\hline 319 & 0.727 & 799 & 0.931 & 1279 & 0.767 \\
\hline 324 & 0.734 & 804 & 0.933 & 1284 & 0.764 \\
\hline 329 & 0.740 & 809 & 0.935 & 1289 & 0.761 \\
\hline 334 & 0.746 & 814 & 0.938 & 1294 & 0.759 \\
\hline 339 & 0.753 & 819 & 0.940 & 1299 & 0.756 \\
\hline 344 & 0.759 & 824 & 0.942 & 1304 & 0.754 \\
\hline 349 & 0.765 & 829 & 0.945 & 1309 & 0.751 \\
\hline 354 & 0.772 & 834 & 0.947 & 1314 & 0.748 \\
\hline 359 & 0.778 & 839 & 0.949 & 1319 & 0.746 \\
\hline
\end{tabular}




\begin{tabular}{|c|c|c|c|c|c|}
\hline \multicolumn{6}{|c|}{ PGE 2015 Peak Day Load Multiplier A.3 } \\
\hline Time(m) & Multiplier & Time(m) & Multiplier & Time(m) & Multiplier \\
\hline 364 & 0.786 & 844 & 0.951 & 1324 & 0.744 \\
\hline 369 & 0.795 & 849 & 0.953 & 1329 & 0.742 \\
\hline 374 & 0.803 & 854 & 0.954 & 1334 & 0.740 \\
\hline 379 & 0.812 & 859 & 0.956 & 1339 & 0.738 \\
\hline 384 & 0.821 & 864 & 0.957 & 1344 & 0.737 \\
\hline 389 & 0.829 & 869 & 0.959 & 1349 & 0.735 \\
\hline 394 & 0.838 & 874 & 0.960 & 1354 & 0.733 \\
\hline 399 & 0.846 & 879 & 0.962 & 1359 & 0.731 \\
\hline 404 & 0.855 & 884 & 0.963 & 1364 & 0.730 \\
\hline 409 & 0.864 & 889 & 0.965 & 1369 & 0.728 \\
\hline 414 & 0.872 & 894 & 0.966 & 1374 & 0.726 \\
\hline 419 & 0.881 & 899 & 0.968 & 1379 & 0.724 \\
\hline 424 & 0.890 & 904 & 0.965 & 1384 & 0.720 \\
\hline 429 & 0.900 & 909 & 0.962 & 1389 & 0.715 \\
\hline 434 & 0.910 & 914 & 0.959 & 1394 & 0.710 \\
\hline 439 & 0.920 & 919 & 0.956 & 1399 & 0.705 \\
\hline 444 & 0.929 & 924 & 0.953 & 1404 & 0.700 \\
\hline 449 & 0.939 & 929 & 0.950 & 1409 & 0.695 \\
\hline 454 & 0.949 & 934 & 0.946 & 1414 & 0.690 \\
\hline 459 & 0.959 & 939 & 0.943 & 1419 & 0.685 \\
\hline 464 & 0.969 & 944 & 0.940 & 1424 & 0.680 \\
\hline 469 & 0.978 & 949 & 0.937 & 1429 & 0.675 \\
\hline 474 & 0.988 & 954 & 0.934 & 1434 & 0.670 \\
\hline
\end{tabular}




\begin{tabular}{|c|c|c|c|c|c|}
\hline \multicolumn{7}{|c|}{ PGE 2015 Peak Day Load Multiplier A.3 } \\
\hline Time(m) & Multiplier & Time(m) & Multiplier & Time(m) & Multiplier \\
\hline 479 & 0.998 & 959 & 0.931 & 1439 & 0.666 \\
\hline
\end{tabular}

\section{A.0.3 MATLAB Dynamic Study}

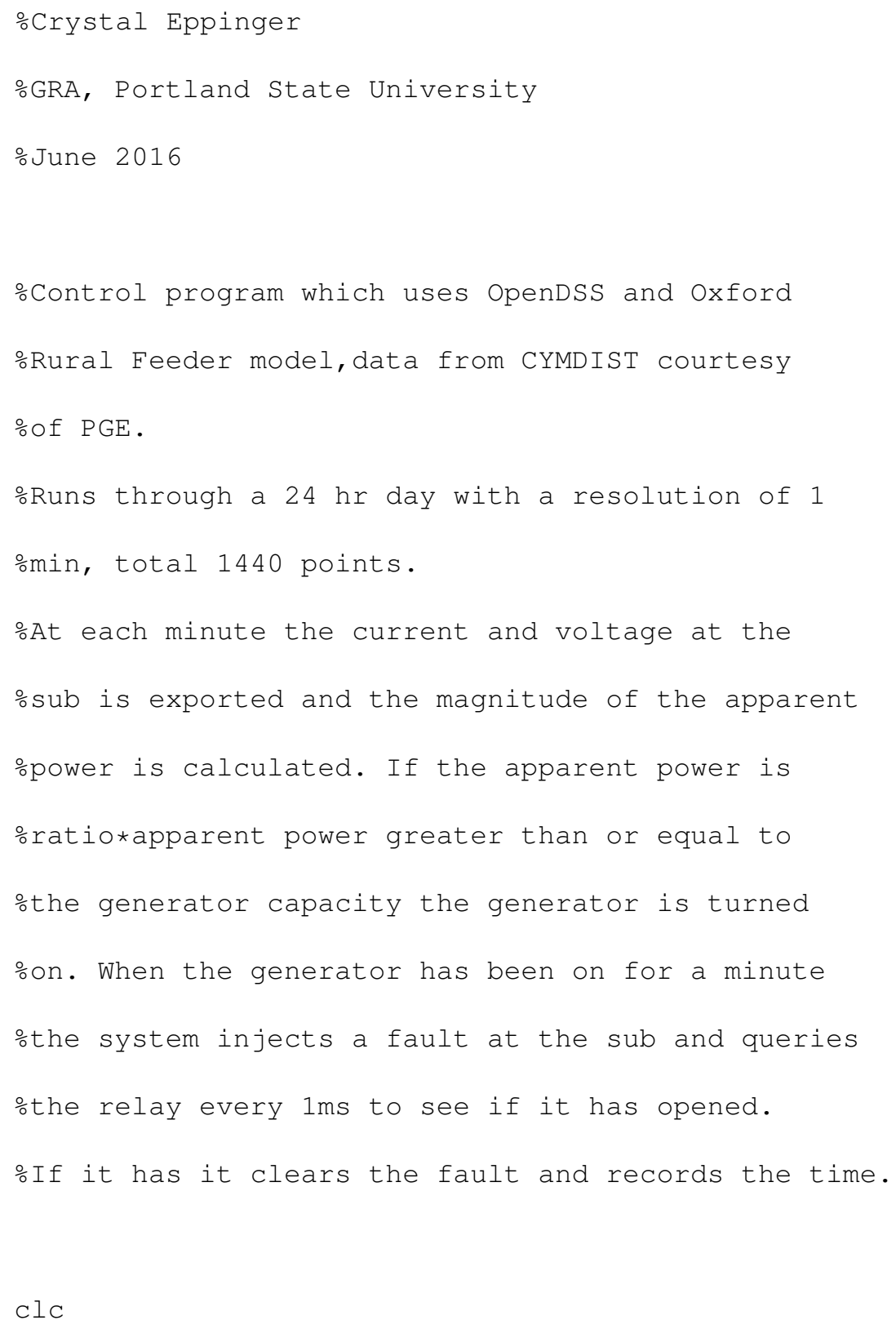




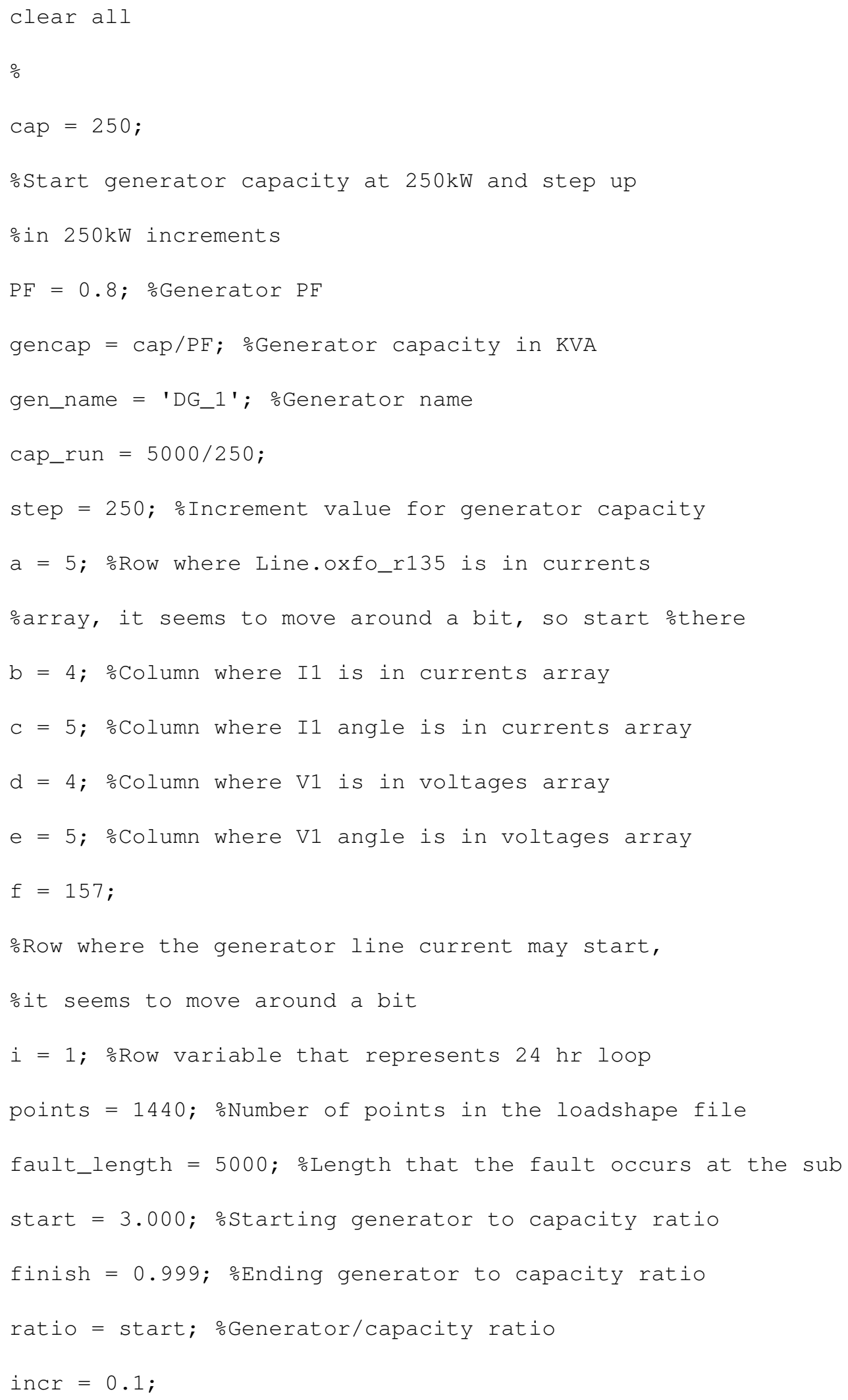




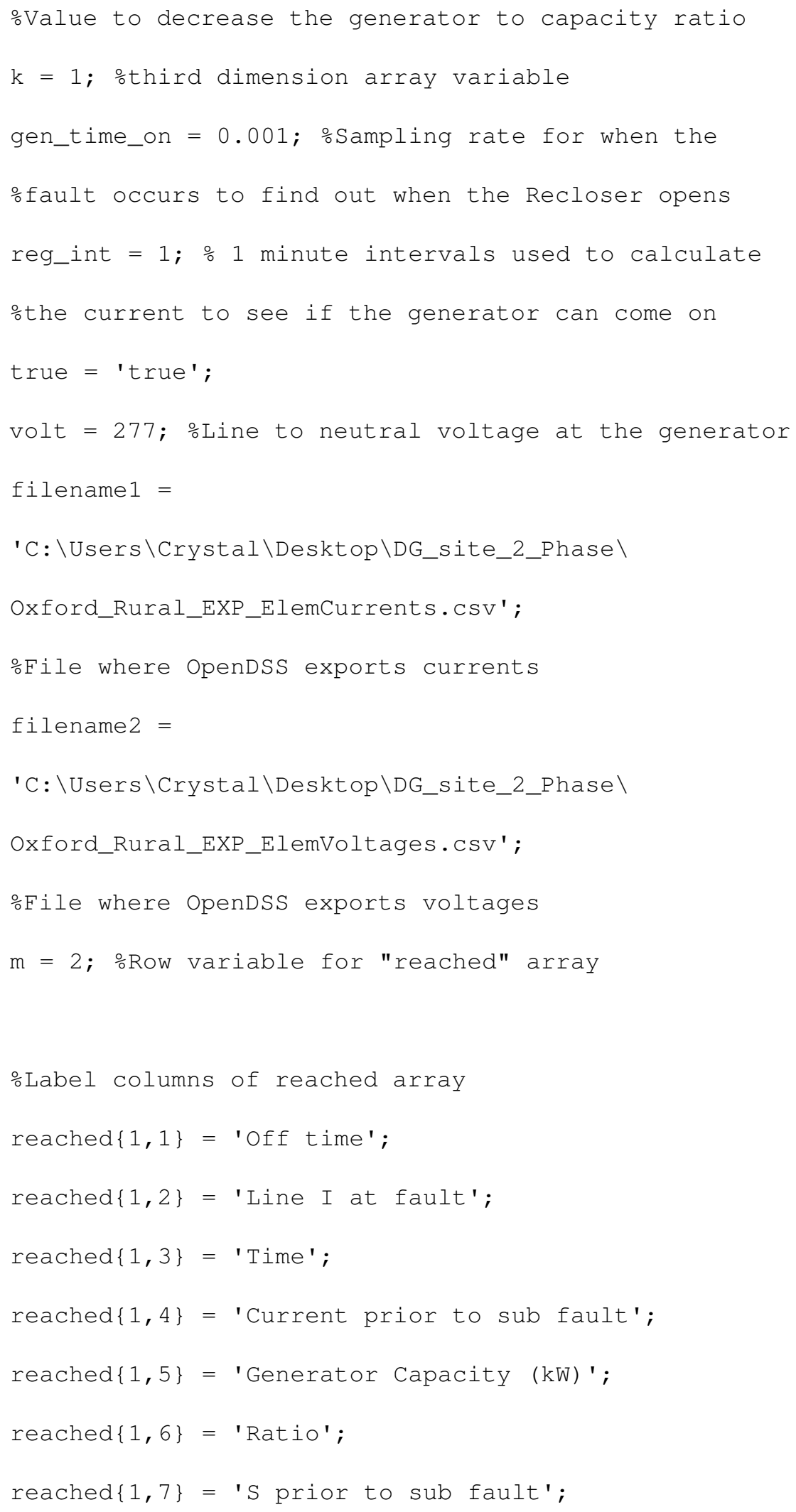




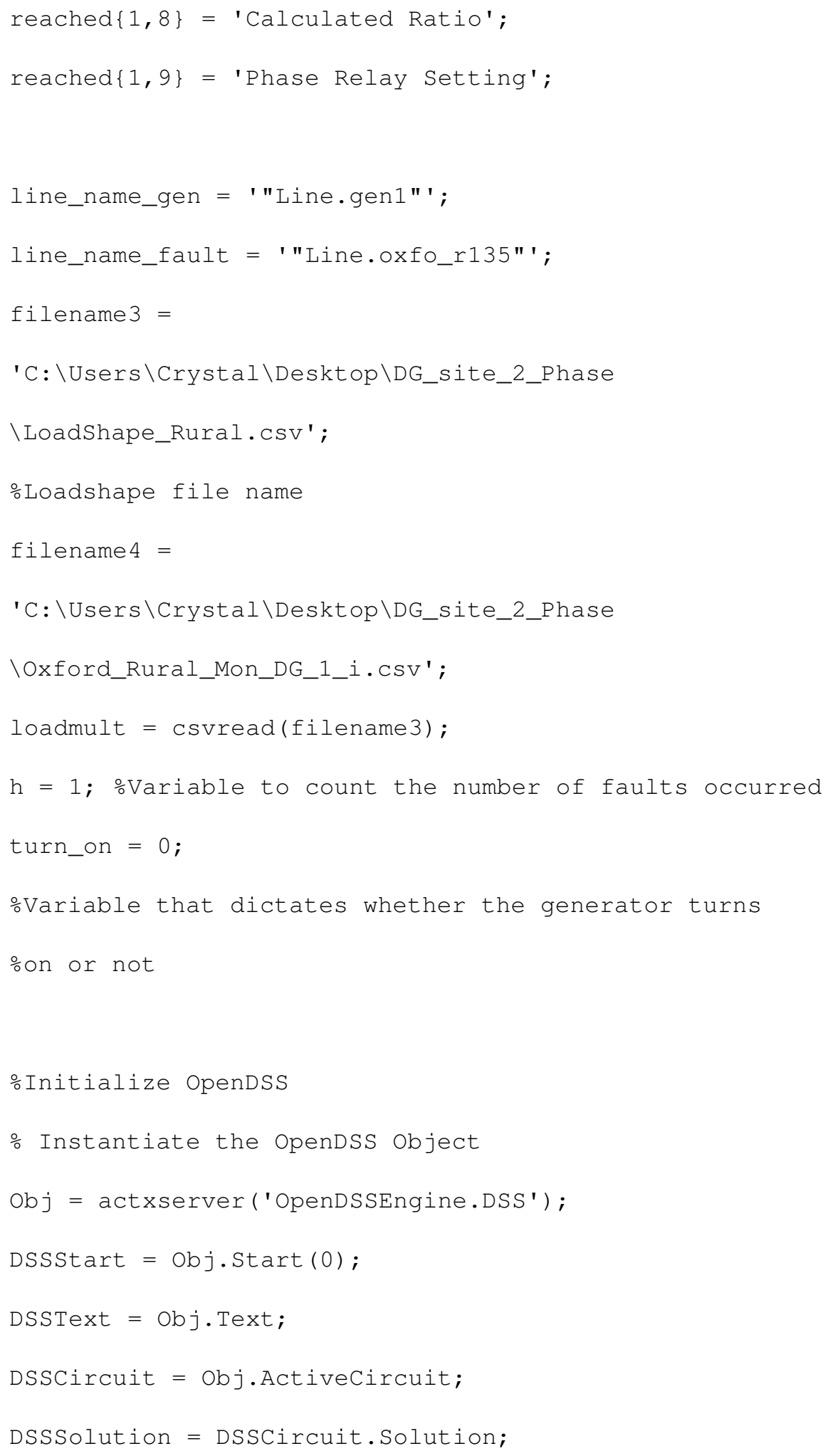




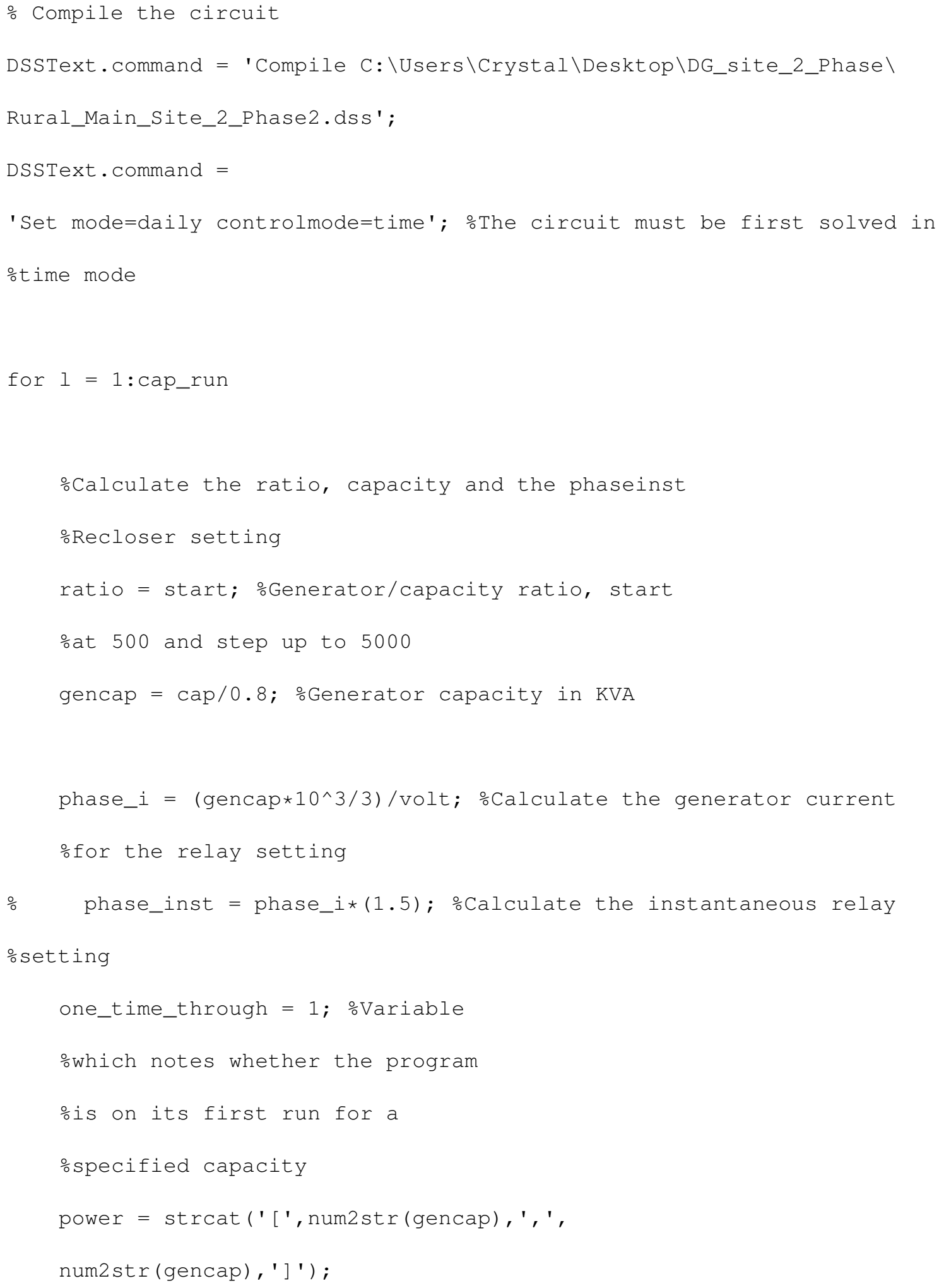




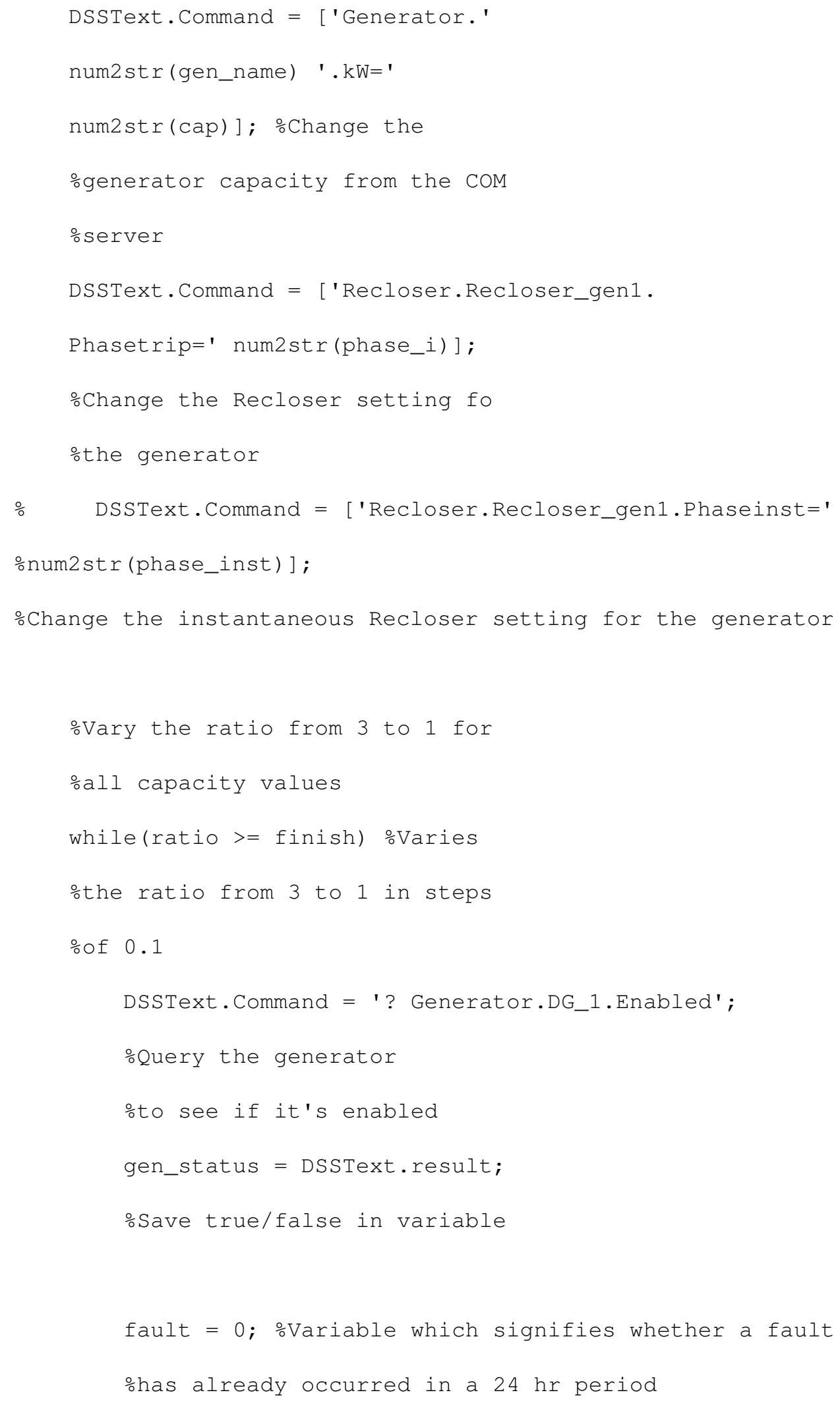




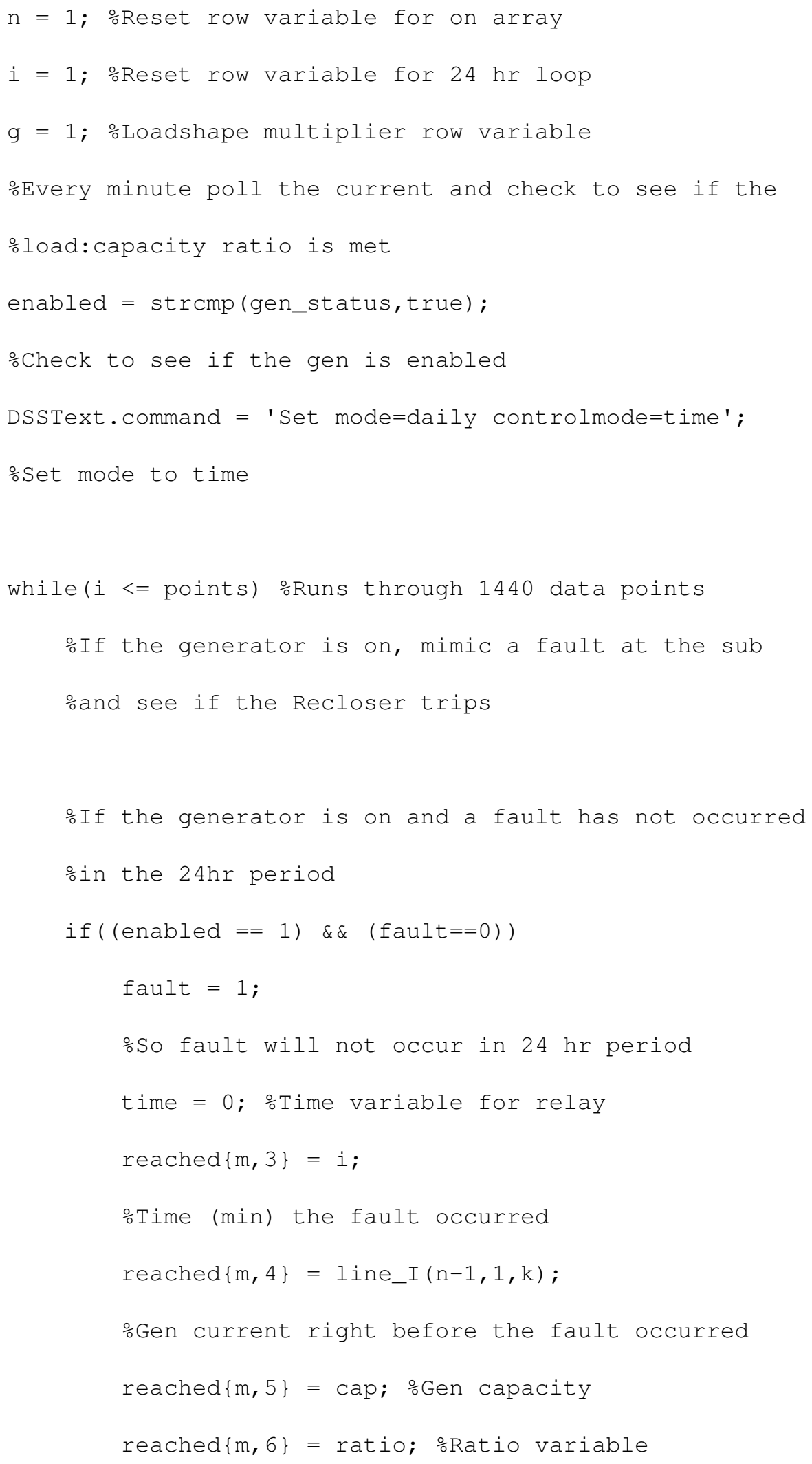




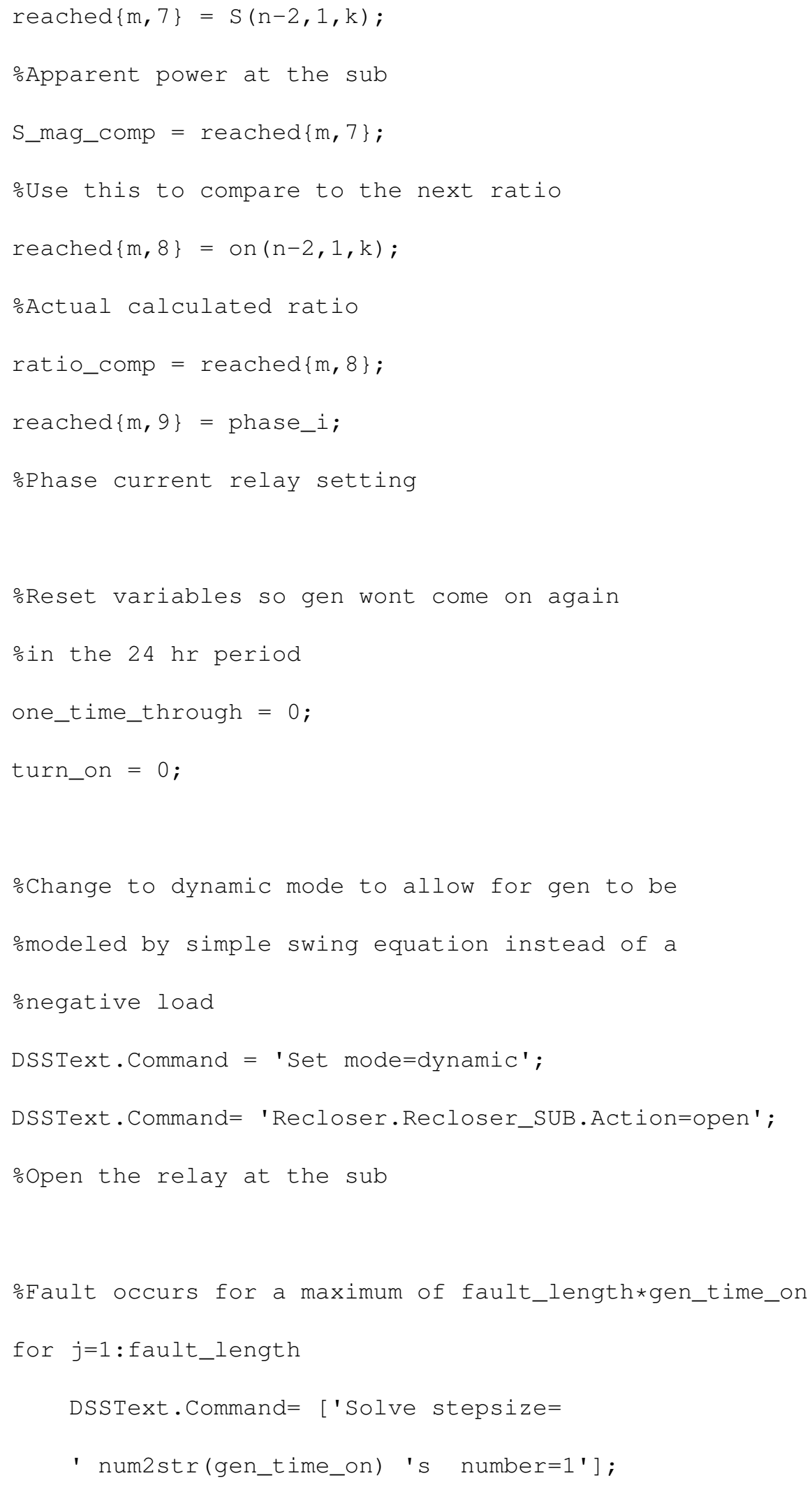




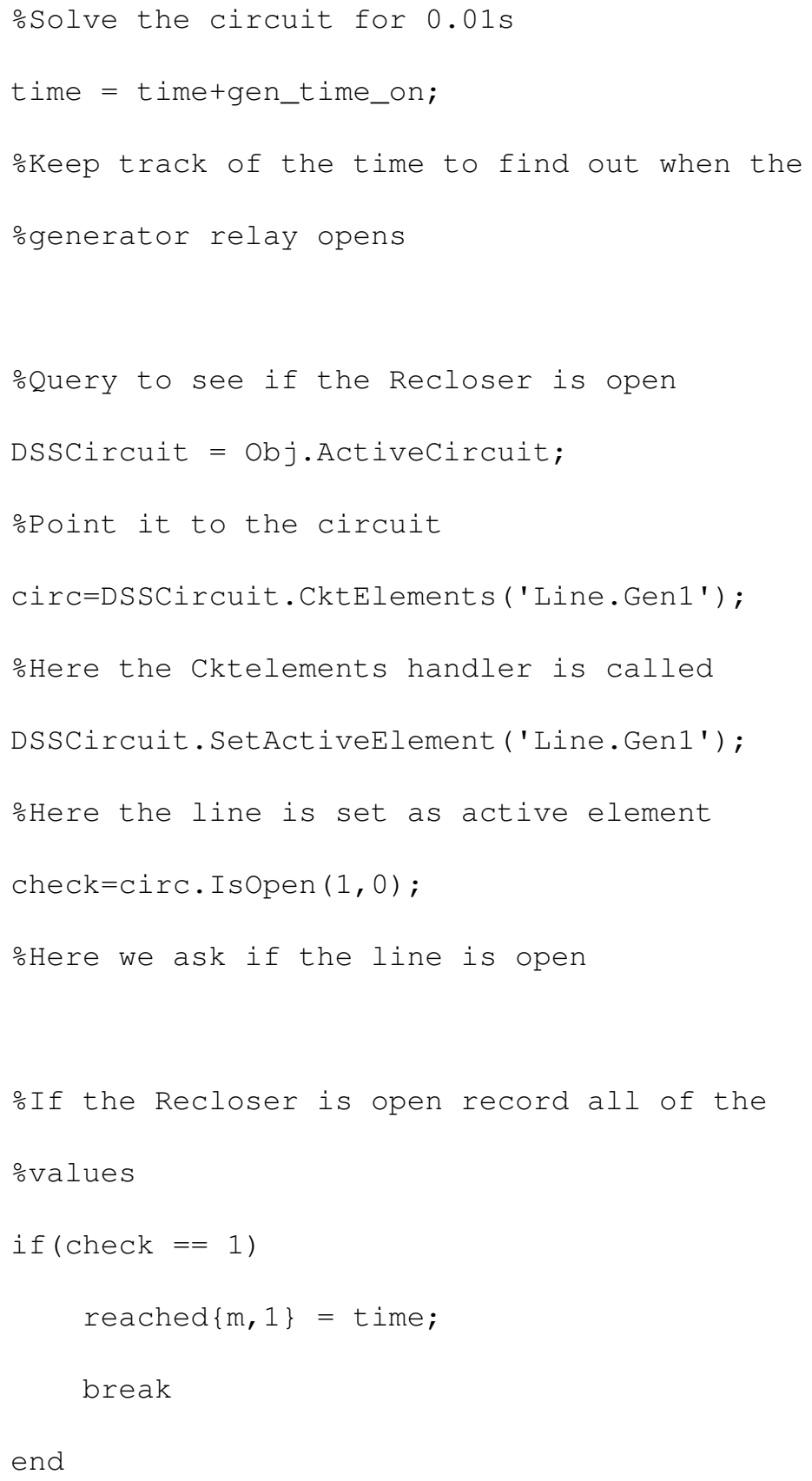




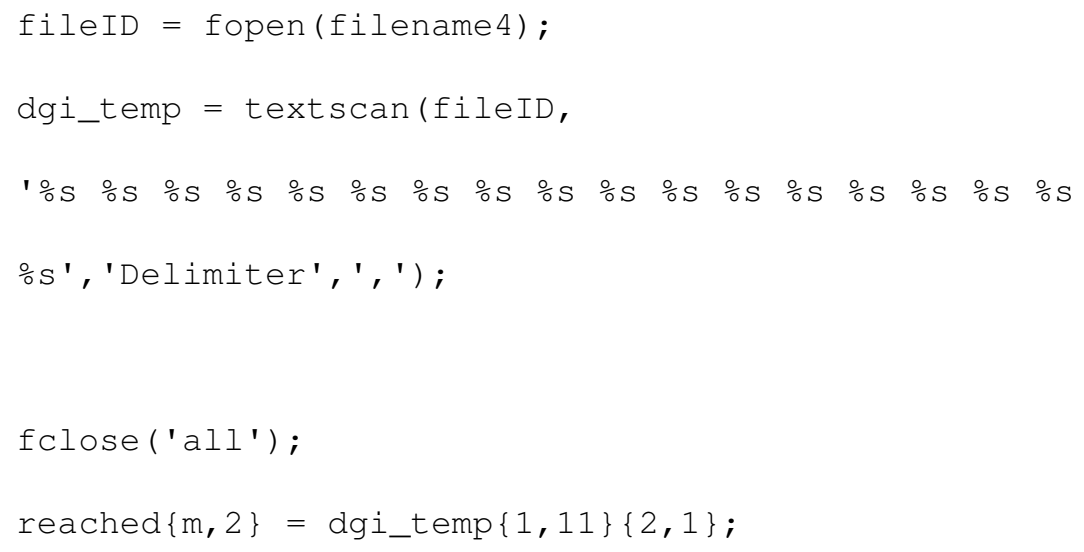




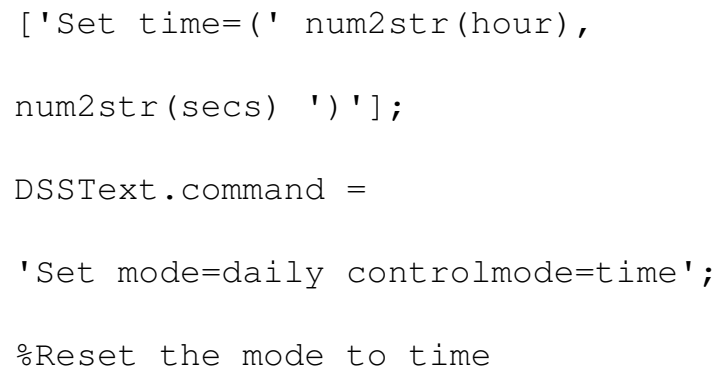




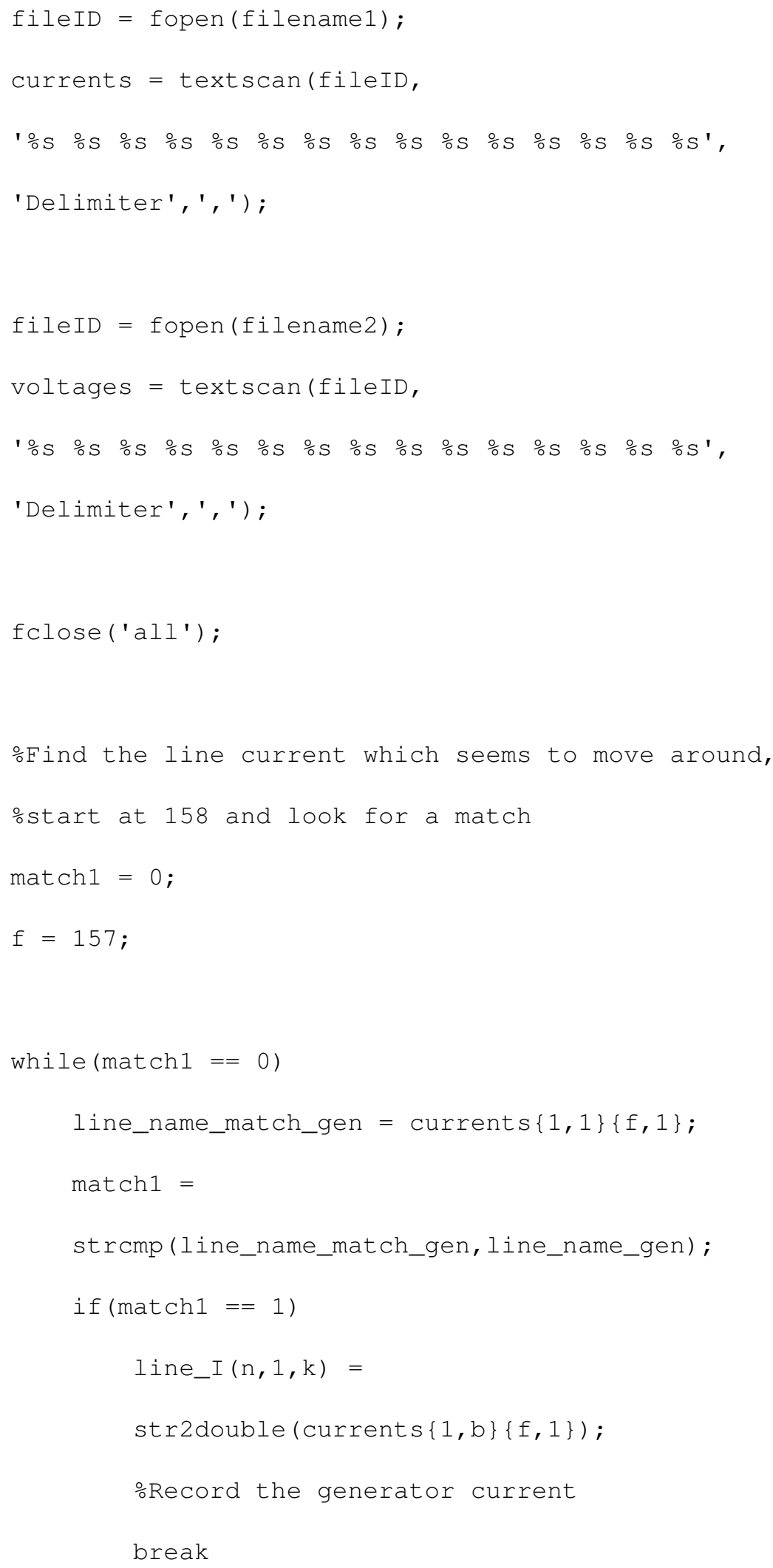




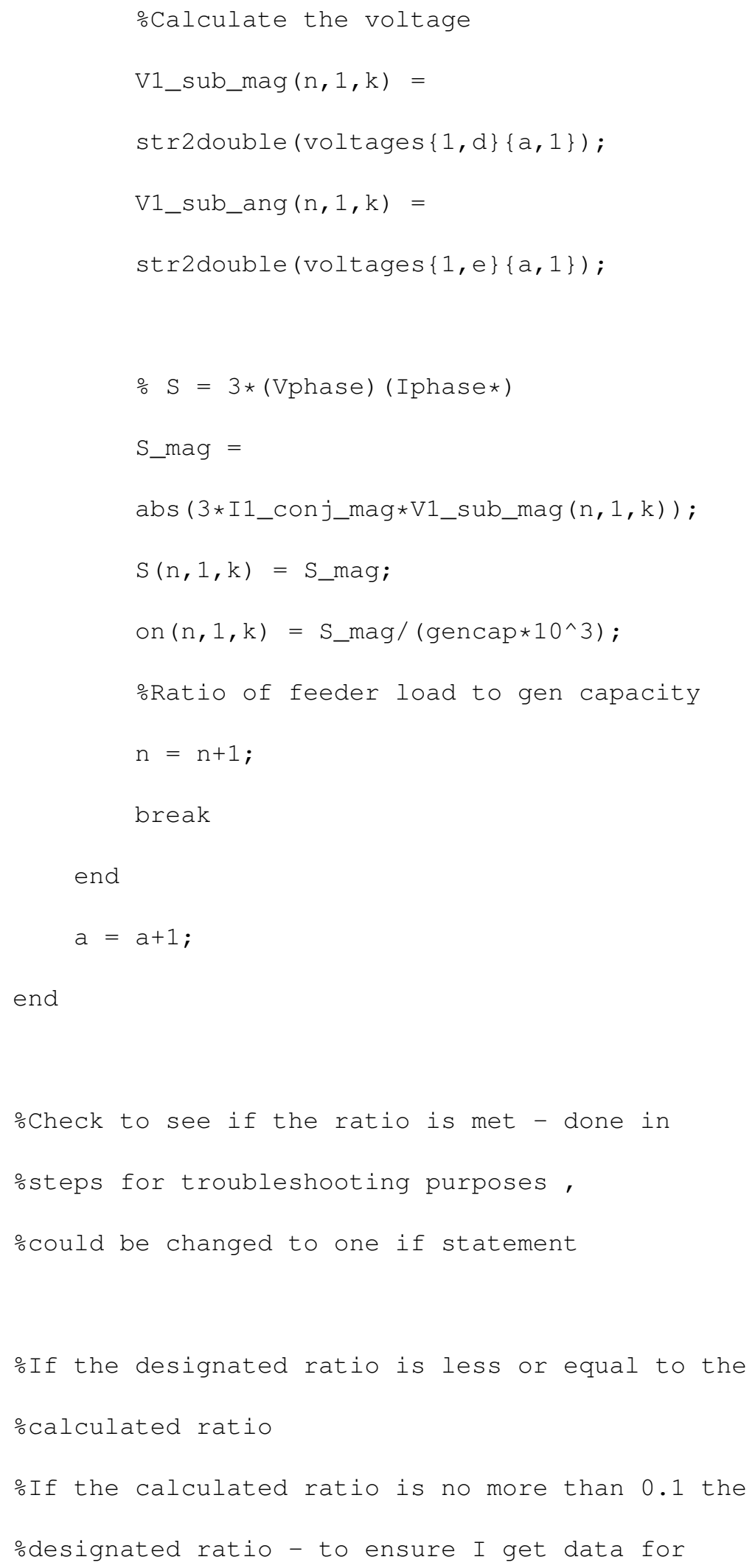




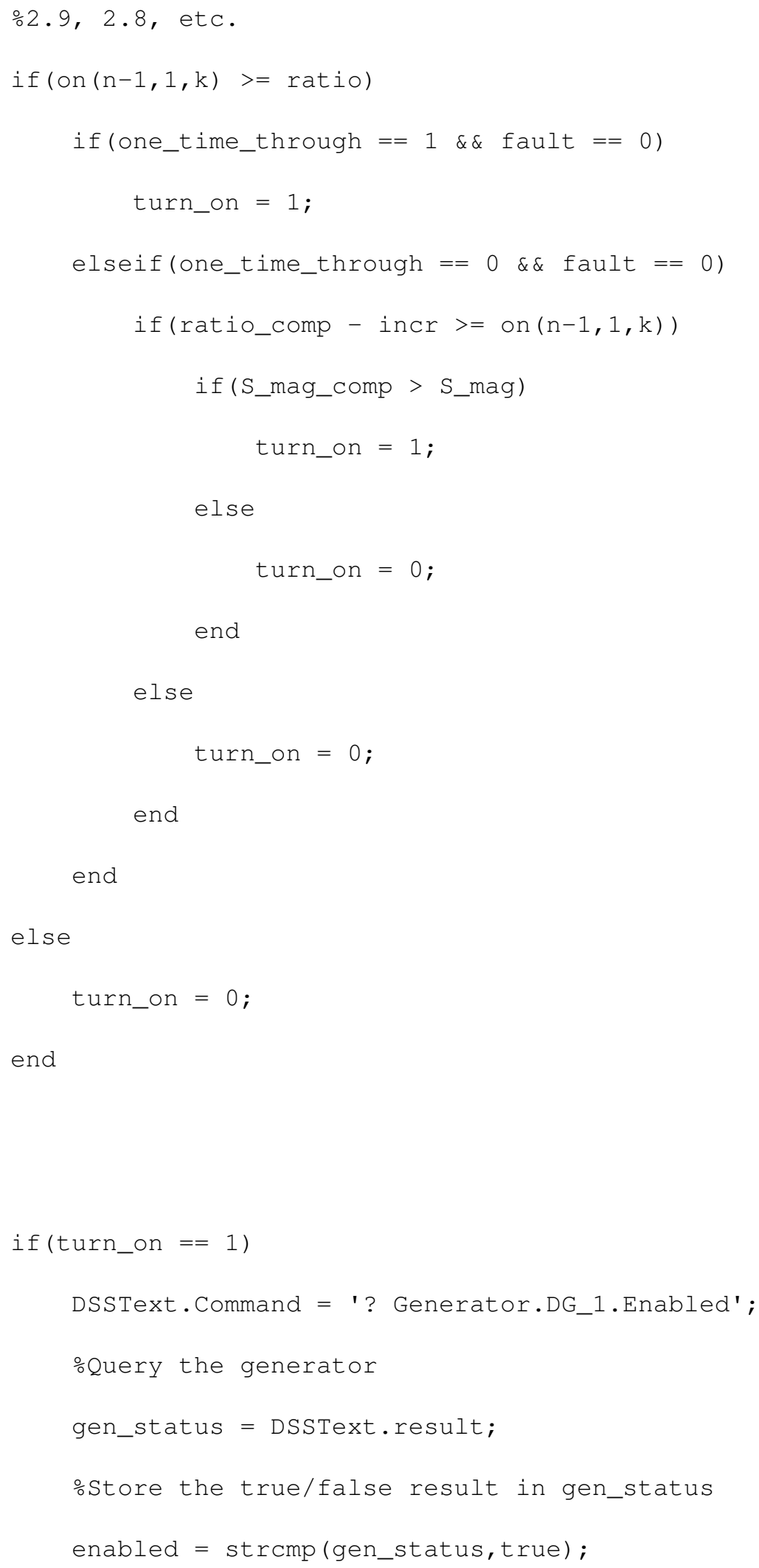




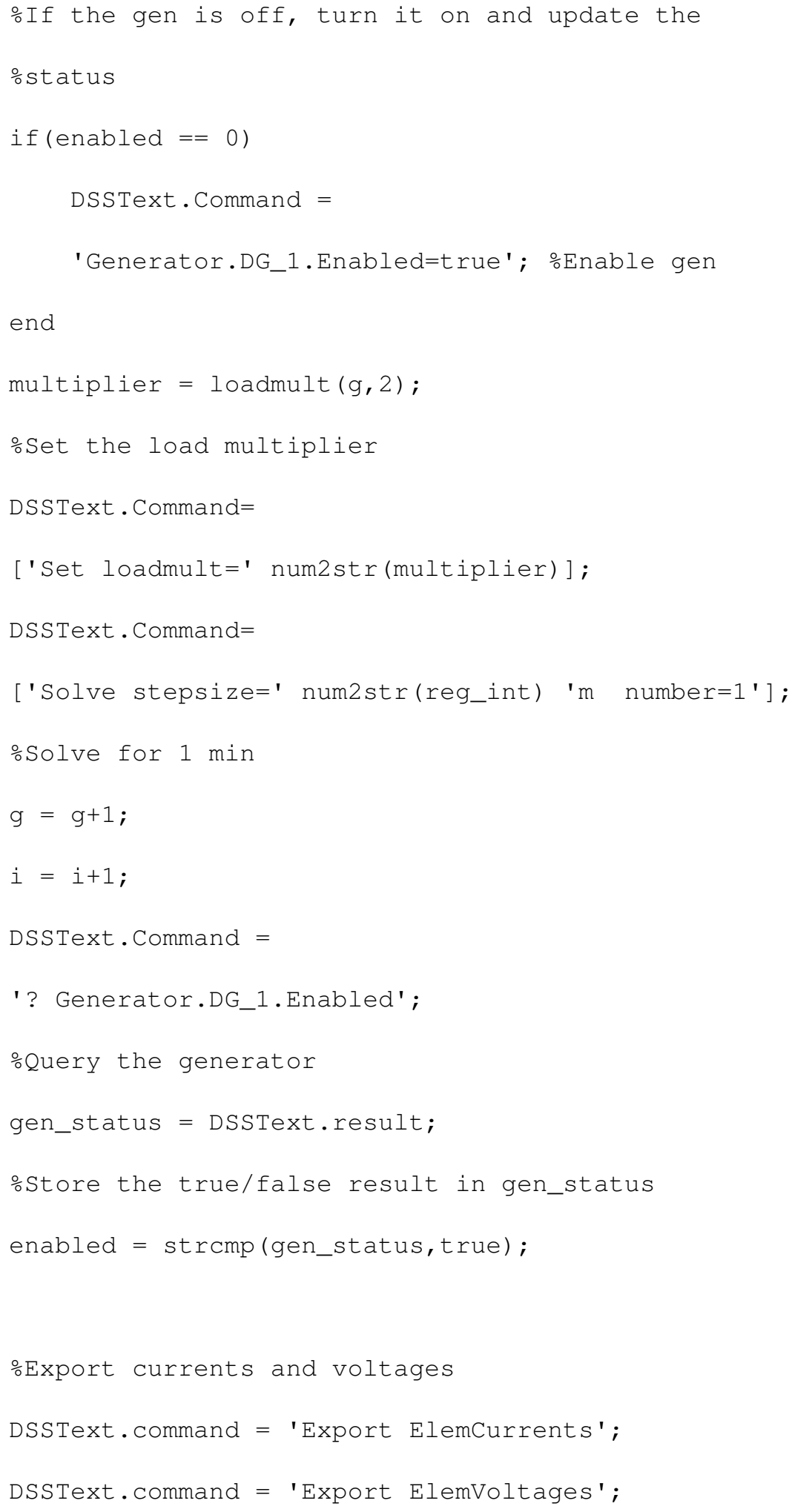




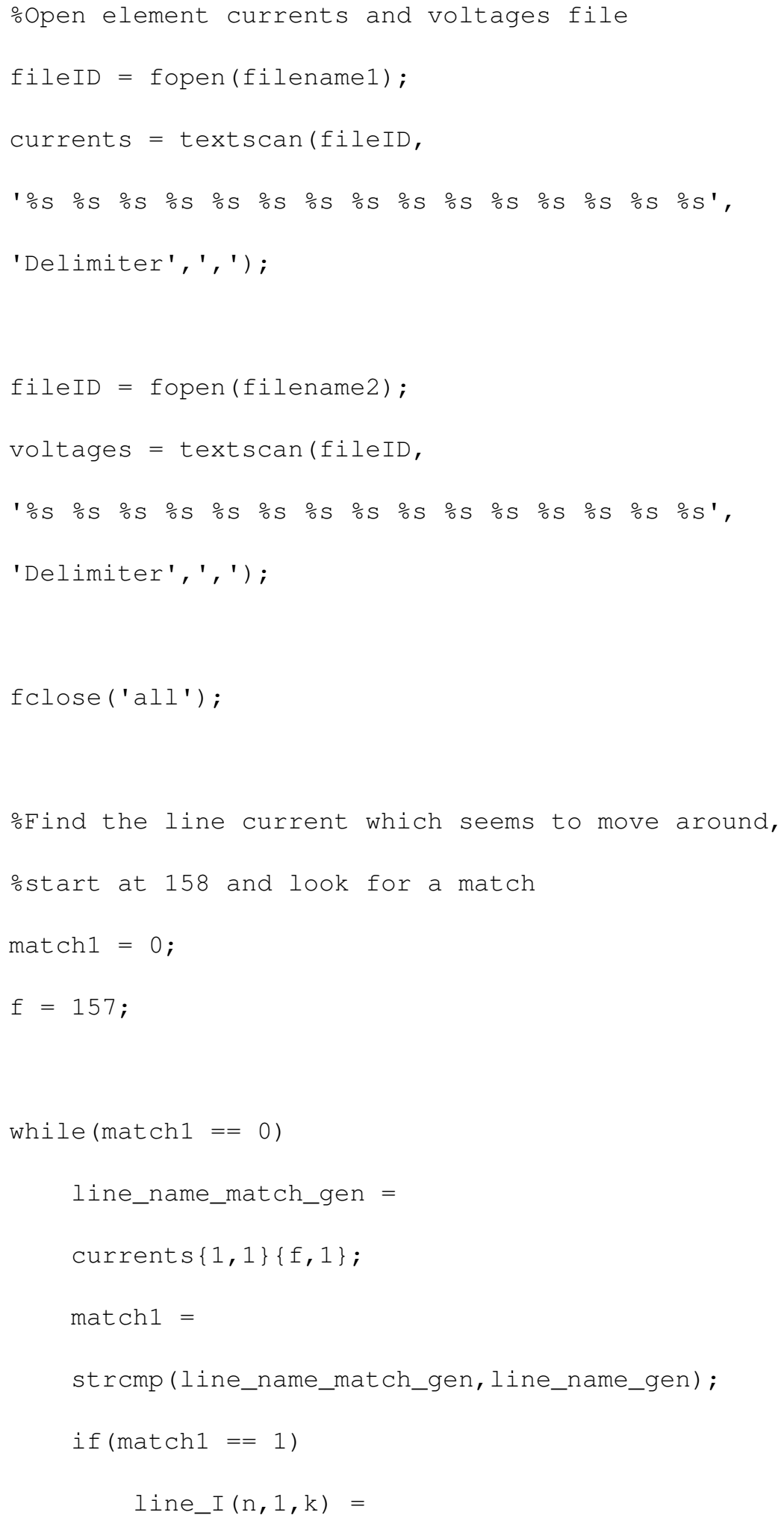




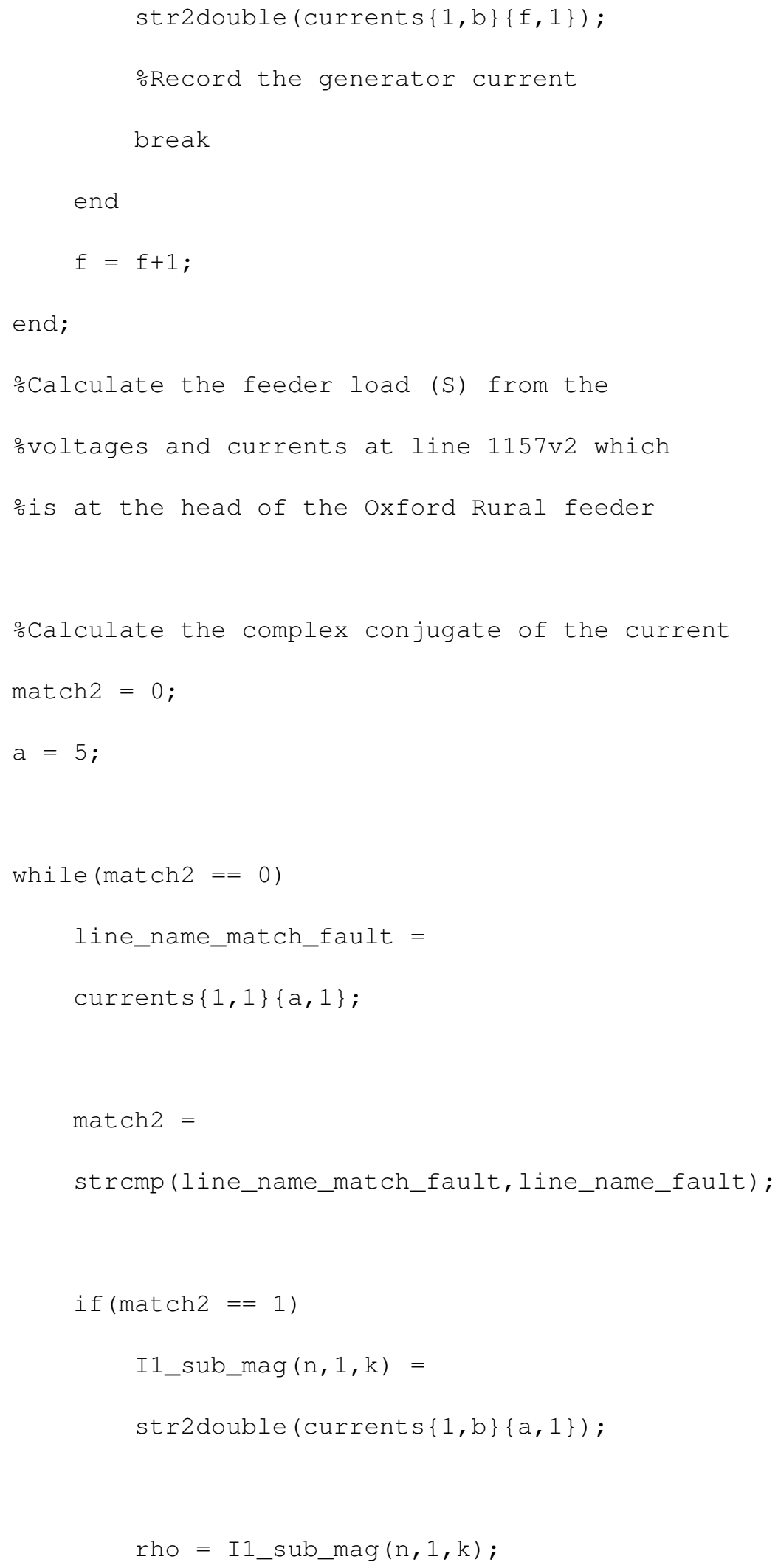




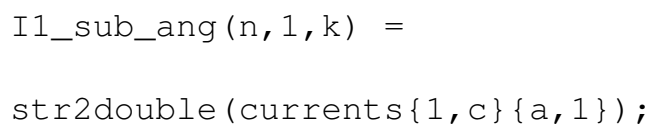

end 


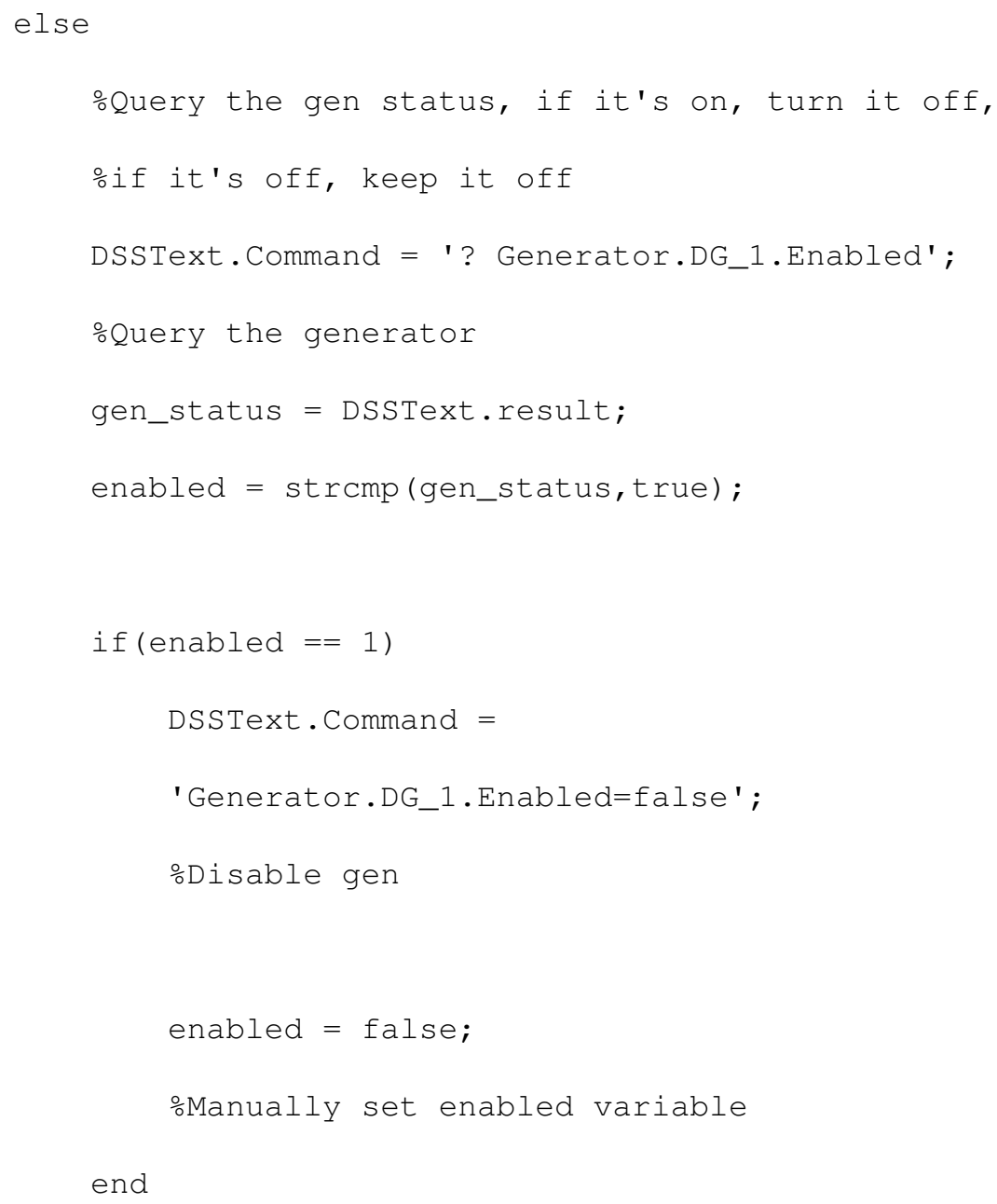


disp (ratio)

$\mathrm{k}=\mathrm{k}+1$; $\frac{\circ}{\mathrm{o}}$ Increase the third dimension of the array

owhich keeps the ratio, s, current, etc.

end

ostore it all in a really big array, unpack in a structure

ofor easier plotting

$\operatorname{arrays}\{1,:\}=$ reached I1_sub_mag on S V1_sub_mag $\}$;

oArray of array names to rename with the

ogenerator capacity value included

cap $=$ cap + step; $\frac{\circ}{\circ}$ Increment generator capacity

$\operatorname{disp}(\operatorname{cap})$

end

$\circ$

filename $=$

' $\backslash \backslash$ khensu $\backslash$ Home06 $\backslash$ eppinger $\backslash$ Desktop \DG_site_2_Inst

Reached_site2_inst.xlsx';

xlswrite (filename, reached) 


\section{Appendix B: Model Based Volt-Var Injection}

\section{B.0.1 Fmincon}

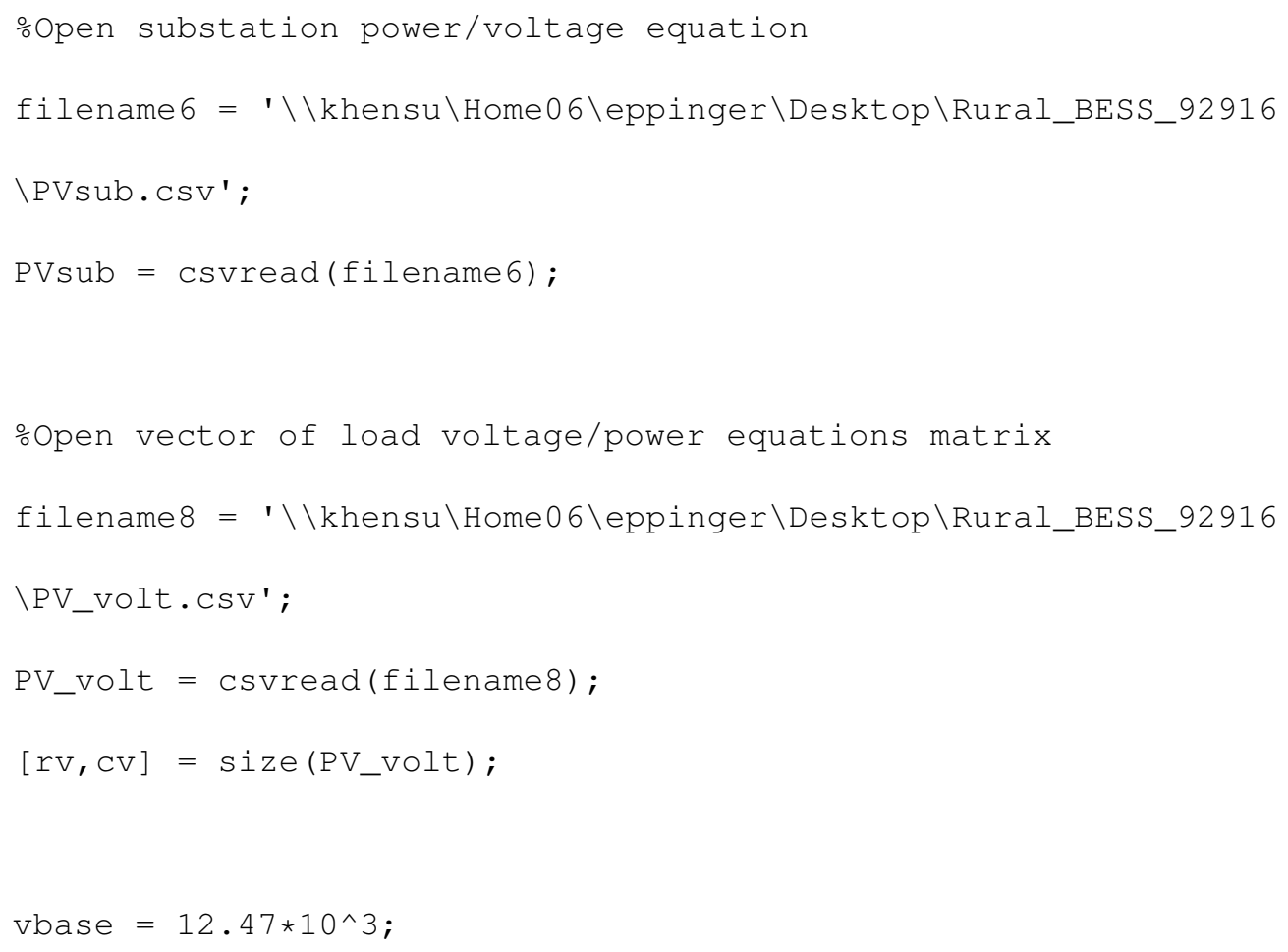




$$
\begin{aligned}
& \mathrm{b}(j+1,1)=-0.95 * \text { vbase }+ \text { PV_volt }(i, 2) ; \\
& j=j+2 ;
\end{aligned}
$$

end

\section{B.0.2 Lagrange Multipliers}

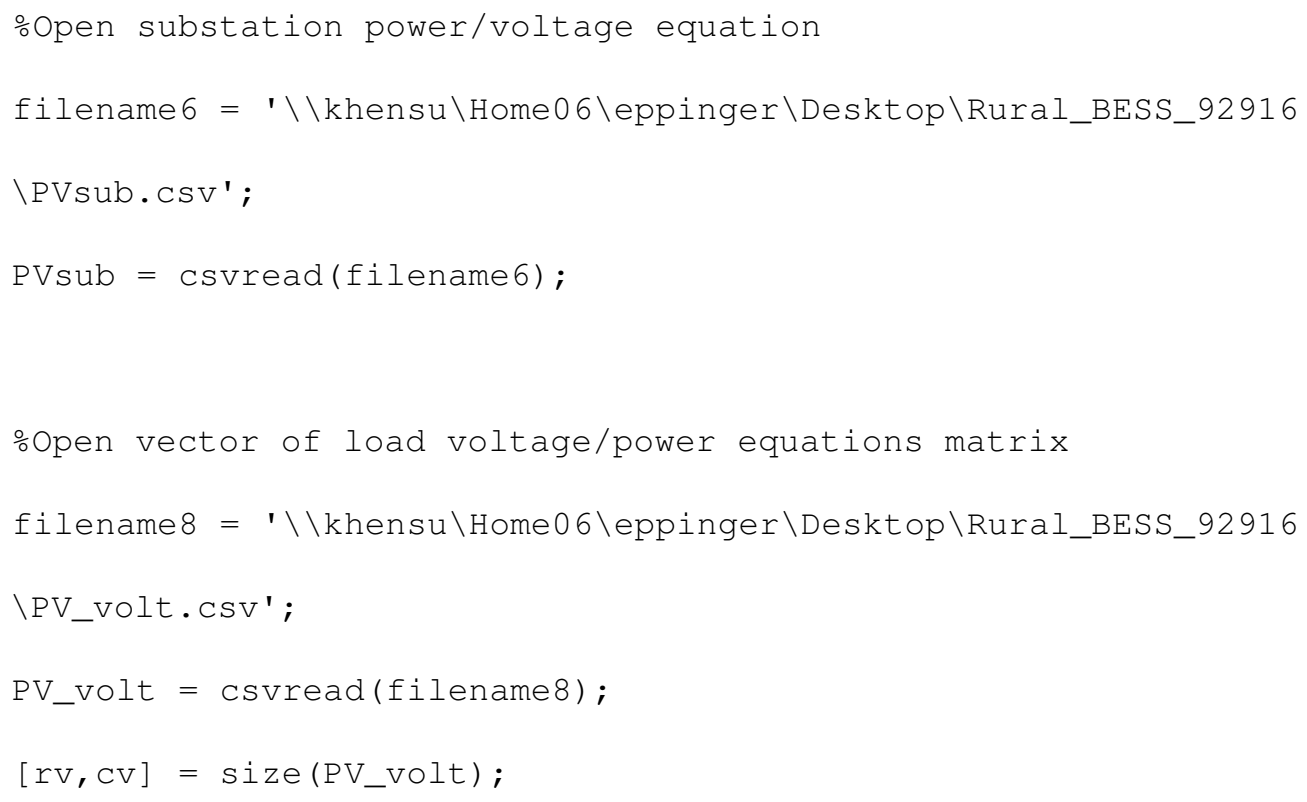




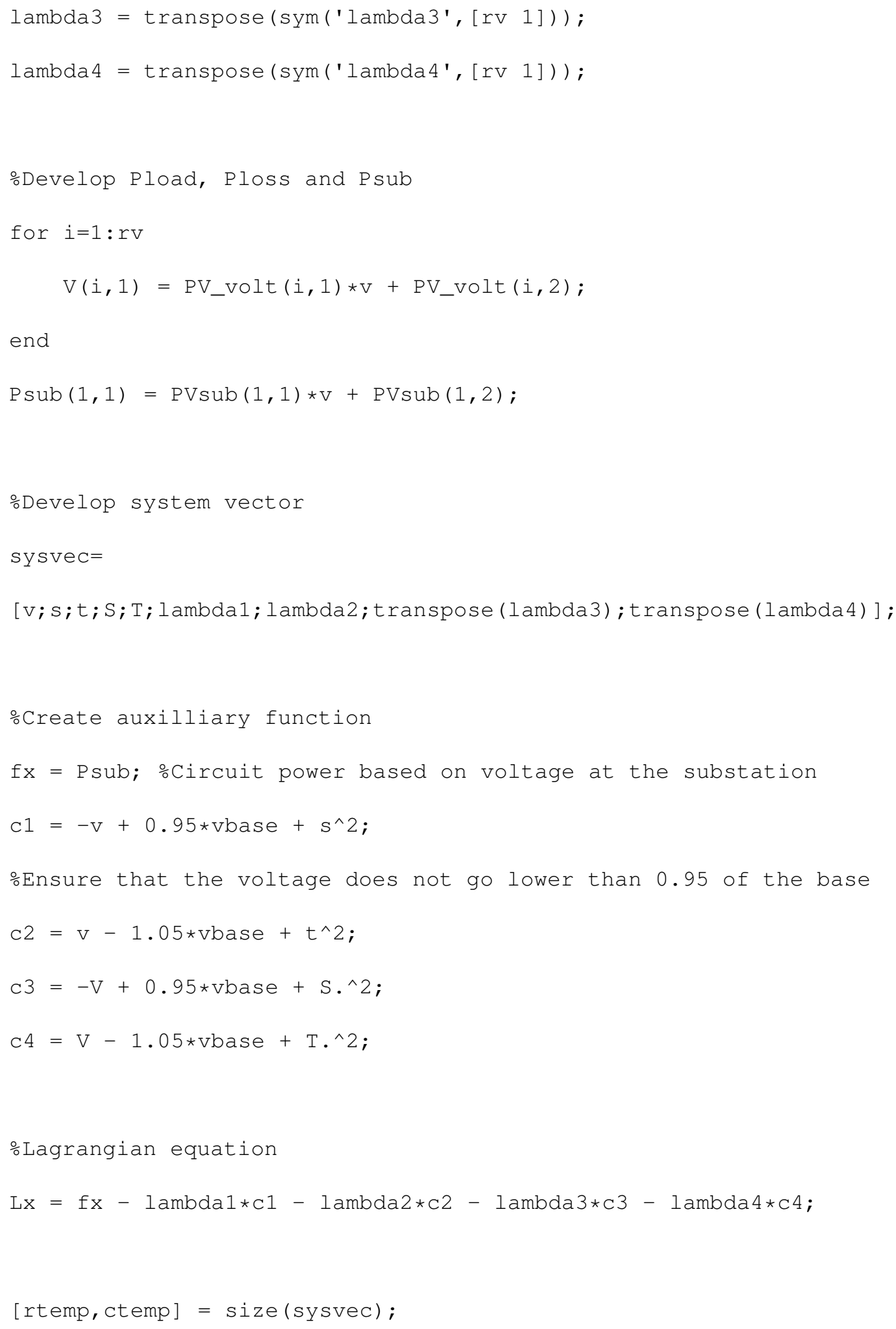




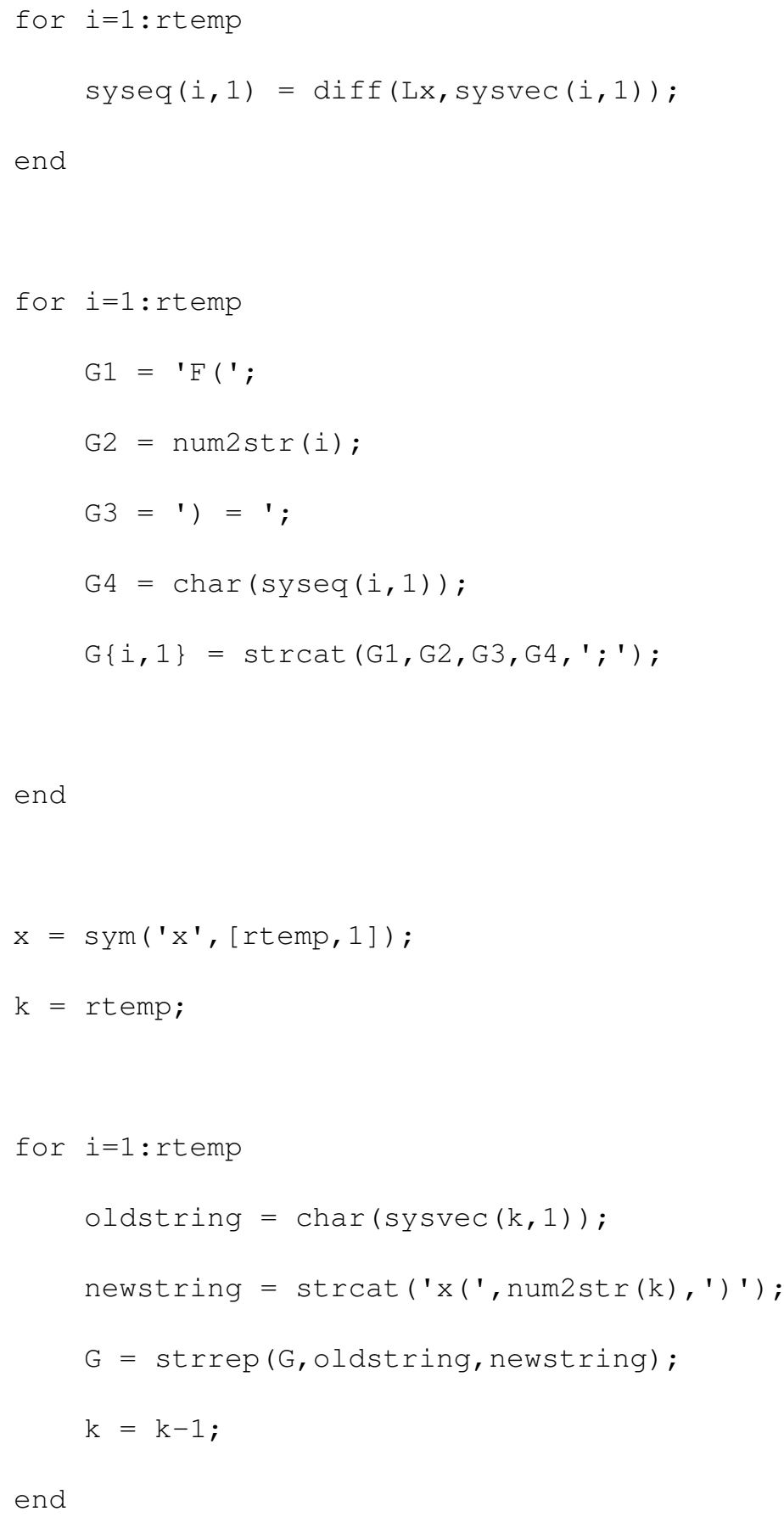

\section{B.0.3 Optimization Routine}

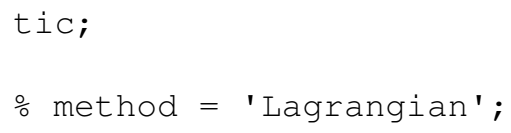




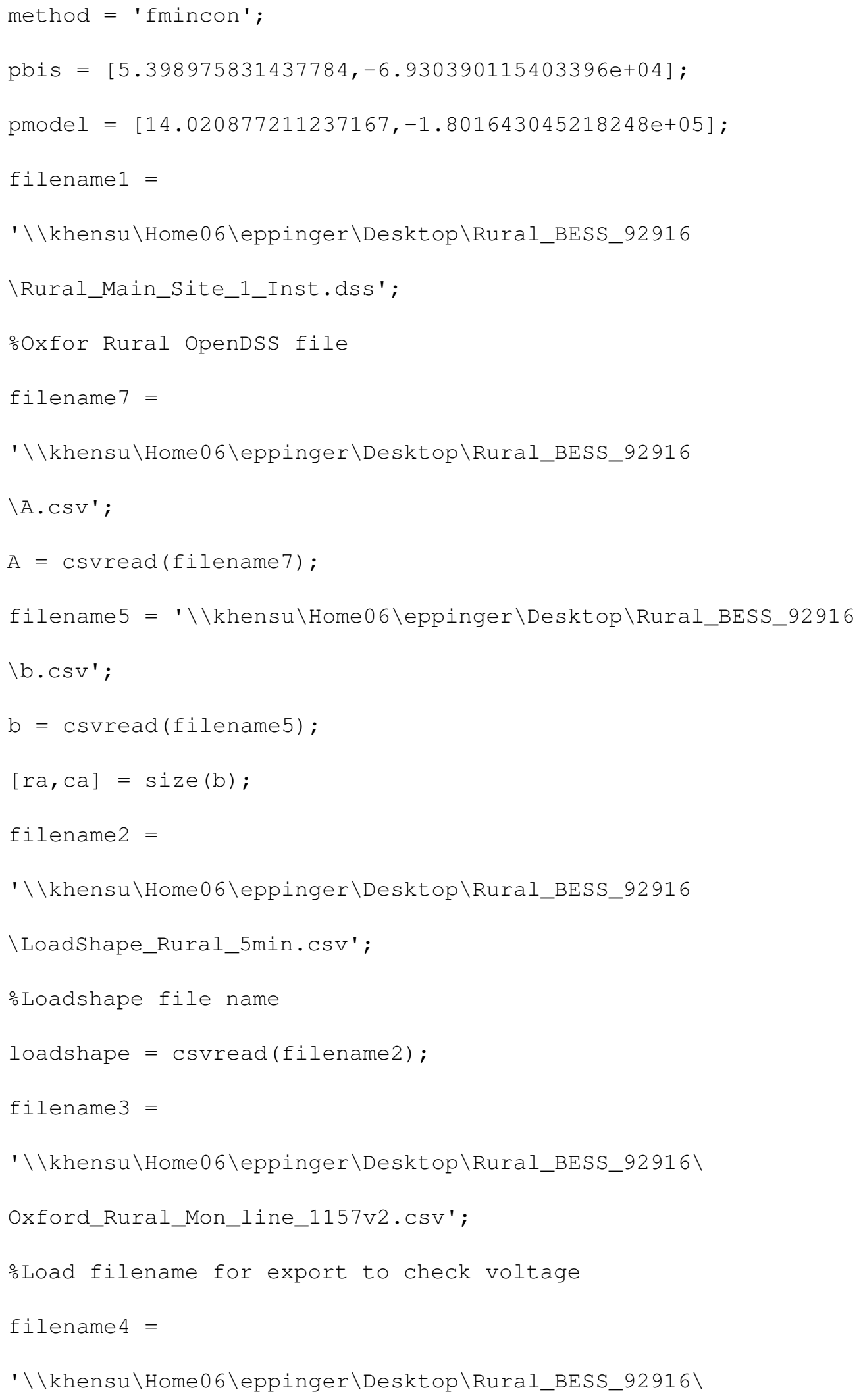




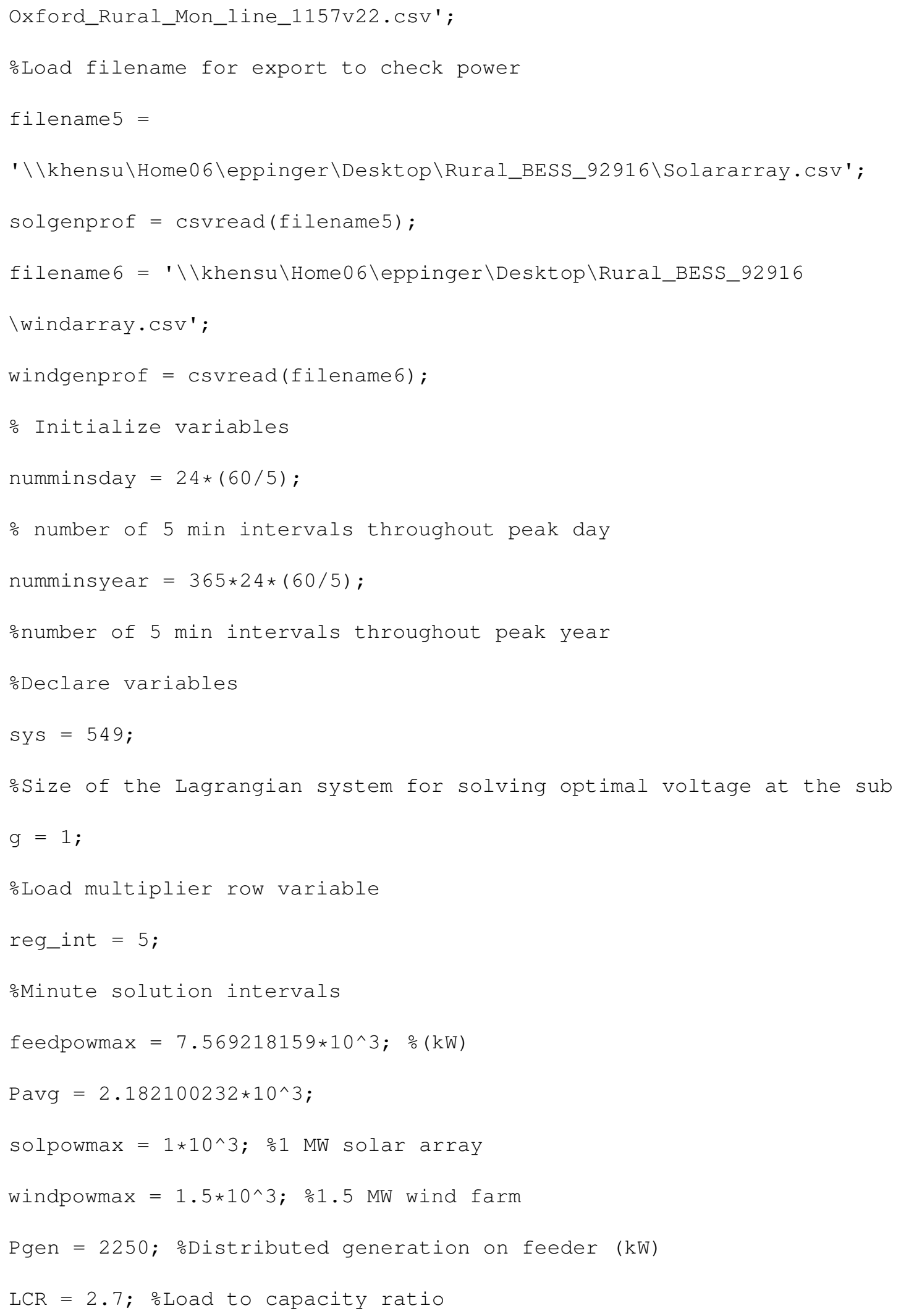




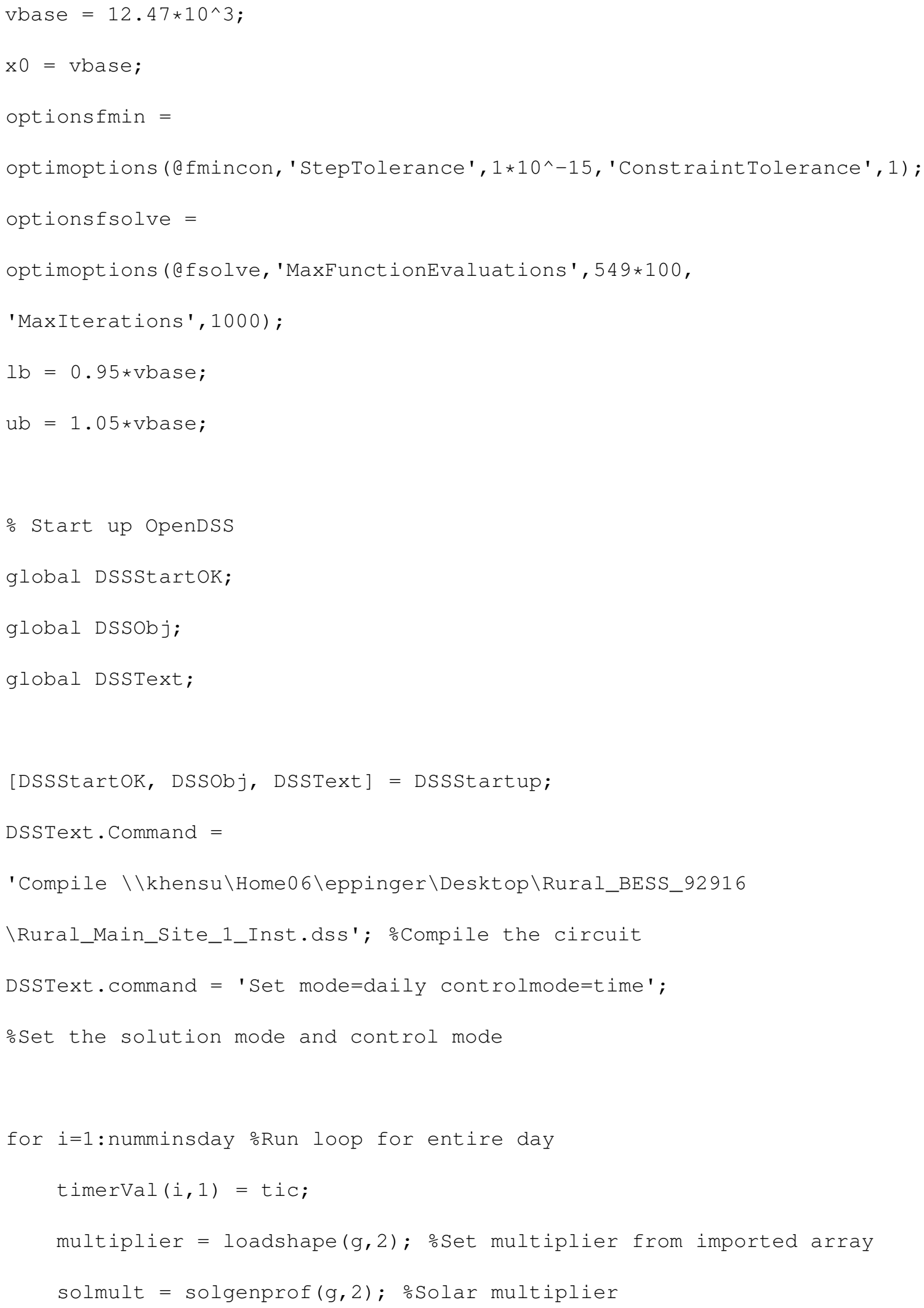




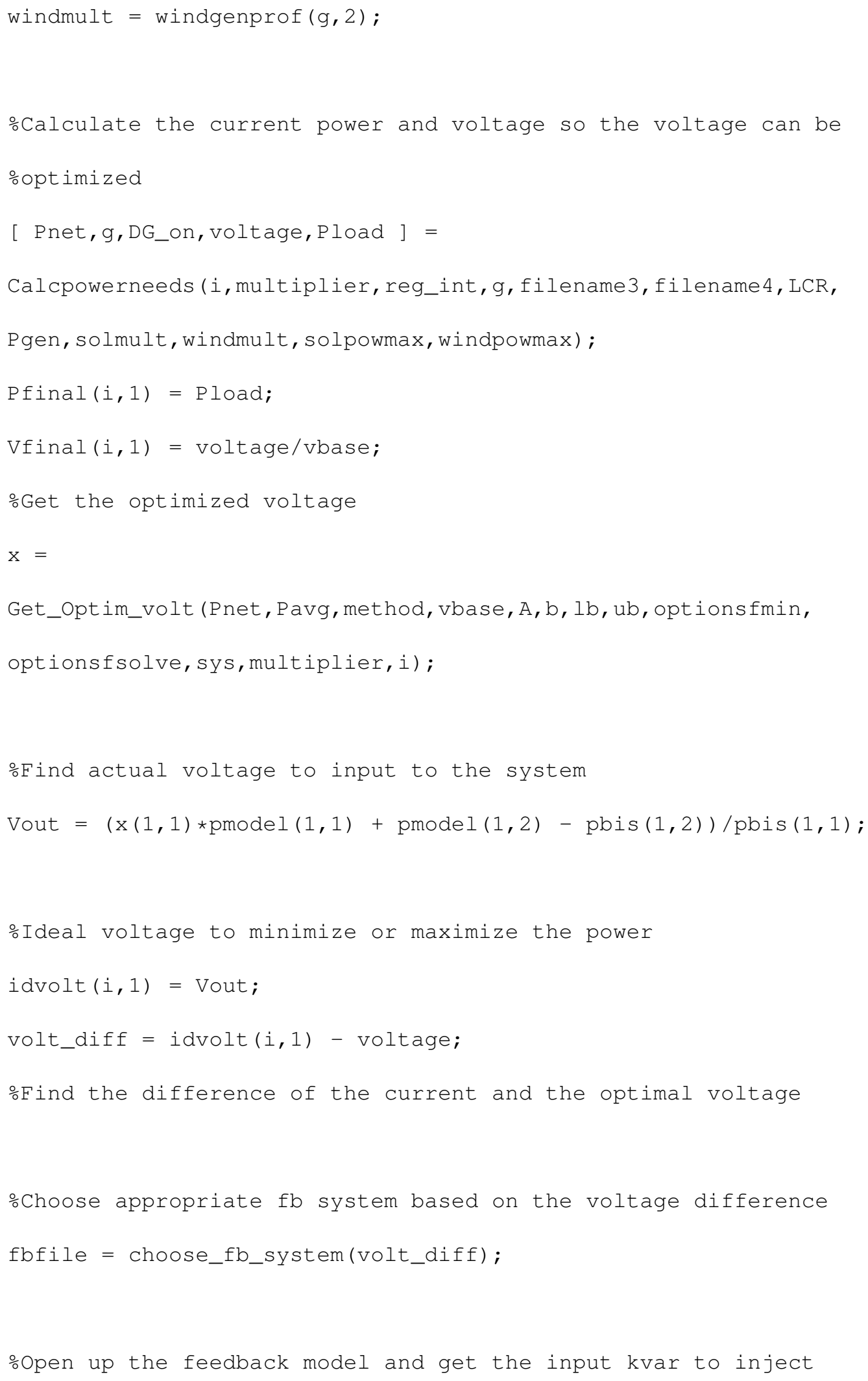




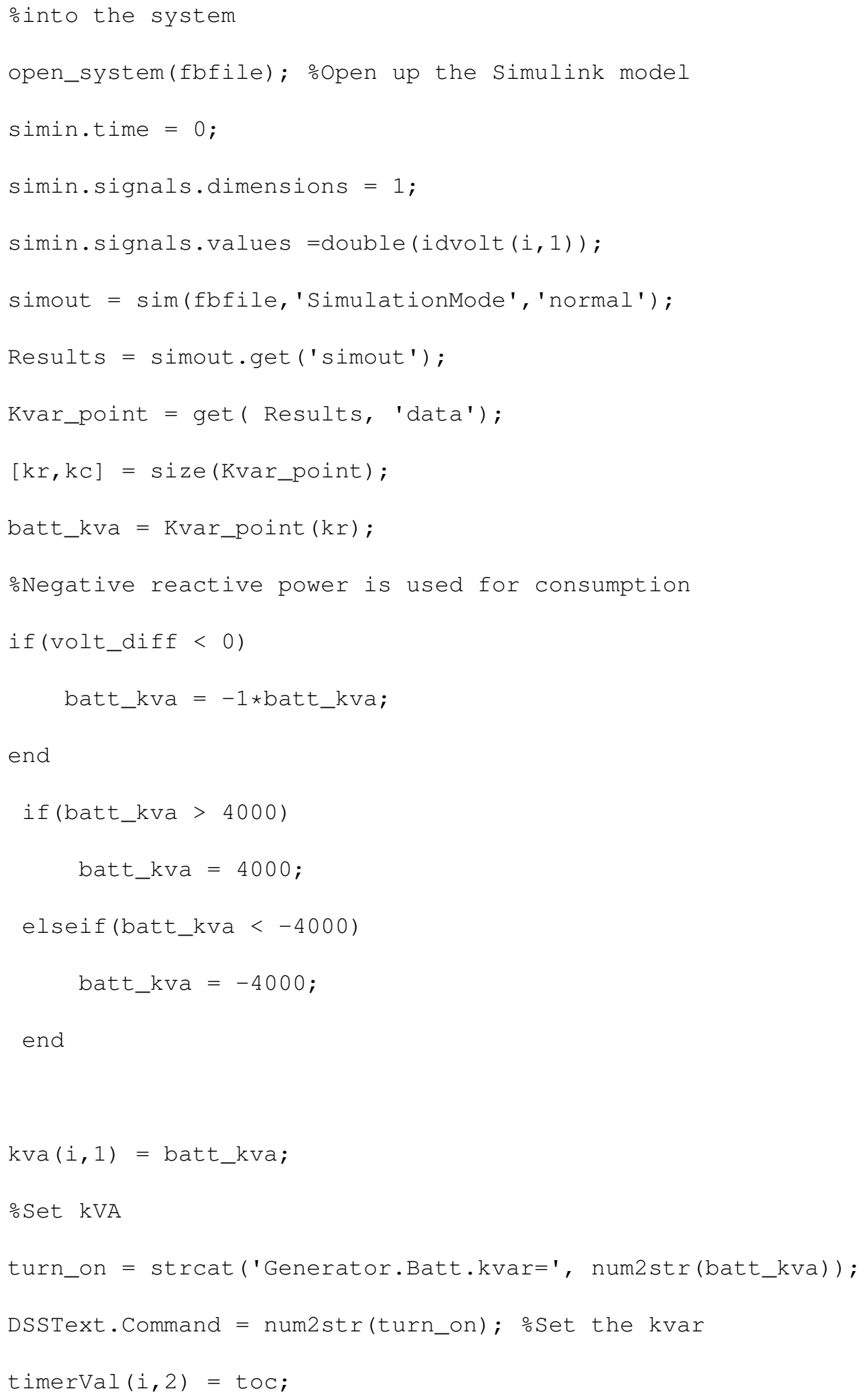




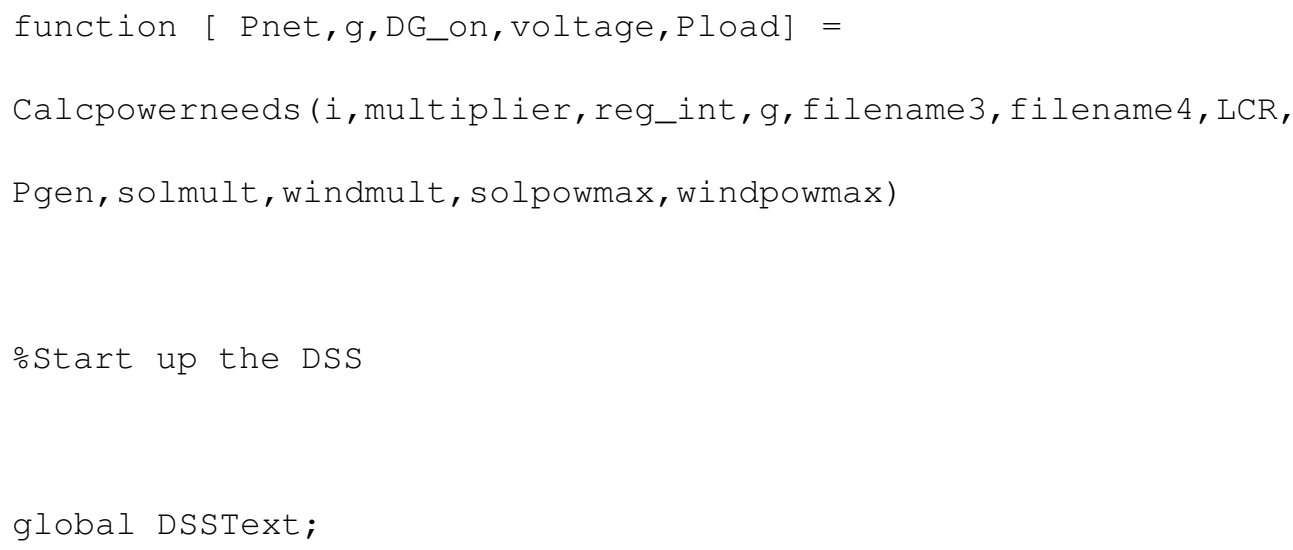




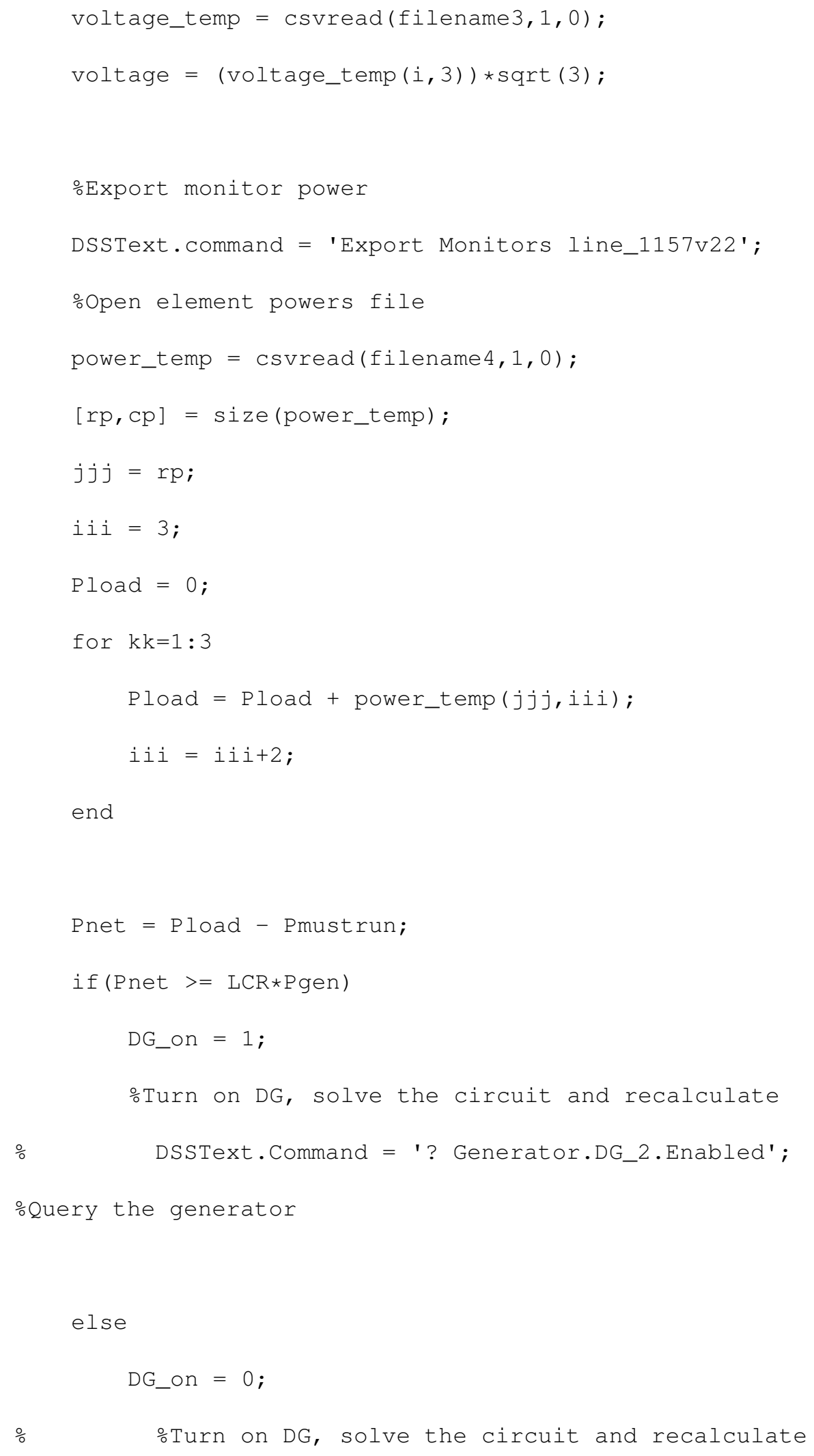




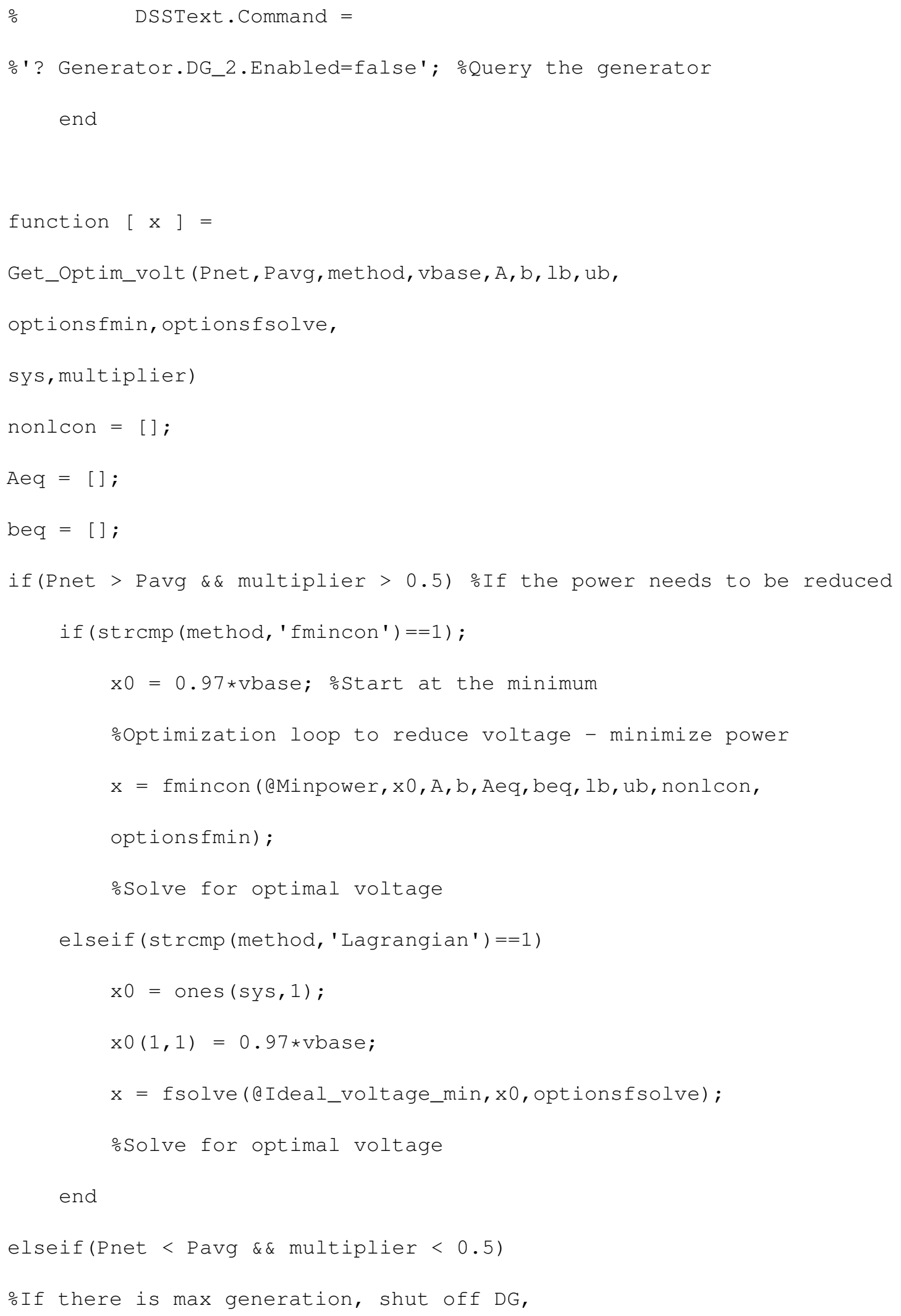




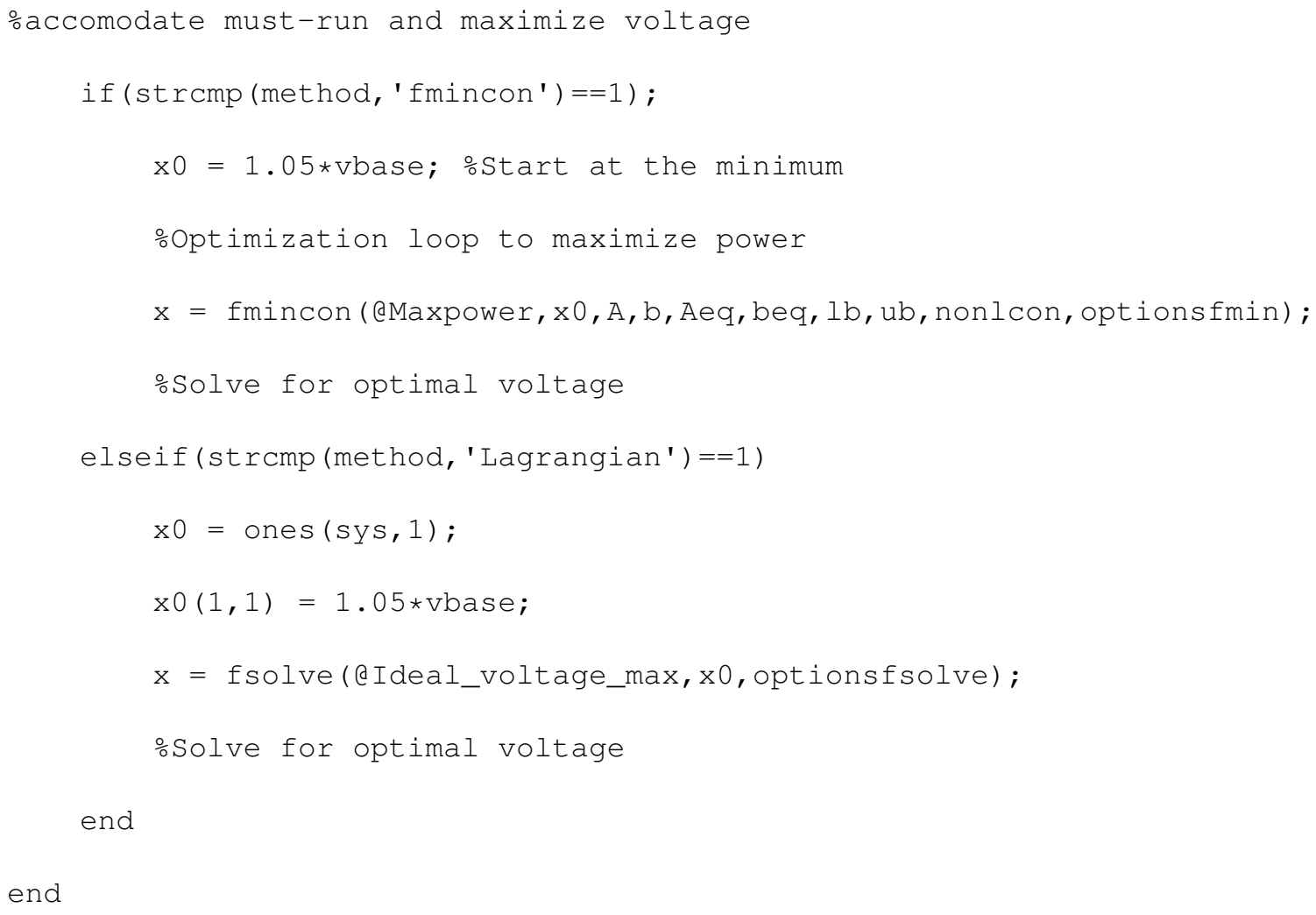




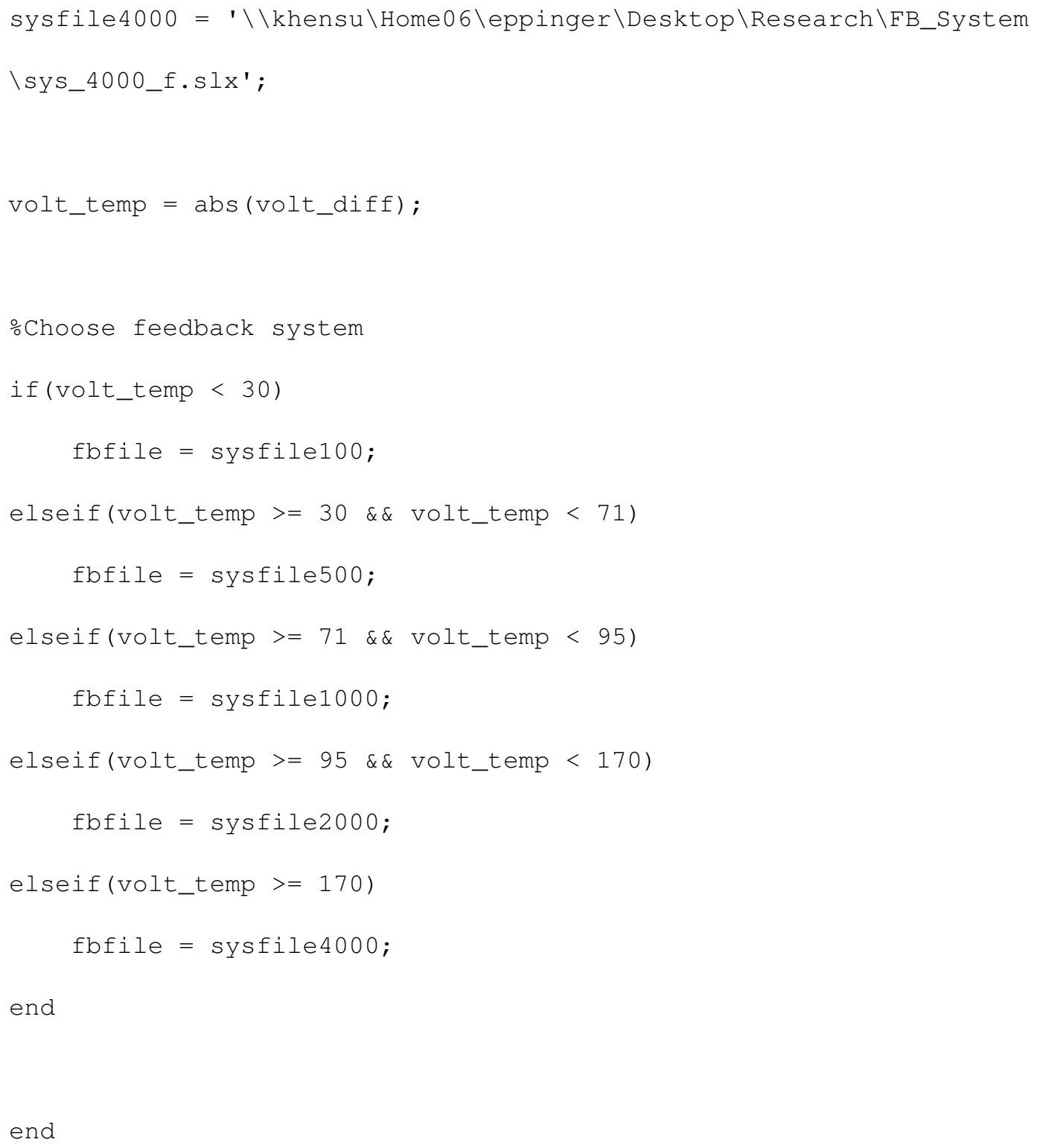

